Consenvation

-

Division of Buildings

and

Community Systems

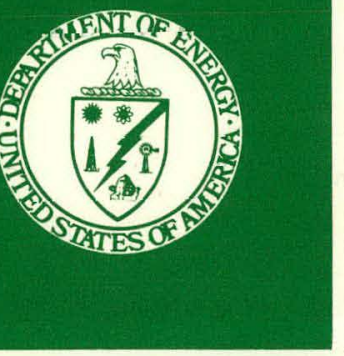

\title{
MASTER
}

\section{A Computer Simulation of Steady-State Performance of Air-to-Air Heat Pumps}

\author{
R. D. Ellison \\ F. A. Creswick
}




\section{DISCLAIMER}

This report was prepared as an account of work sponsored by an agency of the United States Government. Neither the United States Government nor any agency Thereof, nor any of their employees, makes any warranty, express or implied, or assumes any legal liability or responsibility for the accuracy, completeness, or usefulness of any information, apparatus, product, or process disclosed, or represents that its use would not infringe privately owned rights. Reference herein to any specific commercial product, process, or service by trade name, trademark, manufacturer, or otherwise does not necessarily constitute or imply its endorsement, recommendation, or favoring by the United States Government or any agency thereof. The views and opinions of authors expressed herein do not necessarily state or reflect those of the United States Government or any agency thereof. 


\section{DISCLAIMER}

Portions of this document may be illegible in electronic image products. Images are produced from the best available original document. 
Printed in the United States of America. Available from National Technical Information Service

U.S. Department of Commerce

5285 Port Royal Road, Springfield, Virginia 22161

Price: Printed Copy $\$ 6.50$; Microfiche $\$ 3.00$

This report was prepared as an account of work sponsored by an agency of the United States Government. Neither the United States Government nor any agency thereof, nor any of their employees, contractors, subcontractors, or their employees, makes any warranty, express or implied, nor assumes any legal liability or responsibility for any third party's use or the results of such use of any information, apparatus, product or process disclosed in this report, nor represents that its use by such third party would not infringe privately owned rights. 
Contract No. W-7405-eng-26

Energy Division

A COMPUTER SIMULATION OF STEADY-STATE PERFORMANCE

OF AIR-TO-AIR HEAT PUMPS

R. D. Ellioon

F. A. Creswick

Department of Energy

Division of Buildings and Community Systems

Date Publ ished: March 1978

This report was prepared as an account of work spuisuied by the United States Liovemment. Neither the United States nor the United States Department of Energy, nor any of their emplayees, nor any of their cinillacturs, subcontractors, or their employees, makes any warranty, express or implied, or assumes any lega! linbility or responsibility for the accuracy, completeness or usefulness of any information, apparatus, product or process disclosed, or represents thet its uss wnuld not inl'ringe privately owned rights.

OAK RIDGE NATIONAL LABORATORY

Oak Ridge, Tennessee 37830

operated by

UNION CARBIDE CORPORATION

for the

DEPARTMENT OF ENERGY 
THIS PAGE

\section{WAS INTENTIONALLY LEFT BLANK}


CONTENTS

Page

ABSTRACT ........................... . . v

1. INTRODUCTION . . . . . . . . . . . . . . . . . . 1

2. DESCRIPTION OF THE MODEL . . . . . . . . . . . . . . 2

2.1 Organization and Calculational Procedure . . . . . . 2

2.2 Refrigerant Flow Balance Model . . . . . . . . . 3

2.3 ORNL Compressor Model . . . . . . . . . . . . . 6

2.3.1 Model formulation . . . . . . . . . . . 6

2.3.2 Model calibration . . . . . . . . . . . 10

2.4 Condenser and Evaporator Models . . . . . . . . . . . 11

2.4.1 Effectiveness-N ${ }_{\text {tu }}$ relationship . . . . . . . 12

2.4.2 Surface properties . . . . . . . . . . . 12

2.4.3 Condenser . . . . . . . . . . . . . 13

2.4 .4 Evaporator . . . . . . . . . . . . . 13

3. RESULTS . . . . . . . . . . . . . . . . . . 14

4. PLANNED MODIFICATIONS . . . . . . . . . . . . . . 16

4.1 Heat Exchanger Configuration . . . . . . . . . . 16

4.2 Alternative Refrigerant Metering Device . . . . . . . 17

4.3 Variation in Compressor Loss and Efficiency

Parameters . . . . . . . . . . . . . . . 17

4.4 Refrigerant Mass Inventory . . . . . . . . . . . 18

4.5 Incomplete Condensation and Evaporation . . . . . . . . 18

5. UTILIZATION . . . . . . . . . . . . . . . . . . 19

ACKNOWLEDGMENTS . • • • • • . . . . . • • . . . . . . . 19

REFERENCES . • . . . • • . . . . . • . . . . . . . . . . . 21

APPENDIX A - INPUT PARAMETERS FOR THE ORNL HEAT PUMP SIMULATOR . : 25

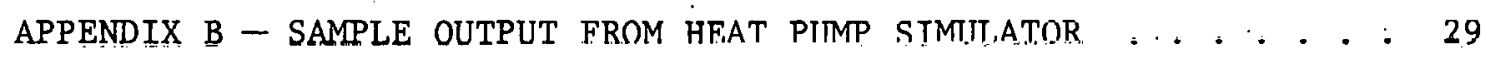

APPENDIX C - COMPUTER PROGRAM LISTING . . . . . . . . . . . 39 
THIS PAGE

\section{WAS INTENTIONALLY \\ LEFT BLANK}




\section{ABSTRACT}

A computer model by which the performance of air-to-air heat pumps can be simulated is described. The intended use of the model is to evaluate analytically the improvements in performance that can be effected by various component improvements. The model is based on a trio of independent simulation programs originated at the Massachusetts Institute of Technology Heat Transfer Laboratory. The three programs have been combined so that user intervention and decision making between major steps of the simulation are unnecessary. The program was further modified by the authors by substituting a new compressor model and adding a capillary tube model, both of which are described. Performance predicted by the computer model is shown to be in reasonable agreement with performance data observed in our laboratory. Planned modifications by which the utility of the computer model can be enhanced in the future are described. User instructions and a FORTRAN listing of the program are included. 


\section{INTRODUCTION}

Initial evaluation of possible improvements to a heat pump can be performed accurately and expeditiously by mathematical analysis. Such analysis should, for the sake of efficiency, precede the more expensive and time consuming laboratory testing of changes. Because a change in performance of any component of the system will affect the performance of all others, it is necessary to analyze the whole system under a variety of operating conditions in order to evaluate the worth of a single change of component or configuration. Obviously, a repetitious task of this magnitude should be undertaken with the aid. of computers. Hiller and: Glicksman ${ }^{1}$ have provided an elegant trio of computer programs that comprise a sophisticated model of a heat pump. They have also provided.a good bibliography of the literature relevant to heat pump modeling. .

The study for which Hiller and Glicksman wrote their programs (the "MIT model") focused principally on variable-capacity heat pump systems and ultimately upon the compressor. Their compressor model is necessarily very detailed and calls for design parameters that may not be available to most investigators; reasonably enough, some other portions of their model are most suited to the specific heat pump in their laboratory. It is the intent of the present authors to provide a program that may be used more easily to analyze a variety of heat pump configurations.

Our model retains the structure of the MIT model and makes extensive use of its collection of very useful "service routines" for calculation of thermodynamic properties of refrigerants and air, forced convection heat transfer, and fluid flow pressure drops. The use of these routines dictates that we work in the units (English) employed therein.

This report of our preliminary version of a heat pump model presents a new compressor model. which is based on loss parameters that can be evaluated in the laboratory. Also reported are variations of the calculation of refrigerant pressure and flow balance that allow modeling of refrigerant flow control devices other than thermal expansion valves. Refinement and generalization of these and other portions of the program will be presented in a later report; we believe, however, that this . preliminary version is a useful tool in its present form. 


\section{DESCRIPTION OF THE MODEL}

\subsection{Organization and Calculational Procedure}

Since the structure of the MIT program has been retained for the Oak Ridge National Laboratory (ORNL) model of an air-to-air heat pump, a brief review of the calculatonal procedures common to both models may be useful. Methods employed in portions of the MIT program that have been retained with little or no change will be described briefly; detailed descriptions of new routines are presented in later sections of this report. The model is organized in three sections, the first of which establishes compressor power consumption, mass-flow rates, pressure balances, and thermodynamic states for the refrigerant. The second and third sections are detailed models of the condenser and of the evaporator; they are used to predict performance by calculating energy balances at these heat exchangers.

Rather than start with indoor and outdoor air temperatures against which the heat pump is working, and then iterate over the entire thermodynamic cycle, the reverse procedure is used in order to promote calculational efficiency. The refrigerant mass-flow rate is established from assumed values for evaporating temperature, superheat of the refrigerant reaching the compressor, and the degree of subcooling of refrigerant leaving the condenser; dimensions of the interconnecting pipes and the metering device, and (for the MIT program) detailed design parameters of the compressor are also used. By iteration over the saturation temperature in the condenser until a pressure balance is achieved, thermodynamic states of the refrigerant at the condenser and evaporator are established. The refrigerant states calculated for the condenser entry are used as input to the condenser model which calculates an energy balance between refrigerant and air to find the heat rejection rate of this heat exchanger and to predict the temperature of refrigerant leaving the condenser. This temperature is compared with the previously assumed subcooling of the refrigerant; iteration over the degree of subcooling is performed until agreement is reached. Finally, the evaporator model is used to calculate its heat absorption rate for several air temperatures. The saturation 
temperature and superheat of the refrigerant leaving the evaporator may then be compared with those used to calculate the refrigerant flow rate in order to determine which air temperature is appropriate for the assumed conditions. Both heat exchanger models require detailed dimensions of the tubing and fins as well as airflow rates and temperatures. Refrigerant states and mass-flow rates calculated in the refrigerant flow rate routines are the other inputs to these programs. Power consumption by air fans or blowers has not been calculated; the MIT program does not calculate a coefficient of performance.

\subsection{Refrigerant Flow Balance Model}

As previously mentioned, the refrigerant mass flow is established from an assumed evaporating temperature, the superheat of refrigerant leaving the evaporator, and the amount of subcooling of refrigerant in the condenser. An initial guess of the condensing temperature is provided along with diameters and equivalent lengths of the interconnecting pipe (including fittings), and a description of the refrigerant metering device. The ORNL model will accommodate a thermal expansion valve (as will the MIT) or capillary tubes. The parameters required for the ORNL compressor model are displacement, motor speed, and loss parameters, as described in Sect. 2.3.

The thermodynamic cycle being modeled is shown in Fig. 1, a somewhat distorted pressure vs enthalpy $(p-h)$ diagram. Thermodynamic states of the refrigerant are calculated using subroutines from Kartsounes and Erth ${ }^{2}$ as modified by Hiller and Glicksman. ${ }^{1}$ Viscosity, thermal conductivity, and specific heat are obtained from subroutines that reproduce plots 3,4 of these properties (as functions of temperature) from curve fitting parameters. These routines, as well as the pressure-drop routines, are due to Hiller and Glicksman. I Single-phase pressure drops in the connecting pipes are calculated from the standard incompressible flow relation and the Moody friction factor; single- and two-phase pressure drops in the heat exchangers are calculated by the Lockhart-Martinelli ${ }^{5}$ method.

Calculation of the refrigerant mass-flow rate and the pressure drops begins in both the MIT and ORNL models by calling the compressor subroutine. 


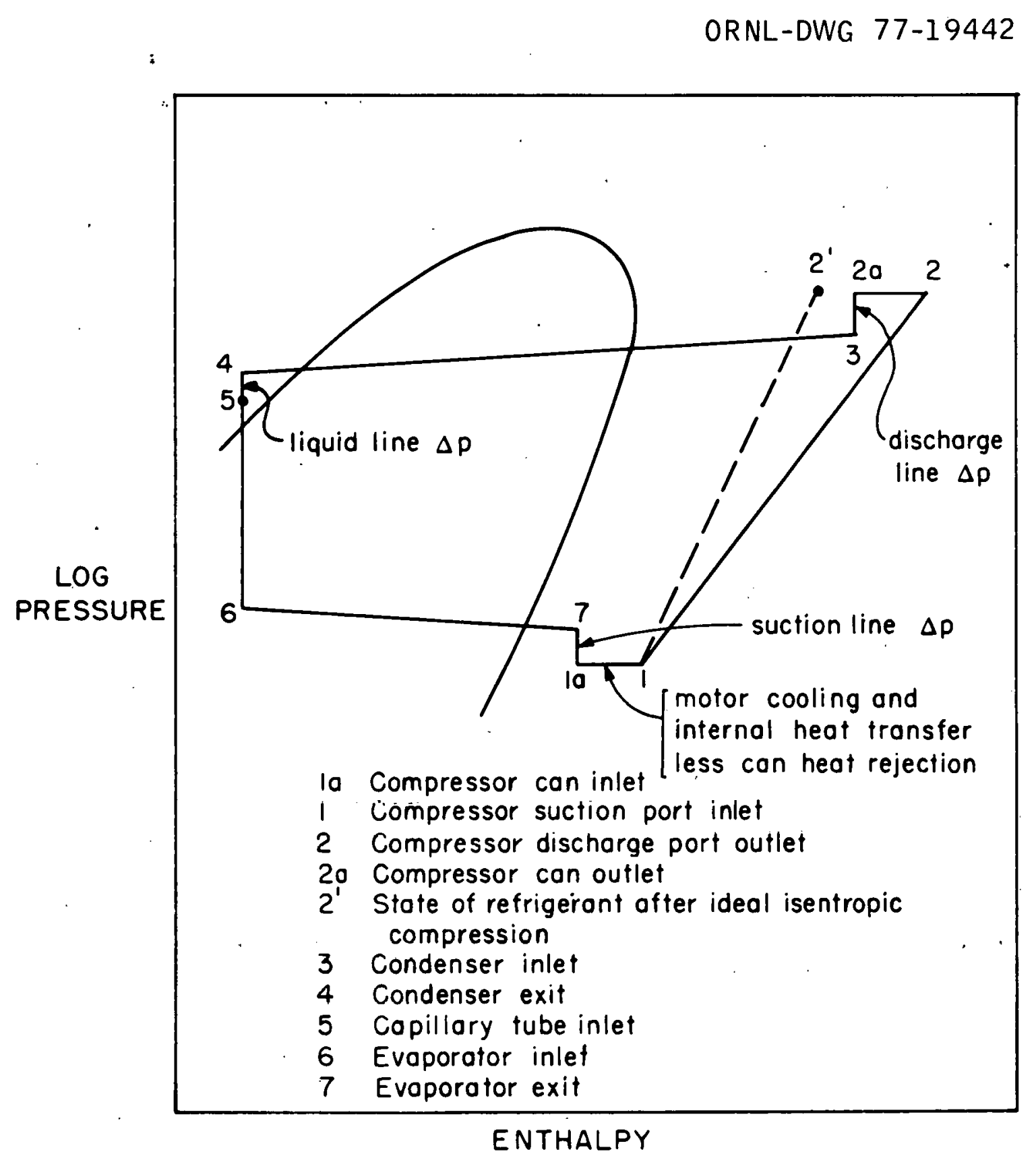

Fig. 1. Pressure vs enthalpy diagram for the heat pump cycle. 
From the evaporating saturation temperature and superheat of the vapor (if evaporation is incomplete, quality is used), i.e., the state represented by point la on the diagram, and the estimated condensing temperature, the ORNL compressor routine calculates the refrigerant mass-flow rate, compressor motor power consumption, and the temperature, enthalpy, and pressure of the refrigerant at point 1, the compressor suction port; and at point $2 a$, the compressor can exit. This subroutine also calculates the pressure drop in the discharge line, that is, between points $2 a$ and 3 , the compressor exit and condenser entrance.

The pressure drop in the condenser must be calculated as though the entire condenser were experiencing two-phase flow because the length of condenser tubing occupied by the single-phase desuperheating and subcooling regions has not yet been found. Thus, the pressure at point 4 in the $p-h$ diagram is known; calculation of the pressure drop in the liquid line from condenser to flow metering device yields the pressure at entry to that device, point 5 .

If the flow metering device is a capillary tube (ORNL model only), refrigerant flow through it is calculated using the pressure just found and a routine based on curve fitting parameters that reproduce the ASHRAE Guide and Data Book ${ }^{6}$ correlation. This flow through the capillary tube is compared to the flow rate predicted by the compressor routine; if the two do not agree, the condensing saturation temperature is adjusted and the entire calculation is repeated until the refrigerant mass flow predicted by the compressor model matches that which the capillary tube can accommodate.

If the flow metering device is a thermal expansion valve (TXV) as allowed in both models, it is necessary to calculate the pressure drops through the evaporator and suction line and thus the pressure at evaporator entry. The difference between this pressure and that at the entry to the thermal expansion valve is compared to the pressure drop calculated separately for the TXV and distributor nozzles and tubes as explained by Hiller and Glicksman. ${ }^{1}$ If these two pressure drops differ, the condensing saturation temperature is adjusted and iteration proceeds until a pressure balance is achieved. 


\subsection{ORNL Compressor Mode1}

The objective in formulating the ORNL compressor model was to utilize performance parameters that are descriptive of the efficiency of the device and for which quantitative values could possibly be derived from experimental data. This is in contrast to using design parameters for input, as is done for the heat exchanger models used in this simulation. The computation or simulation of compressor performance from design parameters is not a well-established art at present, and attempting to do so in this study would have led to considerable additional complication and risk. Accordingly, we have a model that will predict how changes in compressor efficiency affect the heat pump system, but the model cannot be used to determine which specific compressor design changes might lead to the improved efficiency. This is compatible with the intended use of the simulation.

\subsubsection{Model formulation}

The parameters used to model the compressor are the following:

\begin{tabular}{ll} 
Parameter & \multicolumn{1}{c}{ Definition } \\
Motor efficiency & $\begin{array}{l}\text { Ratio of shaft work to } \\
\text { electrical energy input }\end{array}$ \\
Volumetric efficiency & Ratio of refrigerant \\
& volumetric flow rate at \\
& suction port to swept \\
& cylinder volume per \\
unit of time & \\
& Ratio of ideal isentropic \\
compression work to actual \\
shaft work input required \\
to achieve the same $\Delta \mathrm{p}$ (with \\
this definition, mechanical \\
losses, flow friction losses, \\
and thermal effects are \\
accounted for)
\end{tabular}


Parameter

Can heat loss

Internal heat loss
Definition

Heat rejection from the compressor can surface

Heat transfer from the discharge gas back to the suction gas inside the can, principally from the discharge tube

In addition, four operating variables are required as input to the compressor subroutine: can inlet pressure and temperature, can outlet pressure, and motor speed. Since the compressor is mounted inside a can, it is important to distinguish between the state of the refrigerant condilluns di the inlee and outlet of the can and at the compressor suction and discharge ports, as they will generally be different.

Five energy balances are used in the model: one each for the can, suction gas, compressor, compressor motor, and discharge gas. Figure 2 illustrates the energy balance components we used.

For the compressor can, the enthalpy gain of the refrigerant is equal to electrical power input minus the heat rejection from the can, or

$\dot{\mathrm{m}}_{\text {ref }}\left(\mathrm{h}_{\text {can outlet }}-\mathrm{h}_{\text {can inlet }}\right)-\dot{\mathrm{q}}_{\text {electrical input }}+\dot{\mathrm{q}}_{\text {can loss }}=0$,

where $\dot{\mathrm{m}}_{\text {ref }}=$ refrigerant mass flow rate,

h = specific enthalpy,

$\dot{\mathrm{q}}=$ energy flow rate,

and the subscripts are self-explanatory. This is a combined energy balance, the sum of the remaining energy balances. For the suction gas, heating by the motor losses and the unavoidable internal heat transfer from the discharge are accountcd for, as well as heat rejection from the can. (The inside of the can is at suction pressure; thus, can 1nsses or gains come directly (rom the suction gas.) Accordingly,

$$
\begin{aligned}
& \dot{\mathrm{m}}_{\text {ref }}\left(\mathrm{h}_{\text {suct port }}-\mathrm{h}_{\text {can inlet }}\right)- \\
& \dot{\mathrm{q}}_{\text {Internal }}-\dot{\mathrm{q}}_{\text {motor cooling }}+\dot{\mathrm{q}}_{\text {can loss }}=0 .
\end{aligned}
$$




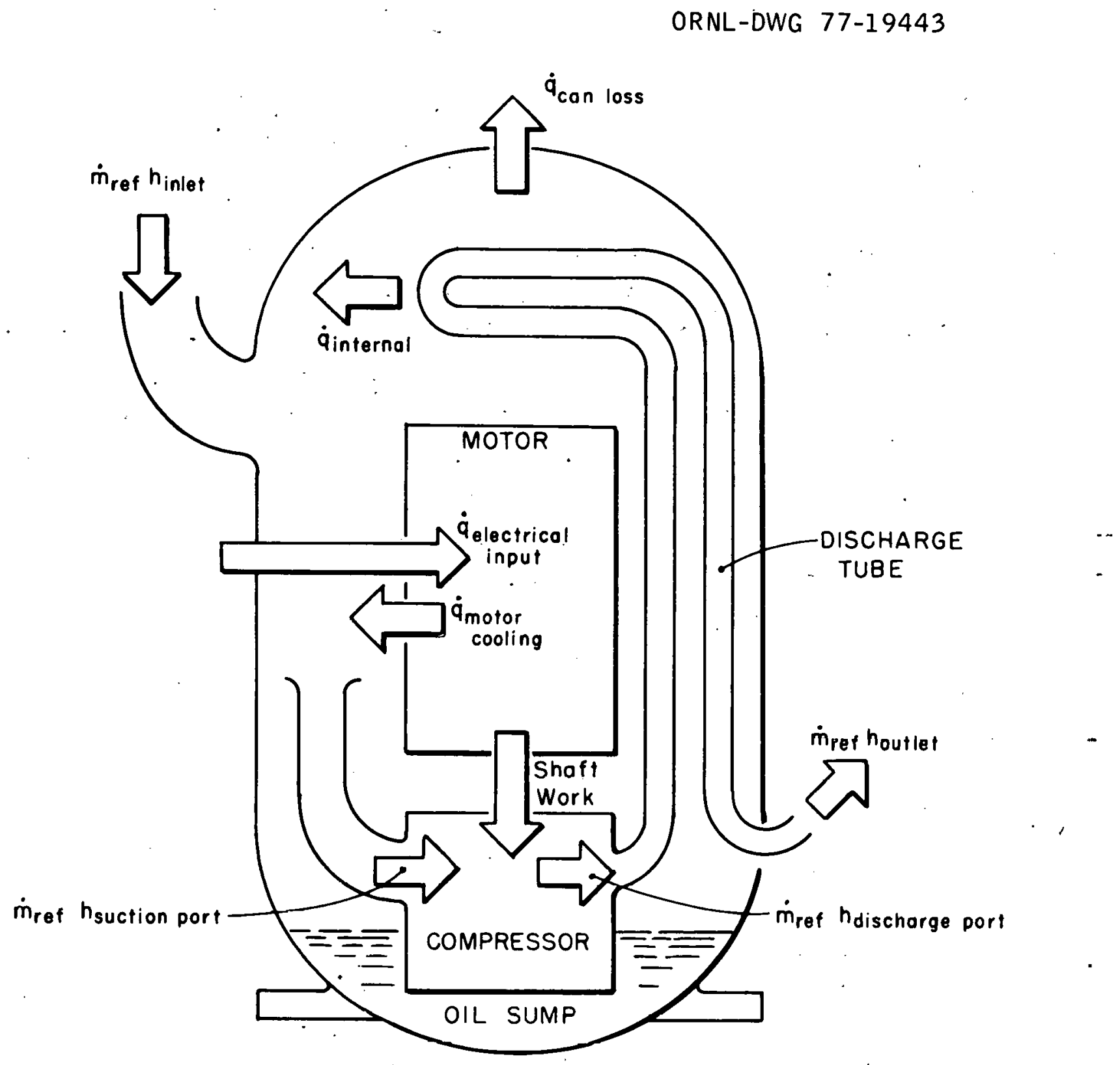

Fig. 2. Compressor can energy balance components. 
Similarly, for the discharge gas,

$$
\dot{\mathrm{m}}_{\text {ref }}\left(\mathrm{h}_{\text {disch port }}-\mathrm{h}_{\text {can outlet }}\right)-\dot{\mathrm{q}}_{\text {internal }}=0 \text {. }
$$

The actual compression work is computed as

$$
\Delta h_{\text {compressor }}=h_{\text {disch port }}-h_{\text {suct port }}=\frac{\Delta h_{\text {isentropic }}}{\eta_{\text {Isentropic }}} \text {. }
$$

where $\Delta \mathrm{h}_{\text {isentropic }}$ is obtained from the thermodynamic properties of the refrigerant and $\eta_{\text {isentropic }}$ is the input value of isentropic efficiency. The compressor energy balance is satisfied by

$$
\text { shaft power }=\dot{\mathrm{m}}_{\text {ref }} \Delta \mathrm{h}_{\text {compressor }} \text {, }
$$

wherein it is assumed that mechanical losses will be dissipated by heating the discharge gas. The motor power input is

$$
\text { motor power input }=\text { shaft power } / \eta_{\text {motor }} \text {, }
$$

where $\eta_{\text {motor }}$ is the motor efficiency, and the heat rejected by the motor to the suction gas is given by

$$
\dot{q}_{\text {motor cooling }}=\left(1-\eta_{\text {mntonr }}\right) \text { (motor power input) }
$$

Since the suction-gas heating is a function of motor power input, and motor power input is in turn a function of the state of the suction gas entering the compressor suction port, an iterative computational procedure is required. Given the conditions of the gas entering the can and the outlet pressure, the iteration is accomplished within the compressor subroutine.

Figure 1 shows the states of the refrigerant gas on a pressure vs enthalpy diagram. State $2^{-}$represents the ideal isentropic discharge condition of the refrigerant. 
The mass-flow rate of refrigerant is computed from the input value . of volumetric efficiency as

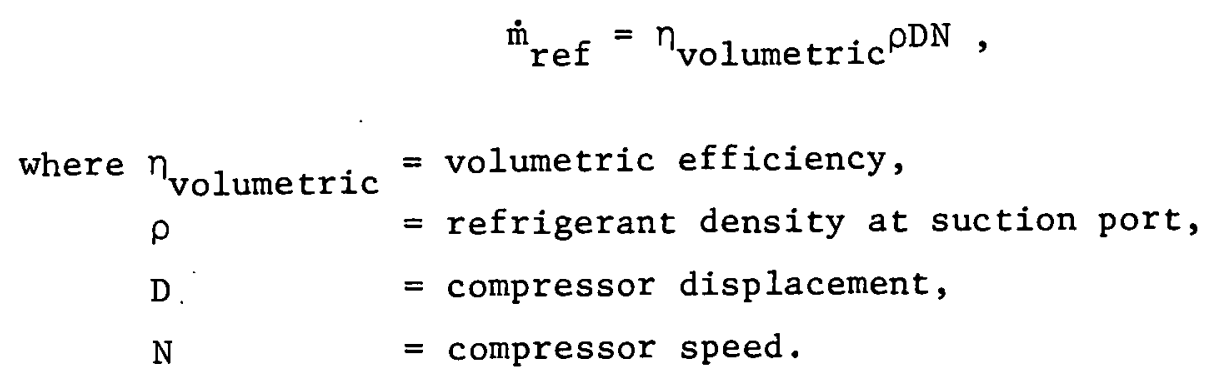

\subsubsection{Model calibration}

The can heat 1oss, $\dot{q}_{\text {can }}$ loss, can be computed directly from experimental data using Eq. (1), assuming the pressures and temperatures of the refrigerant at can inlet and outlet are measured. It is also possible to derive estimates of can heat rejection analytically if the airflow velocity across the can is known. In the present model, $\dot{q}_{\text {can loss }}$ is entered as input; $i . e .$, the magnitude of this loss is not computed within the subroutine.

It is not possible to determine the internal heat transfer from experimental data; however, analytically based estimates can be made.

Volumetric efficiency cannot be derived directly from experimental data for the heat pump system unless the temperature of the suction gas at the compressor suction port is measured. Because measurements inside the compressor can are difficult to obtain, this has not been done as yet in experimental work supporting this modeling effort. A first approximation of volumetric efficiency can be derived on the basis of reexpansion of the cylinder-clearance-volume gas. This value will be optimistic because it will not have accounted for throttling loss through the suction valve. It is also possible to compute directly the volumetric efficiency of open compressors from catalog data.

Similarly, isentropic compression efficiency cannot be computed directly from hermetic-compressor experimental data unless temperatures are measured internally at the suction and discharge ports, but it is possible to compute this parameter for open compressors from performance data. 
Compressor motor efficiency can be determined by test outside the compressor can; also, ideally, manufacturer's data would be available. However, motor efficiency cannot be determined directly from heat pump system data.

Specifically for this study, estimates of can heat loss were determined both analytically and from experimental data; internal heat loss was estimated analytically; and typical values of volumetric, isentropic, and motor efficiencies were derived from published data. Starting with these estimates, parametric studies were made using the compressor model to determine which set or sets of parameters will produce the experimentally observed performance parameters.

It would be hoped that a single set of input parameters would uniquely duplicate the observed performance, and, for practical purposes, this proved to be the case. While precise estimates of the various efficiency parameters could not be determined by this procedure, a narrow range of the parameters could be selected that produced computed performance in reasonable agreement with observed performance.

\subsection{Condenser and Evaporator Models}

The condenser and evaporator models used in the ORNL program are unchanged from the MIT program. The models are predicated on the conventional crossflow configuration and staggered-tube and sheet-fin construction; accordingly, other surfaces in use such as spine-fin or bristle-fin cannot be accommodated at present. Principal input parameters are geometrical constants such as tube diameter and spacing, fin pitch and thickness, overall dimensions, number of parallel tube circuits, etc. All necessary correlations for fluid thermal properties, heat transfer coefficients, and flow friction factors, both air side and refrigerant side, are internal to the program. 


\subsubsection{Effectiveness $-\mathrm{N}_{\text {tu }}$ relationship}

Performance calculations are based on the effectiveness-N ${ }_{\text {tu }}{ }^{*}$ method. Specifically, both models employ the effectiveness $-N_{t u}$ relationship for a crossflow heat exchanger with both fluids unmixed. Thus, only certain refrigerant-side circuiting arrangements can be modeled rigorously, and nonequal parallel flow paths cannot be accommodated. In practice, this assumption probably does not impose serious restrictions on the validity of the mode1, as the effectiveness of evaporators and condensers in the two-phase (refrigerant) regions are relatively insensitive to flow arrangement. Nevertheless, it is not possible with the present program to model the variation in coil performance that can be obtained by changing refrigerant-side circuiting.

The exact equations for computing crossflow (with both fluids unmixed) effectiveness as a function of $\mathrm{N}_{\text {tu }}$ are not in closed form; Hiller and Glicksman ${ }^{1}$ employ an approximate relationship that is in closed form.

\subsubsection{Surface properties}

Heat transfer correlations for single-phase refrigerant flow inside tubes and air-side flow are based on data from Kays and London, ${ }^{7}$ in the form of " $\mathrm{j}$ " factor $\left(\mathrm{N}_{\mathrm{St}} \cdot \mathrm{N}_{\mathrm{Pr}}{ }^{2 / 3}\right)$ as a function of Reynolds number. The correlations for flow inside circular tubes are represented by three straight-line segments (in log-log coordinates) corresponding to laminar, transition, and turbulent flow. Air-side properties are represented by a single straight line (again, on a log-log plot).

Correlations for condensing coefficient are based on the method by Traviss, Baron, and Rohsenow, ${ }^{8}$ and the evaporation coefficient is based on work by Tong. 9

*Effectiveness is defined as the ratio of the actual heat transfer rate to the maximum possible heat transfer rate as limited by the first and second laws of thermodynamics. $N_{t u}$ is the ratio of surface heat transfer capacity to fluid heat transfer capacity, expressed as the product of heat transfer coefficient and surface area divided by the product of fluid flow rate and specific heat. Both are dimensionless parameters. Reference 7 presents a detailed explanation of the effectiveness $-\mathrm{N}_{\text {tu }}$ method of heat exchanger analysis. 
Two-phase flow pressure drop is computed using the LockhartMartinelli correlation, ${ }^{5}$ while single-phase pressure drop is calculated by conventional pipe-flow methods.

\subsubsection{Condenser}

In the condenser program, a computation is made to determine whether the wall temperature at the condenser entrance is less than the refrigerant saturation temperature. If it is not, the fraction of the condenser coil required for desuperheating the refrigerant is computed. Otherwise, it is assumed that two-phase flow begins at the entrance, even though the bulk temperature of the refrigerant may be above saturation.

The fraction of the coil needed to complete condensation (two-phase) is computed next. With the remaining fraction of the coil, the amount of refrigerant subcooling is calculated. Outlet air temperatures are then determined.

\subsubsection{Evaporator}

The model for the evaporator is similar to that for the condenser with the additional provision for computing the amount of air dehumidification, if any. In the method used, it is assumed that the heat transfer coefficient is unaffected by the presence of condensed moisture, and a heat-transfer/mass-transfer analogy is used to compute the rate of moisture removal. Total heat transfer rate is determined on the basis of enthalpy difference.

Initially, a computation is made to determine the dew point of the entering air and whether the wall temperature at the entrance is less than the dew point of the air. If it is determined that condensation from the air will not occur at the entrance, the fraction of the coil used only for sensible heat transfer is computed. (Since the air is being cooled in the evaporator while the temperature of the refrigerant is essentially constant in the two-phase region, the wall temperature will decrease in the direction of airflow and may drop below the dew point.) The performance of that section of the evaporator having 
two-phase evaporation on the refrigerant side and dehumidification on the air side is then computed. Finally, the amount of refrigerant superheating in the remaining fraction of the coil is computed with no allowance for further dehumidification on the air side.

At present, an error indication is given if heat transfer is insufficient to completely evaporate the refrigerant.

\section{RESULTS}

The compressor model was calibrated against observed values of refrigerant mass flow, compressor motor power consumption, and refrigerant temperatures and pressures measured at the inlet and outlet of the container housing the motor and compressor. These measurements were made under a variety of operating conditions. It was found that a single calibration of this preliminary version of the compressor model would not suffice for all system operating conditions because we have not yet incorporated routines that calculate the variation of efficiencies with changing load and pressure ratios. Thus for the case of superheated vapor reaching the compressor, two sets of loss parameters will be needed.for this version; one set for more than $20^{\circ} \mathrm{F}$ of superheat, and another that reduces heat rejection from the can and internal heat transfer rates when the degree of superheat drops below $20^{\circ} \mathrm{F}$. The loss parameters and efficiencies must all be reduced if the refrigerant reaching the compressor can is wet. It is hoped that further elaboration of the program will simplify the calibration of the model:

Using the compressor calibration obtained from two of the sets of laboratory measurements and the accompanying observations of operating conditions, we have run the ORNL heat pump model to calculate the performance of one of the heat pumps in our laboratory. Calculated values of refrigerant mass flow, compressor power consumption, heat exchange rates and coefficient of performance are compared in Table 1 to those observed in two of the laboratory runs. Inspection of the table reveals that agreement is generally good. The largest differences between calculated and observed quantities are those for refrigerant temperatures 
Table 1. Comparison of calculated and observed performance of an air-to-air heat pump

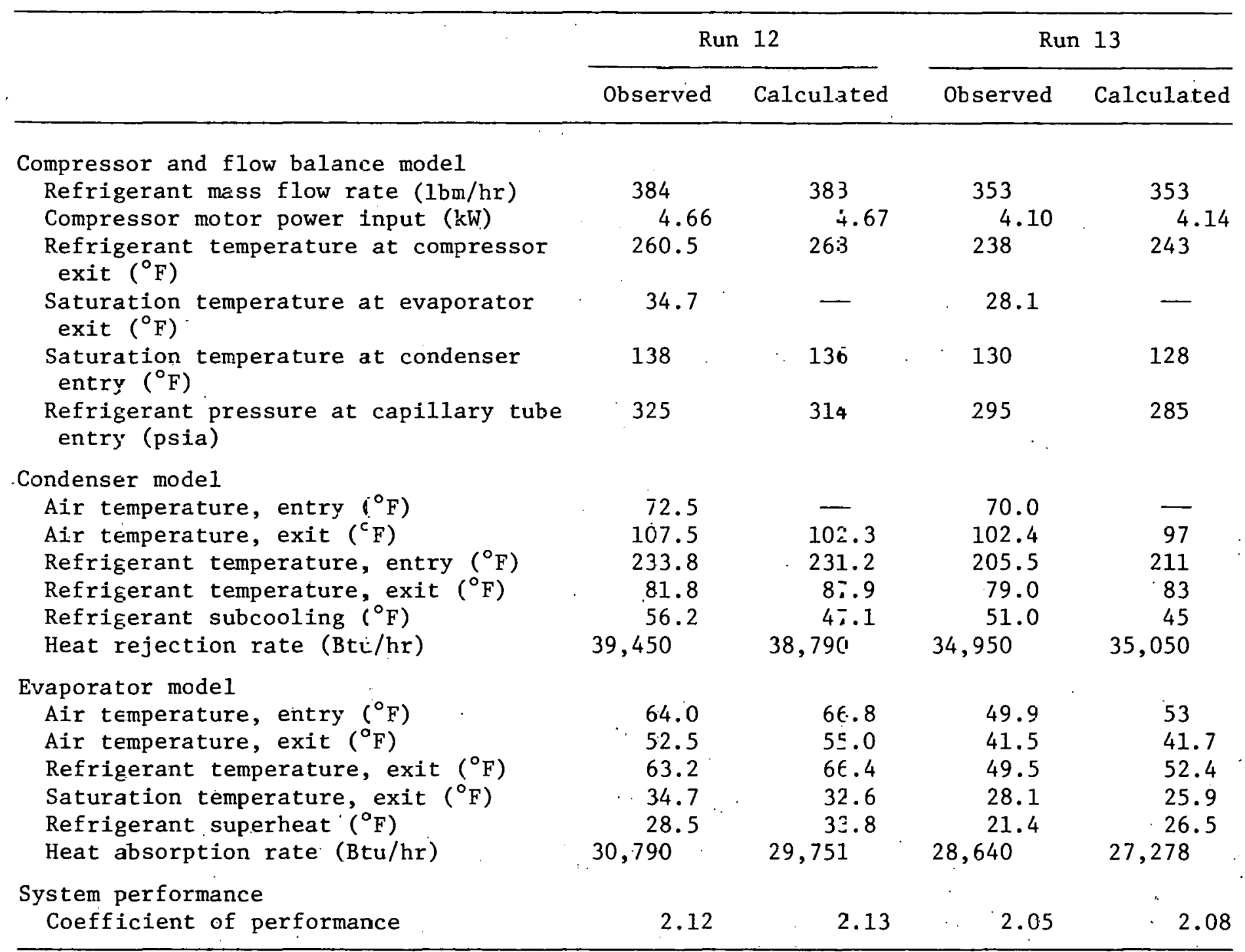


at the condenser inlet and outlet (and consequently the amount of subcooling which is determined from outlet and saturation temperatures), an error that could be introduced by the model's neglect of temperature drops along the interconnecting pipes. However, use of the measured temperature drop along the discharge tube (see card 1 of the input data to the computer program, Appendix A) fails to eliminate the discrepancy. The rather good agreement of calculated and observed heat exchange rates and coefficient of performance leads to the conclusion that the model is working satisfactorily. Neither the ORNL nor the MIT model has been validated for a heat pump operating in the cooling mode.

\section{PLANNED MODIFICATIONS}

The computer model described herein represents a first generation simulation program that can be used to predict the system performance resulting from many of the possible heat pump system improvements that are being contemplated in this study. However, it is planned that additional development work will be conducted on the model to improve its versatility. The changes that are being considered are described in the following paragraphs.

\subsection{Heat Exchanger Configuration}

The present model can accommodate only the conventional staggeredtube, sheet-fin heat exchanger geometry. However, other types are in use, such as spine-fin and bristle-fin. In addition, the exploration of possible advantages of other surface geometries is a valid research concern. Accordingly, it is planned that the program will be modified to accept surface properties of other types of heat exchanger construction. Most likely, this will be handled by making provision for reading in up to two additional sets of friction factor and Colburn " $f$ " factor, one for the condenser and one for the evaporator. Certain geometrical constants would be entered as input also. The program would simply be modified to use the input surface properties whenever they are entered. 
A second contemplated revision in the heat exchanger routines is the accommodation of variations in tube circuiting. This may require that the use of an effectiveness-N tu relationship be dropped and that some form of finite difference computational procedure be substituted. This procedure has not yet been formulated.

\subsection{Alternative Refrigerant Metering Device}

The model is presently equipped to compute refrigerant mass-flow rate in systems using either a capillary tube or thermostatic expansion valve for metering. Because some systems employ a fixed orifice for this purpose, it will be desirable to add an orifice model to the program. Such a model should be capable of simulating two-phase flow as well as the simpler single-phase case.

\subsection{Variation in Compressor Loss and. Efficiency Parameters}

In the present model, all compressor loss and efficiency parameters must be specified as input to each computer run. It may be desirable to compute some of these parameters in the program. For example, motor efficiency and speed as a function of load could be modeled within the program in nondimensional form with peak efficiency and rated motor power as input parameters. With such a scheme, it would not be necessary to enter motor parameters for each computer run. However, this approach does require that the characteristics of the motor be known either from test data or manufacturer's data. Since a strong similarity in the characteristics of different motors of a given type can be expected, it may suffice to enter "typical" motor curves into the program. The original MIT program contained a motor speed and efficiency model for a specific motor.

It should also be feasible to derive an empirical mathematical expression for volumetric efficiency as a function of pressure ratio. A change in volumetric efficiency characteristics of a compressor could then be represented by a revised set of coefficients for the volumetric efficiency model. 
At present, it does not appear to be either necessary or feasible to predict isentropic compression efficiency on the basis of operating conditions. While it might be possible to devise routines for predicting can external heat loss and internal heat transfer, it does not appear advantageous to try to do this at present.

\subsection{Refrigerant Mass Inventory}

In this program, no concern is given to the mass of refrigerant in the system; rather, it is implicitly assumed that the system is charged with exactly the correct amount. This is a satisfactory model for heat pump systems having a suction line accumulator; i.e., the accumulator is modeled satisfactorily by ignoring it. However, in systems that do not employ an accumulator, there can be an excess charge under certain operating conditions. Such a system, properly charged for the cooling cycle, may contain an excess charge during heating operation as a result of the lower system pressures, and the excess refrigerant will migrate to the condenser where it can partially block some of the heat transfer surface. To correctly model this type of system, a refrigerant mass inventory would be necessary as well as routines for deciding where the excess refrigerant will accumulate and what the effect on the thermodynamic cycle will be. No approach to accomplishing this has been formulated, but a study of possible approaches is planned.

\subsection{Incomplete Condensation and Evaporation}

The heat exchanger models developed by MIT are set. up to print an error message if incomplete condensation or evaporation are encountered. However, with capillary tube control, heat pump systems will operate with liquid refrigerant entering the compressor (incomplete evaporation) under low outdoor temperature conditions. It is planned that the program will be revised to accommodate both incomplete condensation and evaporation. This should not be difficult - the MIT authors had anticipated the possible 
need for this change. The ORNL compressor model is already set up to handle wet suction gas.

\section{UTILIZATION}

The ORNL version of the heat pump model is organized for computer use as a batch job on our IBM Model 360 computer. Accordingly, decision making that might otherwise be left to the user of an interactive program has been incorporated in the calling program. The flow diagram shown in Fig. 3 displays the sequence of calculations and the decision points. Input parameters for all of the submodels are read in the subroutine DATAIN and are listed in Appendix A, along with the values of the parameters used to generate the sample output shown in Appendix $B$.

The program is written in FORTRAN IV and makes use of standard FORTRAN supplied mathematical functions and service subroutines; special subprograms and extended libraries of functions are not required. No tapes or other peripheral temporary storage devices are used. Thus, the only control cards needed to run the program are those to compile and link the program and to execute it. All input is from the card reader. The control cards used to run the model on our computers are shown in Appendix B. The program occupies $86 \mathrm{~K}$ bytes of core and typically executes in less than $10 \mathrm{sec}$ on our IBM $360 / 91$ computer. A complete listing of the program is given in Appendix $C$.

\section{ACKNOWLEDGMENTS}

The authors wish to express their appreciation for the comments and suggestions of fellow staff member A. A. Domingorena who also, with the cooperation of $\mathrm{D}$. E. Holt, supplied the data against which the model was calibrated and validated. We are obviously beneficiaries of the work of Dr. Leon Glicksman of the Massachusetts Institute of Technology and Dr. Carl Hiller, now of the Sandia Laboratories, whose efforts provided an excellent starting point for this study. 


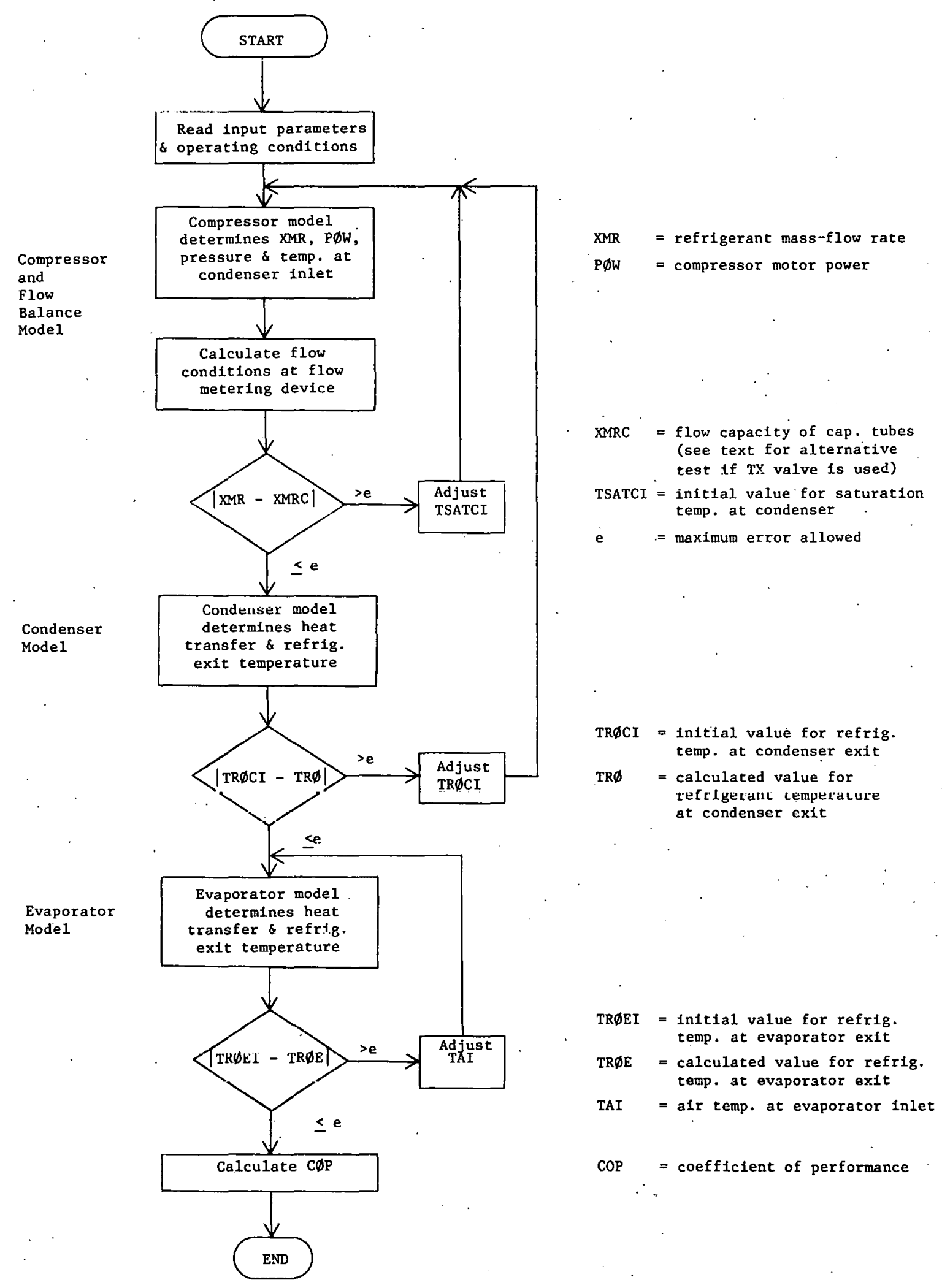

Fig. 3. Computer program flow diagram. 


\section{REFERENCES}

1. C. C. Hiller and L. R. Glicksman, Improving Heat Pump Performance via Compressor Capacity Control - Analysis and Test, Report No. 24525-96, Heat Transfer Laboratory, Massachusetts Institute of Technology, Cambridge, Massachusetts, 1976.

2. G. T. Kartsounes and R.'A. Erth, "Computer Calculation of the Thermodynamic Properties of Refrigerants 12, 22, and 502," ASHRAE Transactions, Vol. 77, Part II, 1971.

3. American Society of Heating, Refrigeration, and Air Conditioning Engineers, Inc., ASHRAE Handbook of Fundamentals, New York, 1972.

4. American Society of Heating, Refrigeration, and Air Conditioning Engineers, Inc., Thermophysical Properties of Refrigerants, New York, 1973.

5. R. W. Lockhart and R. C. Martinelli, "Proposed Correlation of Data for Isothermal Two-Phase, Two-Component Flow in Pipes," Chemical Engineering Progress, $45(1): 39$ (1949).

6. American Society of Heating, Refrigeration, and Air Conditioning Engineers, Inc., ASHRAE Guide and Data Book, Equipment Volume, pp. 20.23-20.28, New York, 1975.

7. W. M.. Kays and A. L. London, Compact Heat Exchangers, The National Press, Palo Alto, California, 1955.

8. D. P. Traviss, A. G. Baron, and W. M. Rohsenow, Forced Convection Condensation Inside Tubes, Report No. 72591-74, Heat Transfer Laboratory, Massachusetts Institute of Technology, Cambridge; Massachusetts:

9. L. S. Tong, Roiling Heat Tranefer and Two-Phase Fluw, Wiley, New York, 1965. 
THIS PAGE

\section{WAS INTENTIONALLY LEFT BLANK}


APPENDICES 
THIS PAGE

\section{WAS INTENTIONALLY LEFT BLANK}


Appendix A

INPUT PARAMETERS FOR THE ORNL HEAT PUMP SIMULATOR

Sample

Symbol

Definition

Value ${ }^{a}$

$\begin{array}{ll}\text { Card } 1 & \text { Format }(5 F 10.0) \\ \text { TLIMIT } & \text { Upper limit for difference between calculated } \\ & \text { subcooling of refrigerant leaving condenser } \\ & \text { and input (assumed) value of subcooling (see } \\ & \text { DTROC below). Used to define convergence }\end{array}$

10.0

DELTC

Temperature drop in discharge line (F)

32.0

XMRTI

Initial guess of refrigerant mass flow rate. Used only to estimate discharge line pressure drop tor tirst iteration ( $1 \mathrm{bm} / \mathrm{hr}$ )

FANPC Energy consumed by condenser fan. (Btu/hr)

2014.0

FANPE Energy consumed by evaporator fan (Btu/hr)

1703.0

Card 2 Format (4F15.5)

DLLOC Diameter of liquid line coming from outdoor coil ( $f t)$

0.0158

XLEQLO Equivalent length of liquid line coming from outdoor coil (L/D - dimensionless)

1923.0

DLLIC Diameter of liquid line coming from indoor coil ( $\mathrm{ft}$ )

0.0158

XLEQLI Equivalent length of liquid line coming from indoor coil (L/D - dimensionless)

1923.0

Card 3 , (4F15.5)

$\mathrm{DSL} \quad$ Diameter of suction line (vapor) ( $\mathrm{ft}$ )

0.0567

XLEQSL · Equivalent length of suction line (L/D dimensionless)

145.3

DDL Diameter of discharge line (vapor) ( $f t$ ) 0.0463

XLEQDL Equivalent length of discharge line (L/D dimensionless)

181.0

Card 4 (4F15.5)

DOC Inside diameter of tubes in outdoor coil ( $f t$ ) 0.0280

\footnotetext{
Values used to produce the nutpit of the program shown in Appendix B.
} 


\begin{tabular}{|c|c|c|}
\hline Symbol & Definition & $\begin{array}{l}\text { Sample } \\
\text { Value }^{a}\end{array}$ \\
\hline DZOC & $\begin{array}{l}\text { Refrigerant flow length in each parallel flow } \\
\text { branch in the outdoor coil ( } f t)\end{array}$ & 64.0 \\
\hline $\mathrm{DIC}$ & Inside diameter of tubes in indoor coil ( $f t)$ & 0.0280 \\
\hline DZIC & $\begin{array}{l}\text { Refrigerant flow length in each parallel flow } \\
\text { branch in the indoor coil ( } f t)\end{array}$ & 61.1 \\
\hline Card 5 & $(F 10.4,3 I 10)$ & \\
\hline DTROC & $\begin{array}{l}\text { Guess for amount of subcooling of refrigerant } \\
\text { leaving condenser (F) }\end{array}$ & 51.0 \\
\hline $\mathrm{NCORH}$ & $\begin{array}{l}\text { Indicator for cooling or heating mode } \\
\text { If "NCORH" }=1 \text { - cooling mode } \\
\text { If "NCORH" }=2 \text { - heating mode }\end{array}$ & 2 \\
\hline NSECTO & $\begin{array}{l}\text { Number of parallel flow sections in outdoor } \\
\text { coil }\end{array}$ & 4 \\
\hline NSECTI & $\begin{array}{l}\text { Number of parallel flow sections in indoor } \\
\text { coil }\end{array}$ & 3 \\
\hline Card 6 & $(3 F 10.2)$ & \\
\hline TSATE & Saturation temp. at exit of evaporator (F) & 28.1 \\
\hline TSATCI & $\begin{array}{l}\text { Saturation temp., entrance to condenser. } \\
\text { Initial guess }\end{array}$ & 130.0 \\
\hline SUPEKK & $\begin{array}{l}\text { Superneat of vapor leaving evaporator and } \\
\text { entering the compressor (F) }\end{array}$ & 25.1 \\
\hline Card 7 & $(7 F 10.2)$ & \\
\hline RPM & Motor speed (rpm) & 3450.0 \\
\hline DISPL & Compressor displacement (all cylinders) $\left(\mathrm{in} .{ }^{3}\right)$ & 4.525 \\
\hline ETAVOL & $\begin{array}{l}\text { Volumetric efficiency of compressor } \\
\text { (fraction.Lt.1) }\end{array}$ & 0.59 \\
\hline ETAMOT & Compressor motor efficiency & 0.65 \\
\hline ETAISN & Isentropic efficiency of compressor & 0.70 \\
\hline QCAN & Heat rejection rate from compressor can (Btúhr) & 4500.0 \\
\hline QHILO & $\begin{array}{l}\text { Heat transfer rate from compressor discharge } \\
\text { line to inlet gas (Btu/hr) }\end{array}$ & 500.0 \\
\hline
\end{tabular}

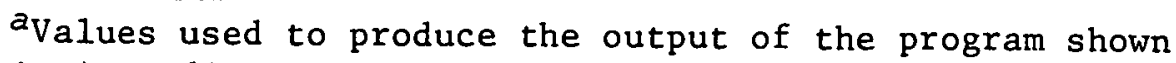
in Appendix $B$. 


\begin{tabular}{|c|c|c|}
\hline Symbol & Definition & $\begin{array}{l}\text { Sample } \\
\text { Valuea }\end{array}$ \\
\hline Card 8 & $(I 5,5 X, I 5,5 X, F 10.2)$ & \\
\hline IREFC & $\begin{array}{l}\text { Indicator for type of refrigerant flow control } \\
\quad=1 \text { for thermal expansion valve } b \text {. } \\
\quad=2 \text { for capillary tube }(s)\end{array}$ & 2 \\
\hline NCAP & Number of capillary tubes (omit if IREFC $=1$ ) & 1 \\
\hline CAPFLO & $\begin{array}{l}\text { Flow factor for cap. tube. See ASHRAE Guide } \\
\text { and Data Book, Equipment Vol. }(1975) \text {, Fig. 4l, } \\
\text { Pp. 20.23-20.28 (omit if IREFC = 1) }\end{array}$ & 2.25 \\
\hline Card 9 & $(6 F 12.6) \quad$ Begin Condenser Input & \\
\hline DEAC & Outside diameter of tubes ( $f t$ ) & 0.0333 \\
\hline DERC & Inside diameter of tuhes $(f t)$ & 0.0280 \\
\hline DELTAC & Fin thickness ( $f t)$ & 0.00053 \\
\hline FPC & Fin pitch (fins/ft) & 168.0 \\
\hline $\mathrm{XKFC}$ & Thermal conductivity of fins (Btu/hr-ft-F) & 128.0 \\
\hline AAFC & Heat exchanger frontal area $\left(\mathrm{ft}^{2}\right)$ & 3.1666 \\
\hline Card 10 & $(2 \mathrm{I} 10)$ & \\
\hline NTC & Number of tubes in direction of airflow & 3 \\
\hline NSECTC & Number of parallel circuits in heat exchanger & 3 \\
\hline Card 11 & $(3 F 15.5)$ & \\
\hline HCONTC & $\begin{array}{l}\text { Contact conductance between fins and tubes } \\
\left(B t u / h r-f t^{2}-F\right)\end{array}$ & 30000 \\
\hline STC & Vertical spacing of tube passes ( $f t$ ) & 0.08333 \\
\hline WTC & Spacing of tube rows in direction of airflow ( $f t)$ & 0.07292 \\
\hline Card 12 & $(2 \mathrm{~F} 10.4)^{\circ}$ & \\
\hline QAC & Airflow rate (cfm) & 1200.0 \\
\hline TAIIC & Air temperature entering condenser (F) & 70.0 \\
\hline
\end{tabular}

aValues used to produce the output of the program shown in Appendix $B$. bParameters for modeling the pressure drop across the TXV must be inserted in DATA statements in subroutine FL $\emptyset$ BAL. See Hiller and Glicksman ${ }^{1}$, pp. 59-61. 


\begin{tabular}{|c|c|c|}
\hline Symbol & Definition. & $\begin{array}{l}\text { Sample } \\
\text { Value }^{a}\end{array}$ \\
\hline Card 13 & Begin Input for Evaporator & \\
\hline DEAE & Outside diameter of tubes ( $f t$ ) & 0.0333 \\
\hline DERE & Inside diameter of tubes $(f t)$ & 0.0280 \\
\hline DELTAE & Fin thickness ( $f t$ ) & 0.00053 \\
\hline FPE & Fin pitch (fins/ft) & 168.0 \\
\hline XKFE & Thermal conductivity of fins (Btu/hr-ft-F) & 128.0 \\
\hline AAFE & Heat exchanger frontal area $\left(\mathrm{ft}^{2}\right)$ & 5.1944 \\
\hline Card 14 & $(2 \mathrm{I} 10)$ & . \\
\hline NTE & Number of tubes in direction of airflow & 3 \\
\hline NSECTE & Number of parallel circuits in heat exchanger & $4^{\circ}$ \\
\hline Card 15 & $(3 F 15.5)$ & \\
\hline HCONTE & $\begin{array}{l}\text { Contact conductance between fins and tubes } \\
\left(\text { Btu/hr-ft } t^{2}-F\right)\end{array}$ & 30000 \\
\hline STE & Vertical spacing of tube passes ( $f t$ ) & 0.0833 \\
\hline WTE & Spacing of tube rows in direction of airflow $(f t)$ & 0.0729 \\
\hline Card 16 & $(2 \mathrm{~F} 10.4, \mathrm{I} 4,2 \mathrm{~F} 10.4)$ & \\
\hline QAE & Airflow rate $(\mathrm{cfm})$ & 2162.0 \\
\hline TAIIE & Air dry bulb temperature entering evaporator (F) & 49.9 \\
\hline INDICE & $\begin{array}{l}\text { Input indicator } \\
\text { If "INDICE" }=1 \text {, inputs are TDB, and TWB } \\
\text { If "INDICE" = } 2 \text {, inputs are TDB, and } \mathrm{RH}\end{array}$ & 2 \\
\hline TWBIIE & Air wet bulb temperature entering evaporator $(F)$ & not used \\
\hline RHIE & Relative humidity of air entering evaporator & 0.30 \\
\hline
\end{tabular}

avalues used to produce the output of the program shown in Appendix $B$. 
Appendix B

SAMPLE OUTPUT FROM HEAT PUMP SIMULATOR 


\section{THIS PAGE}

\section{WAS INTENTIONALLY LEFT BLANK}




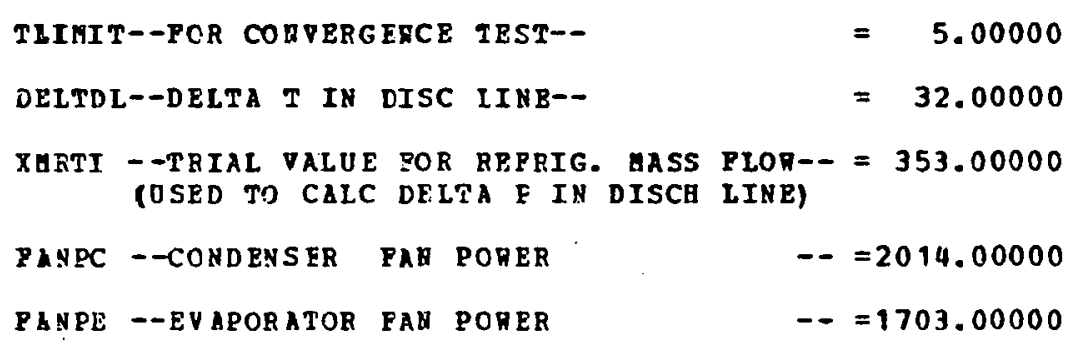

FLORAL IMPUT BCHO:

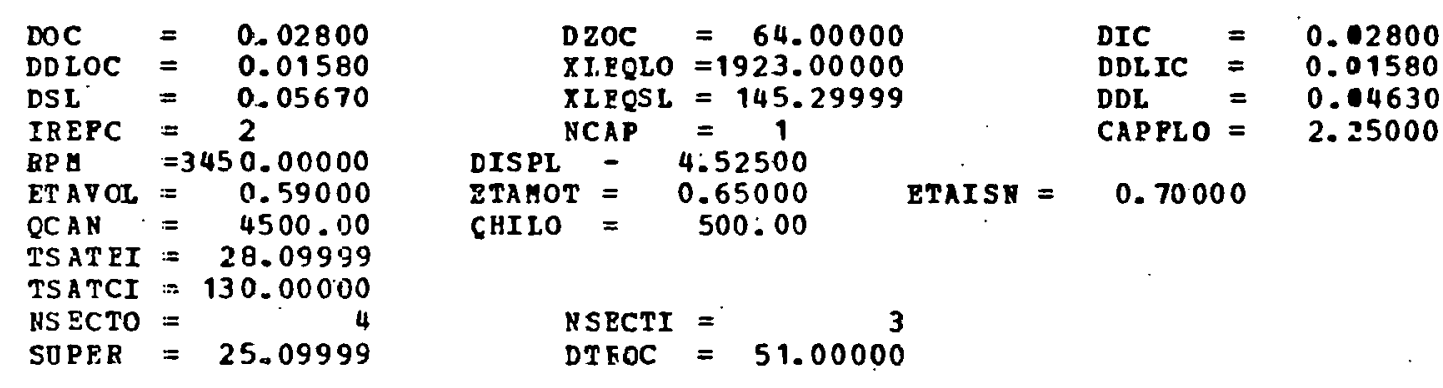

DZIC $=61.09999$ XLEQLI $=1923.00000$ XLEQDL $=181.00000$

RAD OP FLOBAL INPJT

\footnotetext{
${ }^{2}$ See program listing for glossary of symbols.
} 
CONDEHSER INPOT ECHO:

$\begin{array}{ll}\text { DBA }=0.03330 & \text { DER }=0.02800 \\ \text { AAP }=3.167 & \text { RI }=3 \\ \text { HCONT }=30000.0 & \text { ST }=0.0833 \\ \text { QA }=1200.0 & \text { TAII }=70.00\end{array}$

DELTA $=0.530 \mathrm{E}-03$
NSECT $=3$

$\mathrm{PP}=168.00$

$\mathrm{IKP}=128.00$

HCONT $=30000.0$

TAII $=70.00$

CALCOLATHD EXCHANGER CHAHACTERISTICS :

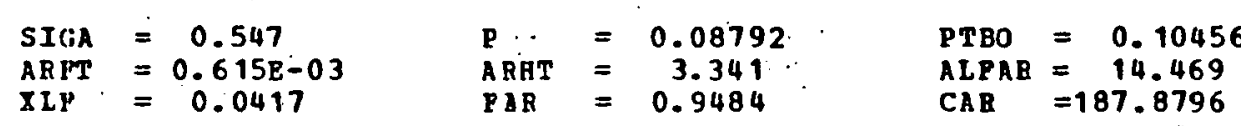

ALPAA $=303.542$

BHD OP CONDENSER INPOT

EVAPOAATOA INPOT ECHO:

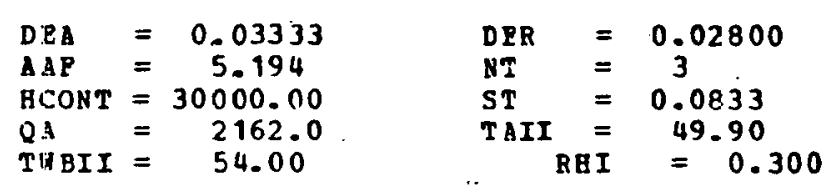

DELTA $=0.500 \mathrm{E}-03$

NSECT $=$

จT $=0.0729$

INDIC $=2$

CALCULATED EXCHANGEA CHARACTERISTICS:

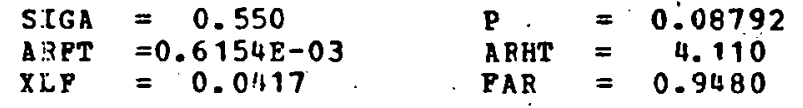

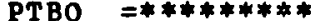

ALPAR $=14.469$

CAR $=198.9131$

ALFAA $=303.556$

PHD OF DATAIN--CALIING FLOBAI 
TOP OP ITERATION IOOP
PRESENT SYSTEY PALUES ARE
TSATE $=28.09999$

TSATC $=128.00000$

XHR

$=352.70605$

CXar

$=361.43872$

BOTTOY OP ITERATION LOOF:

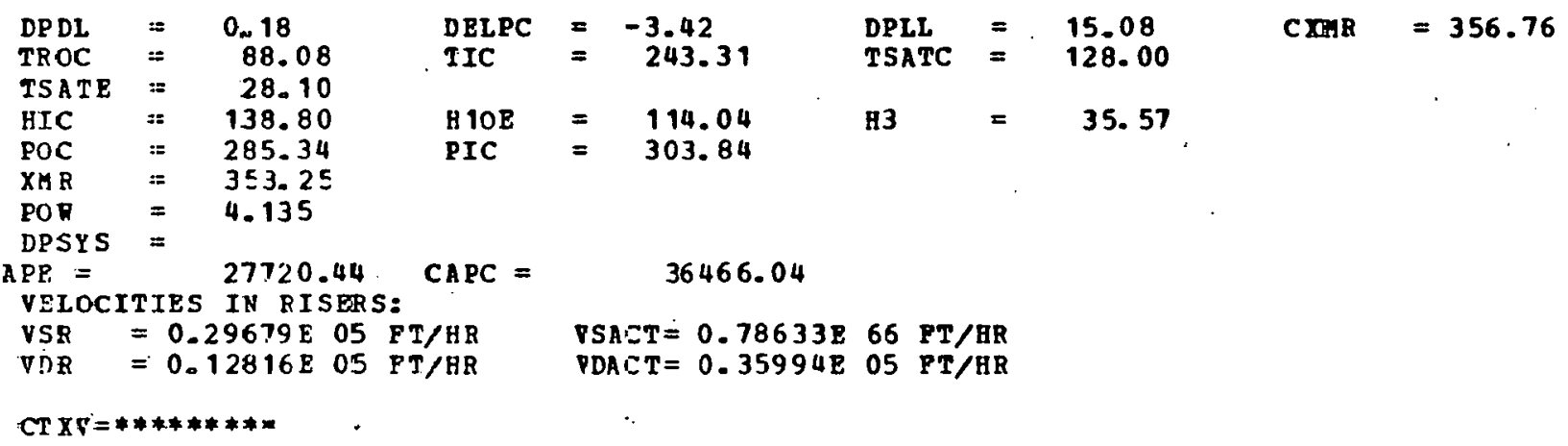

END OP PLOBAL---CALLIHG COND

DATA SENT TO CORD:

$X$ XRI $=353.24707$

$T S A=128.00000$

$T R I=211.31250$ 


$$
\begin{aligned}
& \text { TAI }=70.00 \\
& \text { QA }=-1200.0 \\
& T R I=211.31 \\
& T S A=128.00
\end{aligned}
$$

BEGINING OP CALCOLATION IN SOBROOTINE BXCH :

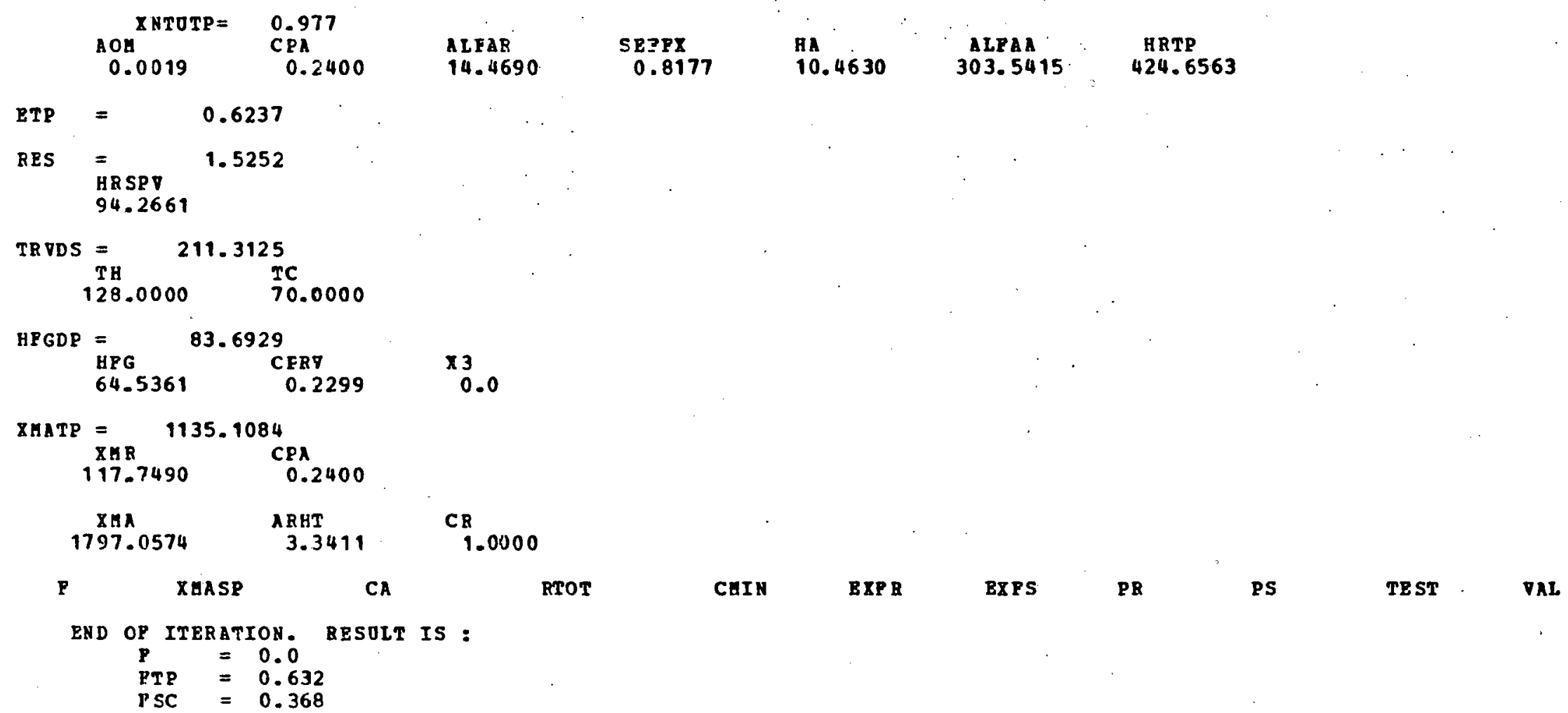


RESOLTS FRO EXCH:

\begin{tabular}{|c|c|c|c|c|c|}
\hline $\begin{array}{l}\mathbf{p} \\
\text { QSP } \\
\text { TAOSP }\end{array}$ & $\begin{array}{l}=0.0 \\
=0.0 \\
=\quad \mathbf{7 0 . 0 0}\end{array}$ & $\begin{array}{l}\text { PTP } \\
\text { CTP } \\
\text { TAOTP }\end{array}$ & $\begin{array}{l}=0.632 \\
=9854.7578 \\
=106.17\end{array}$ & $\begin{array}{l}\text { PSC } \\
\text { QSC } \\
\text { TAOSC }\end{array}$ & $\begin{array}{l}=0.368 \\
=1828.4192 \\
=81.51\end{array}$ \\
\hline $\begin{array}{l}\text { I!AI } \\
\text { TAO = } \\
\text { TRI = } \\
\text { ISA } \\
\text { TRO = } \\
\text { SBCOOL= }\end{array}$ & $\begin{array}{r}=\quad 70.00 \\
=\quad 97.09 \\
=\quad 211.31 \\
=\quad 128.00 \\
=\quad 83.38 \\
=\quad 44.62\end{array}$ & . & & & 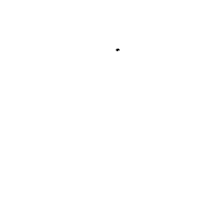 \\
\hline
\end{tabular}

OVBRALL RESULTS POR THIS TAI :

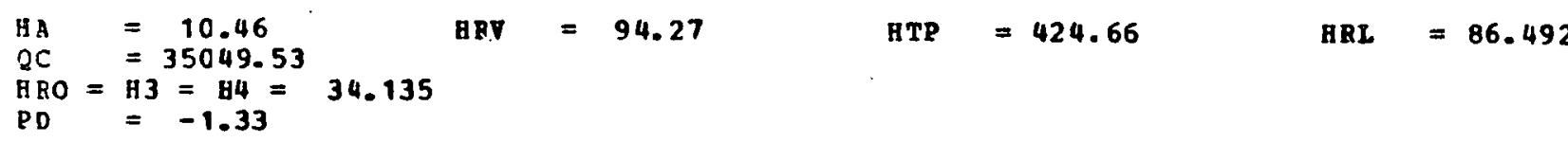

TEST POR CORVERGENCE ON DTROC

TSTAC $=0.12800 \mathrm{E} 03$

DTROC $=0.39917802$

TEST $=0.88083802=$ TSATC - DT KOC

$T R O=0.83385 E 02$ FROA SR COND

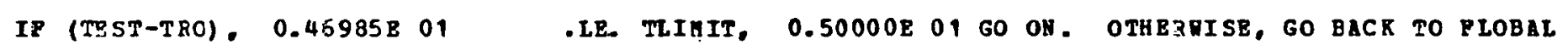


DATA SENT TO EVAPB:

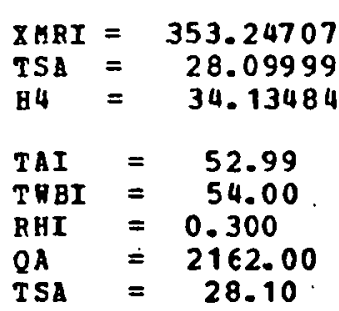

BEGINNING OF CALCOLATION IN SOBROOTIHE BVAP:

TADHI $=16.21$

NO MOISTURE REMOVAL OCCORS

$T$ IOTP $=37.81$

FRACTION OP COIL : OSED POR SINGLE-PHASE VAPOR PLOR IS $=0.2949$

RESULTS PROH SOBEOOTIRB EVAP:

\begin{tabular}{|c|c|c|c|}
\hline $\begin{array}{l}\text { PTP } \\
\text { XMATP } \\
\text { CTP } \\
\text { TDB3 }\end{array}$ & $\begin{array}{l}=0.705 \\
=1768.92 \\
=6445.06 \\
=\quad 37.81\end{array}$ & $\begin{array}{l}\text { P } \\
\text { XIASP } \\
\text { EXFR } \\
\text { QSP } \\
\text { TAOSP }\end{array}$ & $\begin{array}{l}=0.295 \\
=739.84 \\
=0.960 \\
=355.80 \\
=\quad 50.99\end{array}$ \\
\hline $\begin{array}{l}\text { TAI } \\
\text { IWBI } \\
\text { TSA } \\
\text { TRO } \\
\text { SOPBR }\end{array}$ & $\begin{array}{l}=\quad 52.99 \\
=\quad 40.81 \\
=\quad 28.10 \\
=\quad 52.01 \\
=\quad 23.91\end{array}$ & & \\
\hline
\end{tabular}

TRB3 $=0.00$

NOTE THAT THESE HEAT AUD MASS ILONS ARE'FOR ORE SECTION ONLY 
EVAPORATOR PERPORMANCE ROR THIS AIR INLET TEMP:

$$
\begin{aligned}
& X \text { HA }=10035.1 \quad X K R=353.25 \\
& \begin{array}{llll}
G A & =3515.0 & G R & =143493.8 \\
H A & =11.27 & \text { BRV } & =59.08
\end{array} \text { HTP }=511.65 \\
& \text { QTOT }=27203.5 \text { QLAT }=7730555.0 \\
& P D=-5.35
\end{aligned}
$$

PEESSURE DROP THRO EVAPORATOR IS LARGE ENODGH

TO DEPRESS SATORATICA TBKP. CALCOLATIOB RILL BE REPBATBD

FOR TSA $=25.87$

BEGINHIHG OP. CALCULATIOA IN SOBROUTINE EVAP:

TADHI $=19.27 \quad$ TAORP $=36.40$

NO HOISTURE REROVAL OCCORS

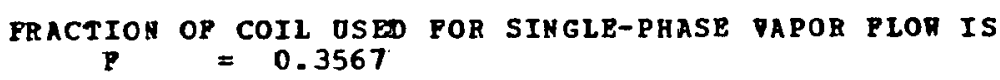

RESOITS PROE SO 3 ROOTINB EVAP:

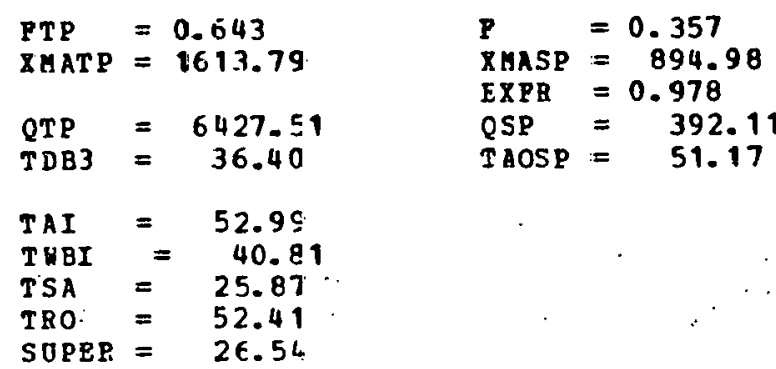

NOTE THAT THESE HEAT AND HASS FLOHS:ARE FOR ONE SECTIOH ONLY 
ETAPORATOR PERPORMANCE POR THIS AIR INLET TEHP:

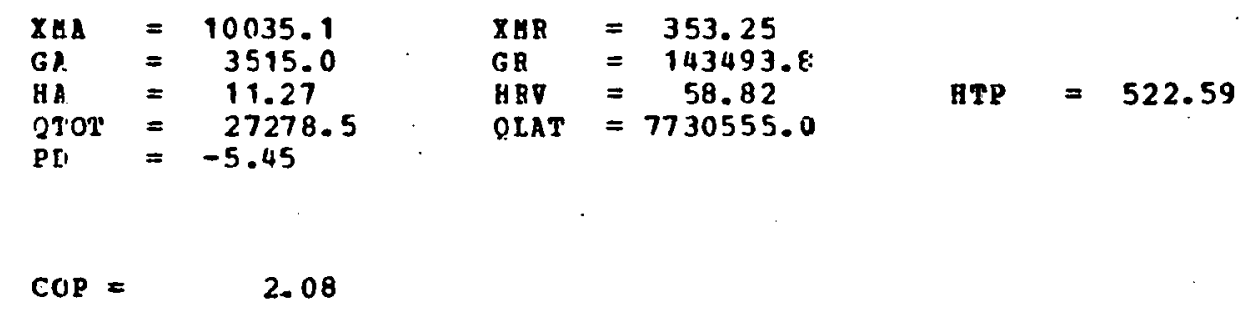

CONTRUL CARDS AND AKRANGEMENT OF DECK

FOR RUN ON IHM 360/91 COMPUTER

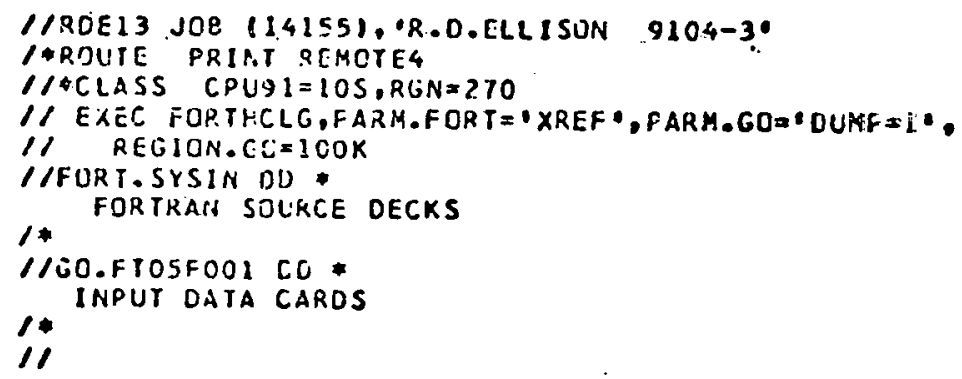


Appendix C

COMPUTER PROGRAM LISTING 
THIS PAGE

\section{WAS INTENTIONALLY LEFT BLANK}


Appendix C

COMPUTER PROGRAM LISTING

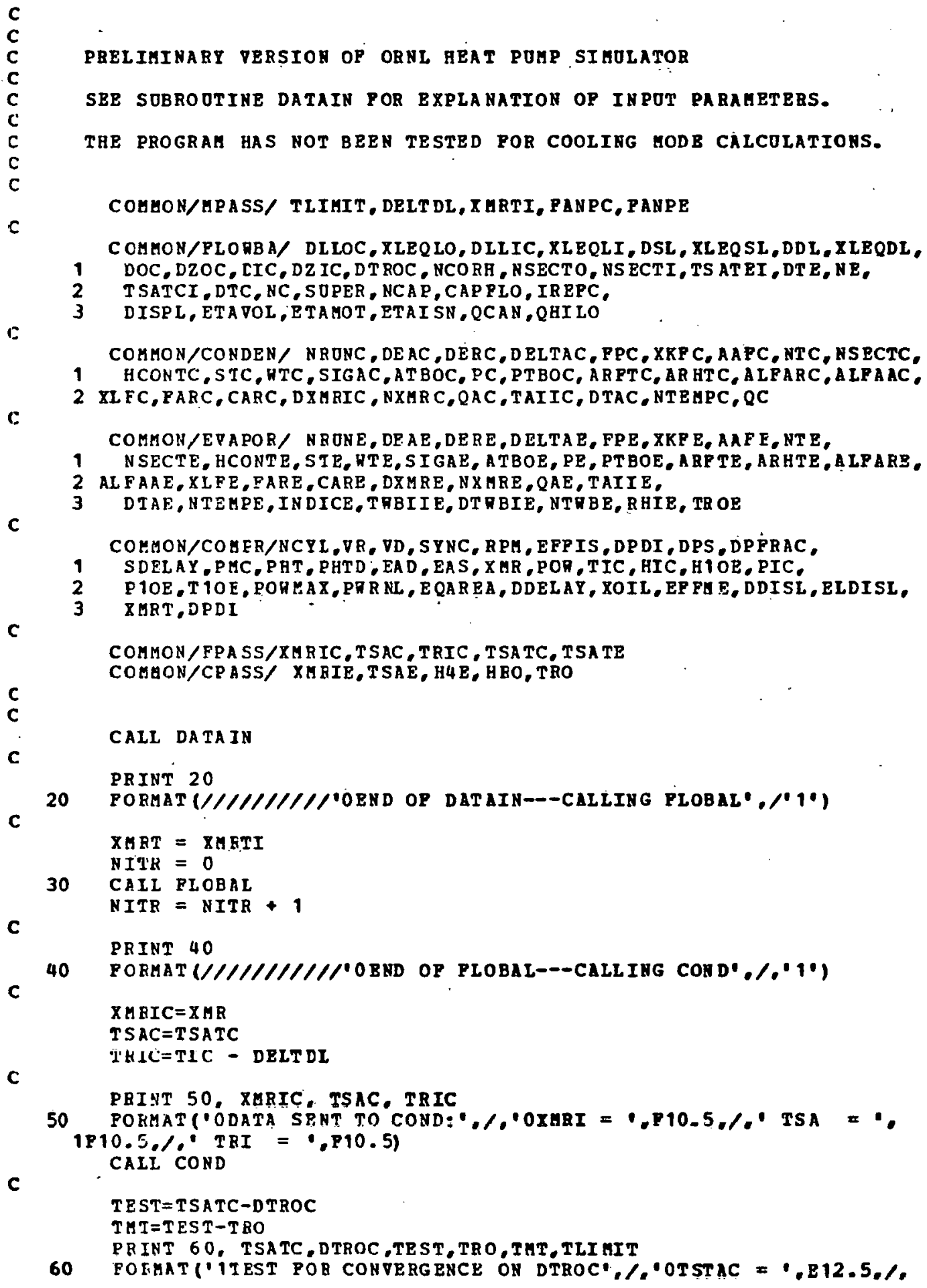




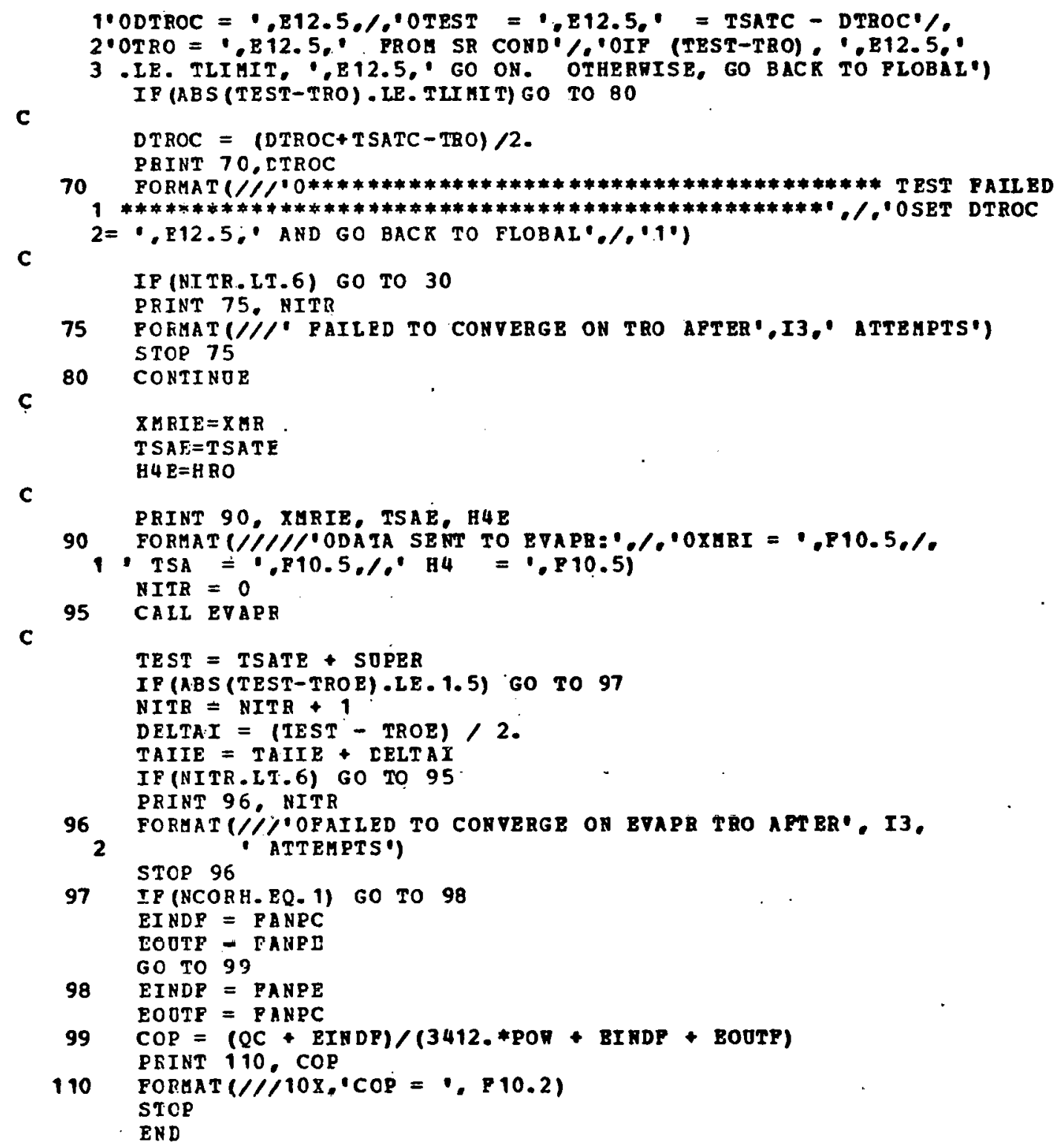




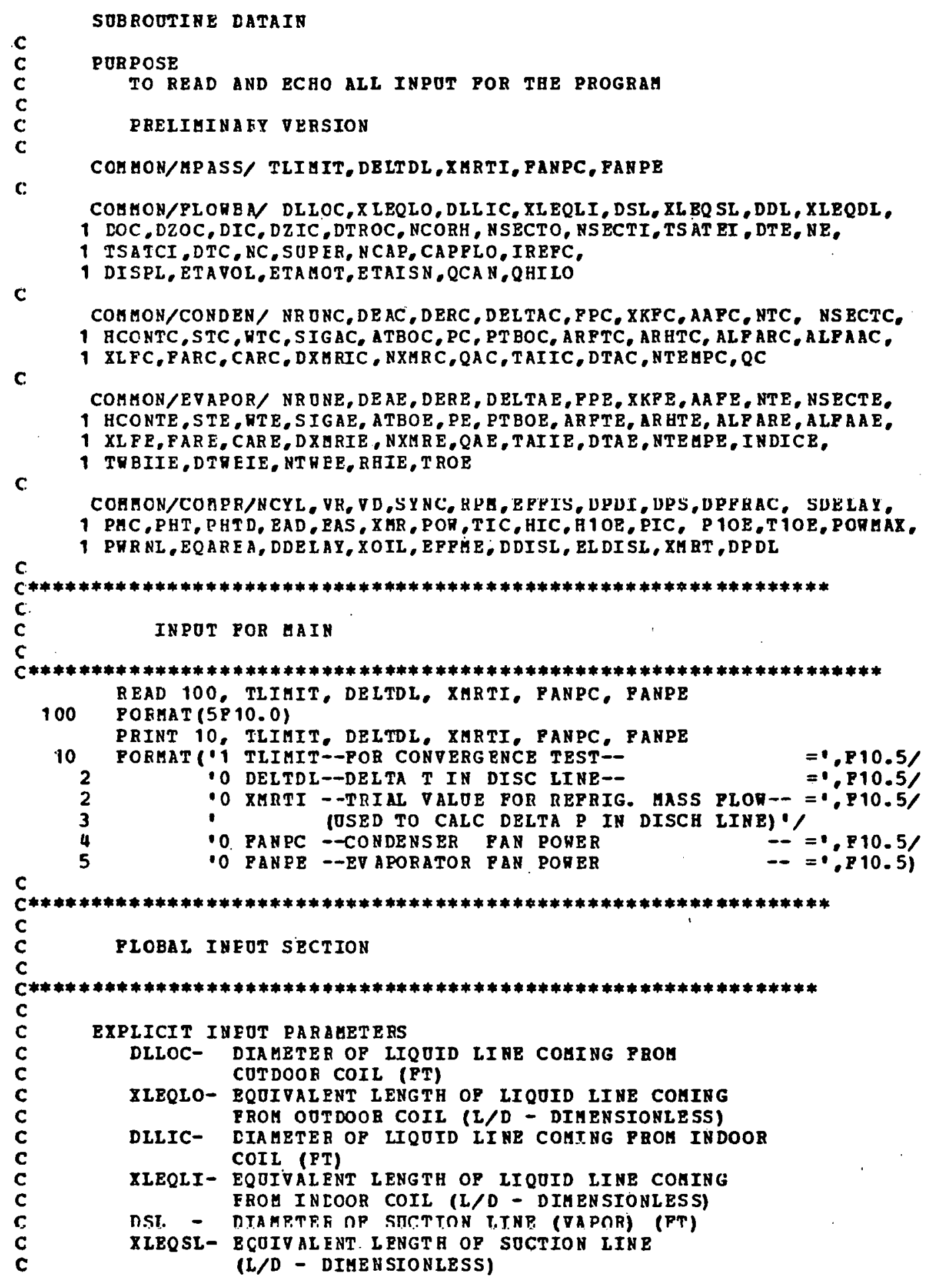




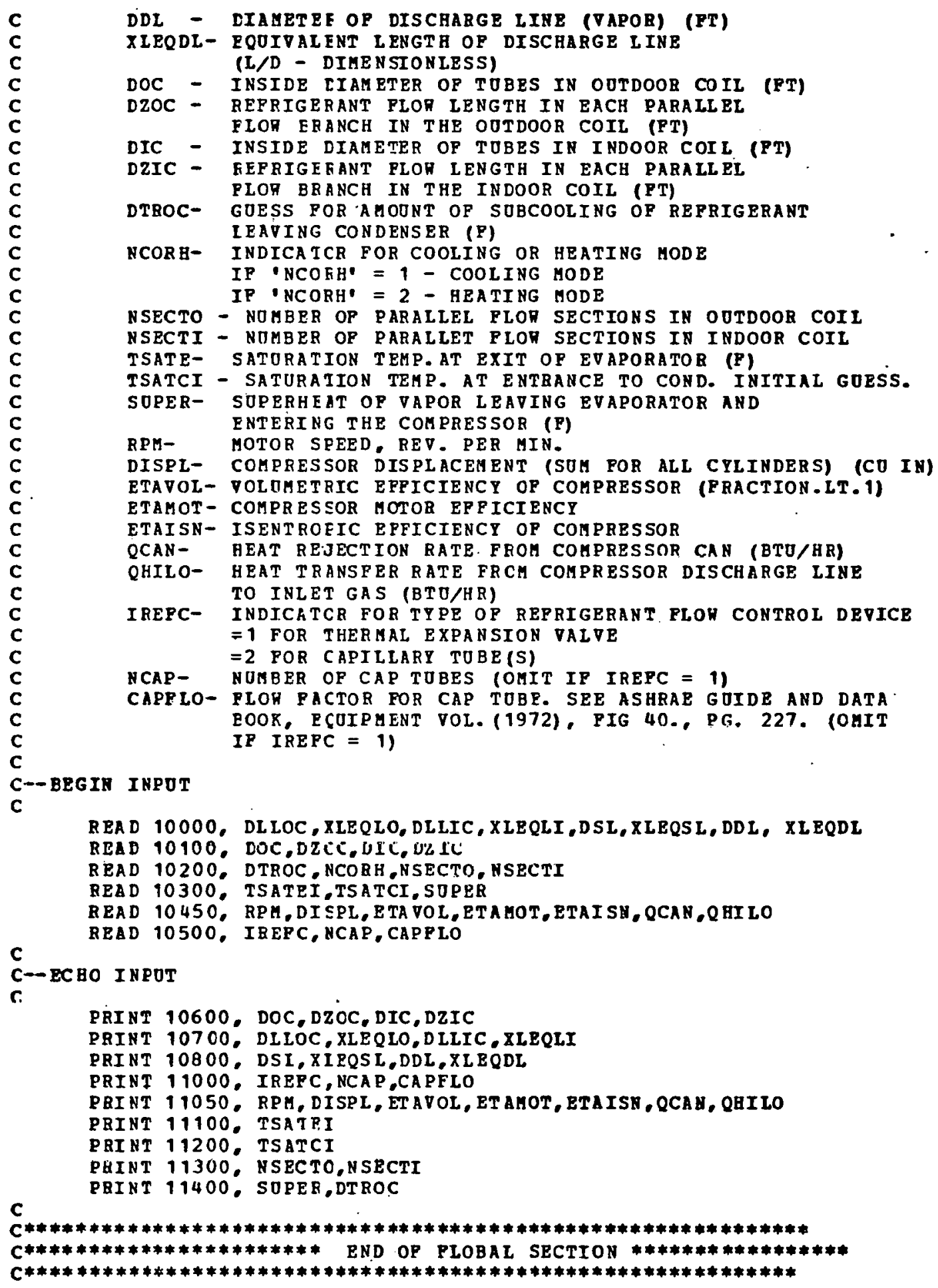




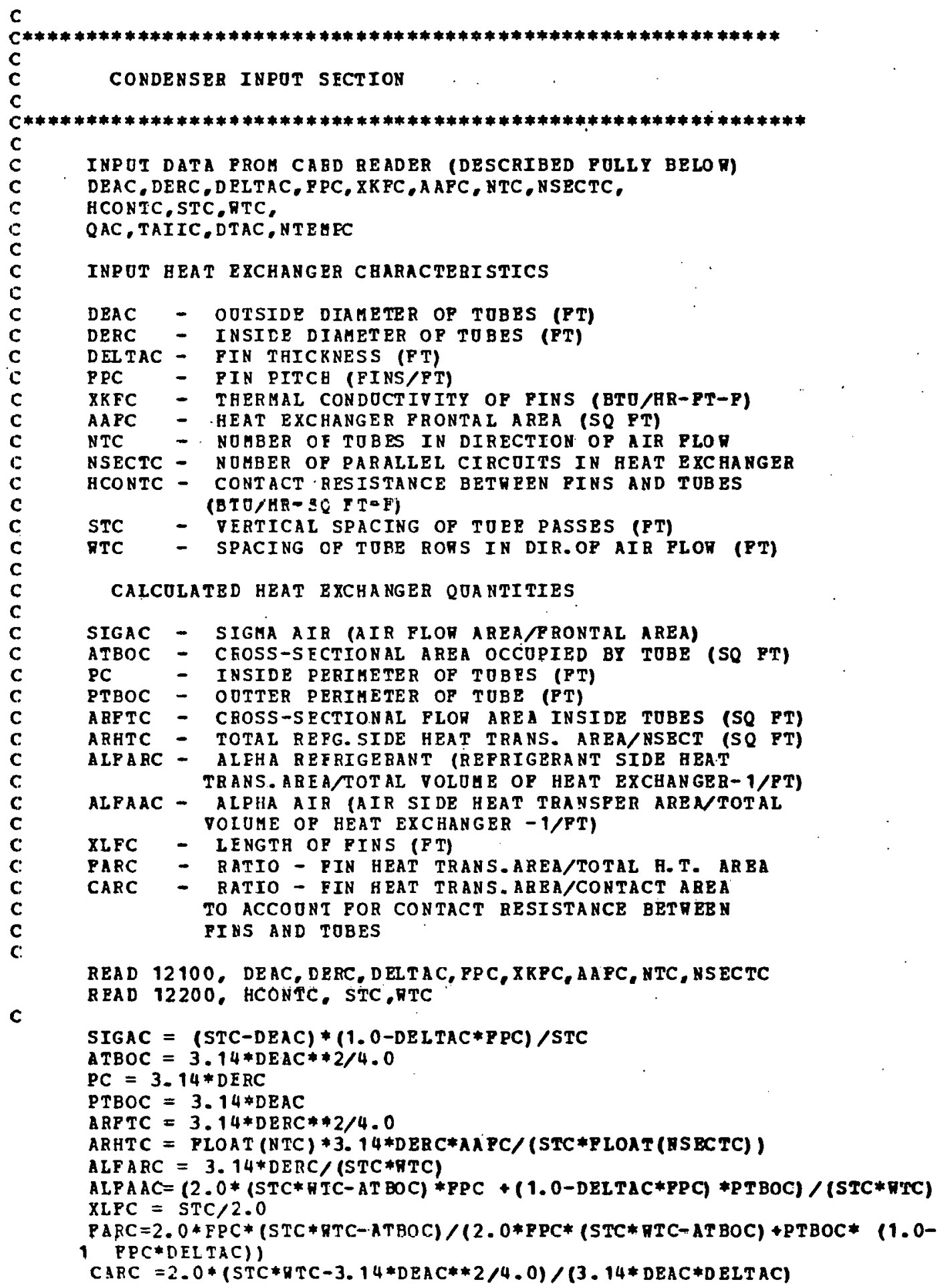




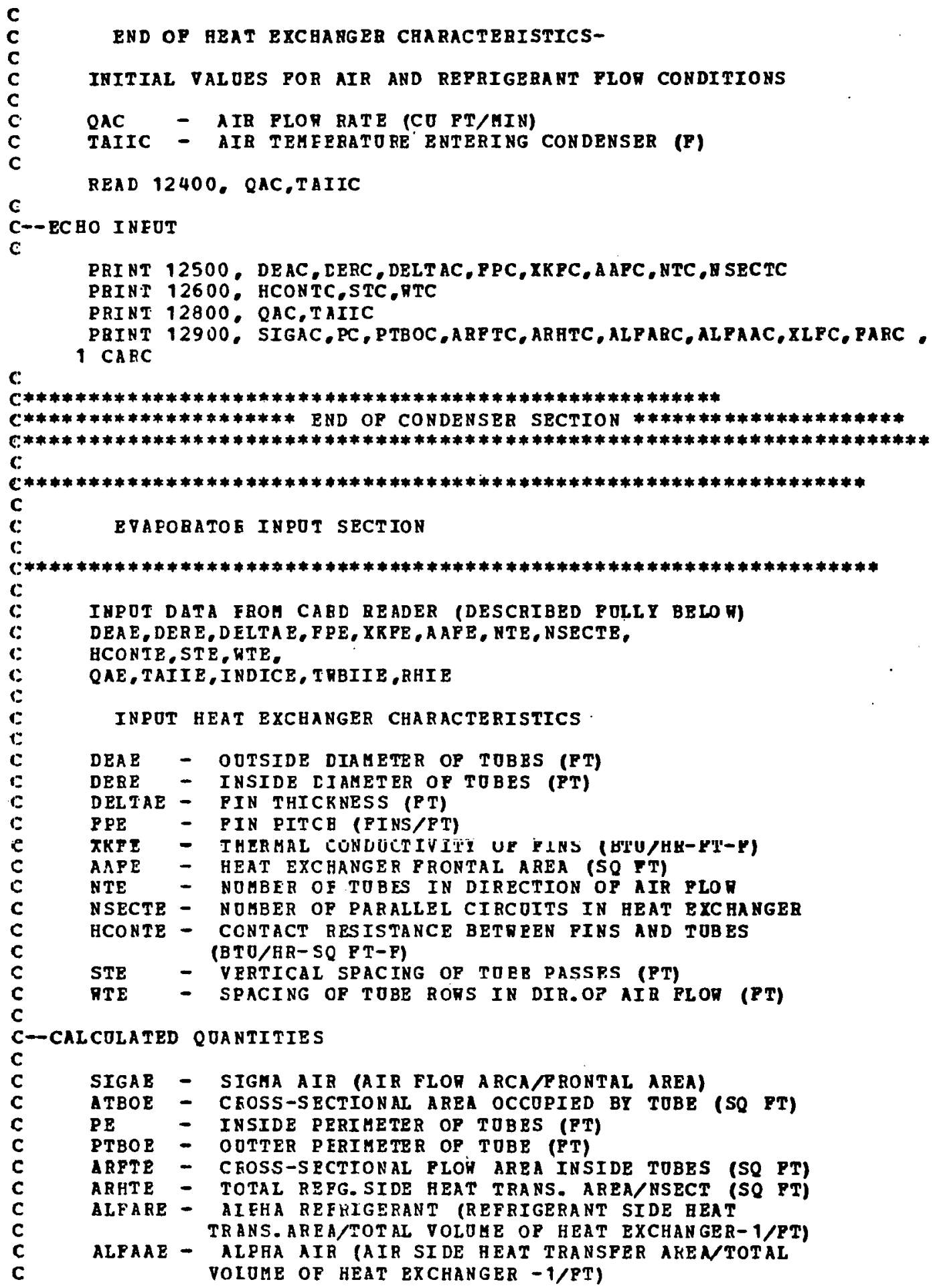




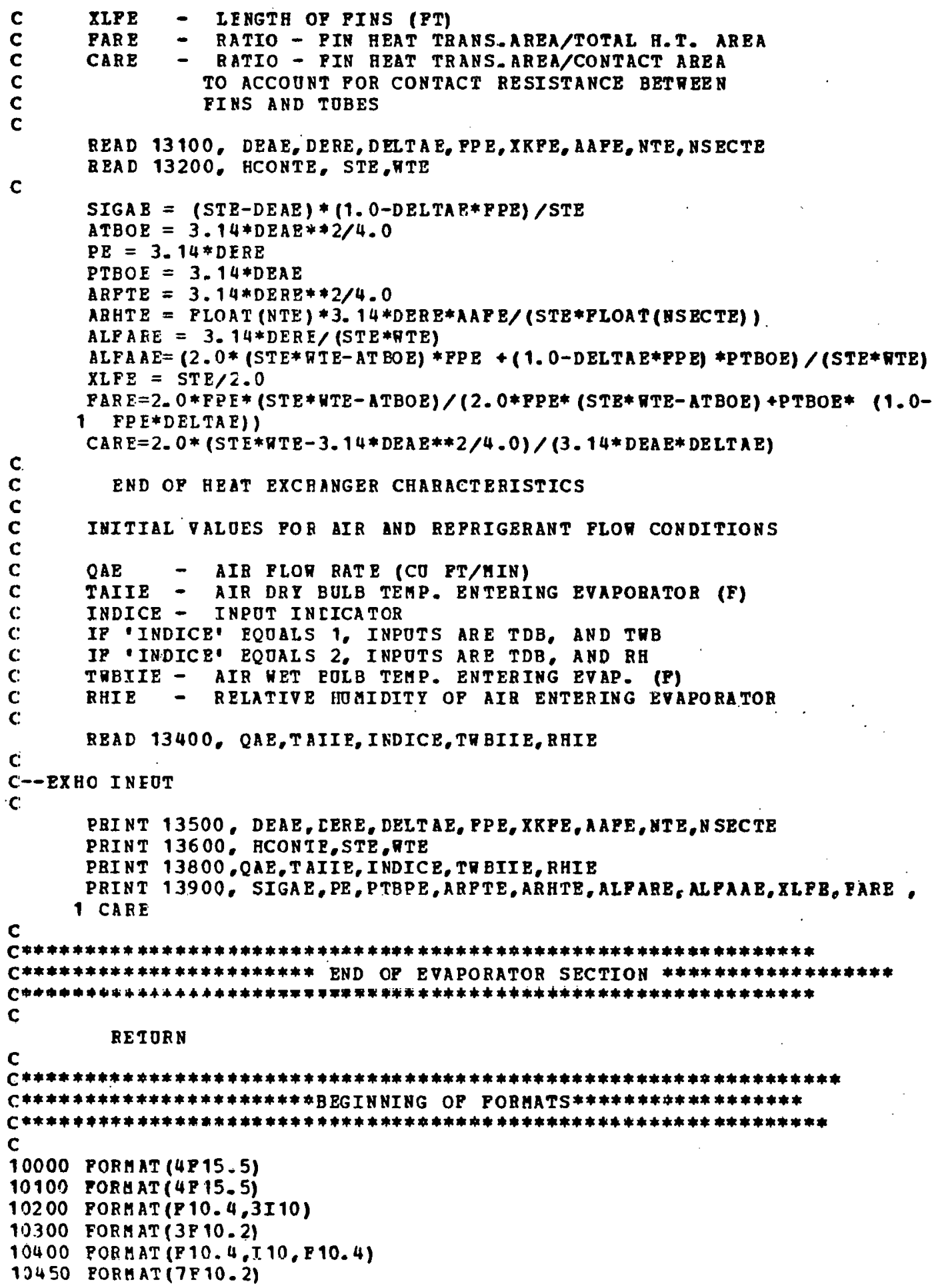




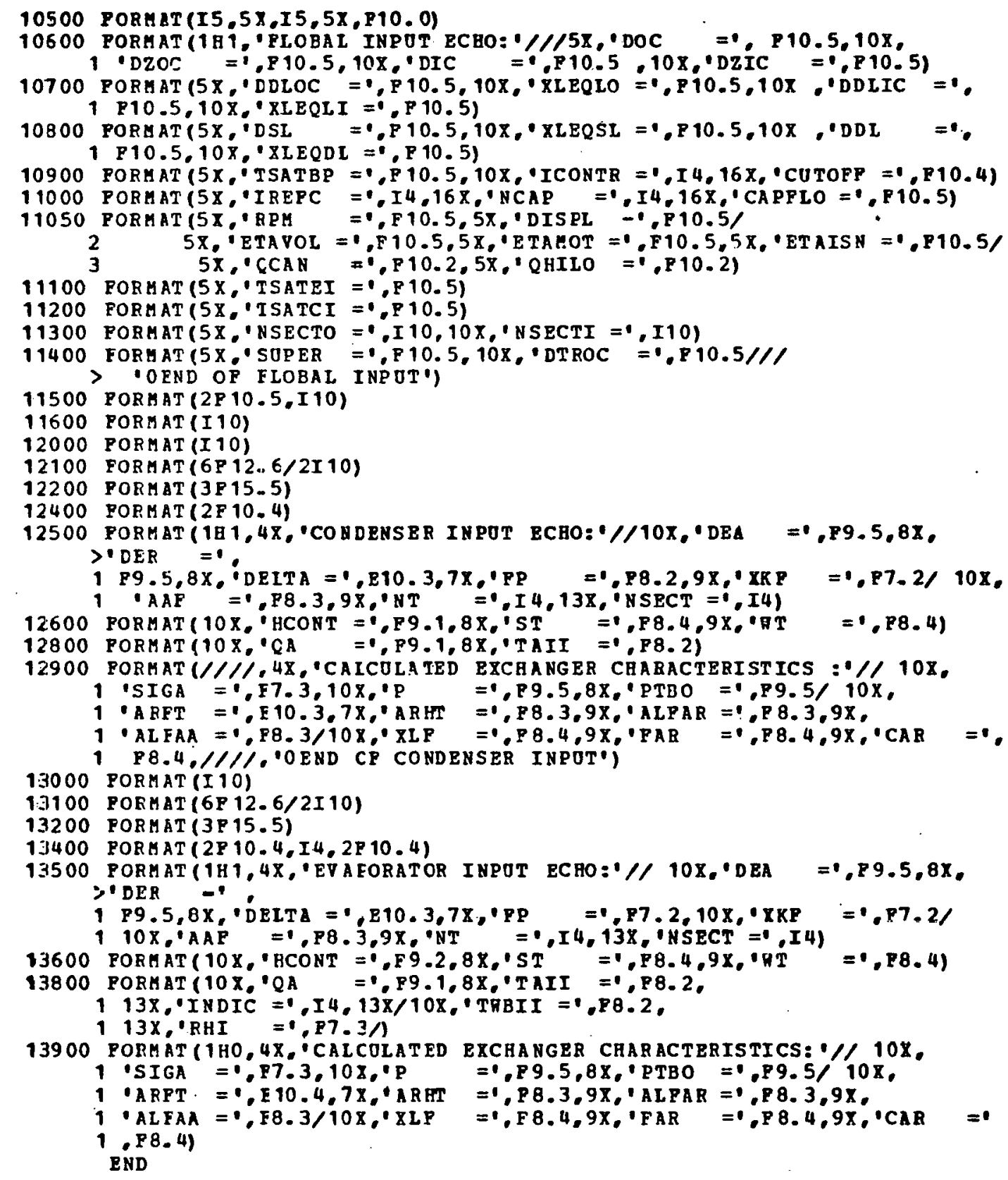


SOBROOTIK B PLOBAL

SYSTEA PLCA BALANCE SOBROOTINE

PORPOSE

TO DETERUINE THE CONDENSER AND EVAPORATOR CONDITIONS

QHICH, RITH GIVEN THERMAL EXPANSION VALVE BE HA VIOR

AND A GIVEN COMPRESSOR (EITHER CONVENTIONAL OR

CAPACITY CONTROIIED) , RILL PRODDCE A MASS FLOD

BALANCE IN THE SYSTEM

OREL VERSION,

MODIPIED PROM INDEPENDENT CALLING PROGRA

BY C. C. HIILER AND L. R. GIICKCHAN, *** BEEORT NO. 24525-96,

HEAT TRA YSFER LABORATORY,

MASSACHOSETTS INSTITOTE OP TECHNOLOGY.

IRPOT DATA CONSTANTS

SLPEAV $\varepsilon$ XINHV - COEFPICIENTS FOR DETERMINING VISCOSITY OP REPRIGERANT VAPOA

$8 \div 1-8 \times 4$

- COEFFICIENTS POR DBTERHINING VISCOSITY OP REPRIGERANT LIQO ID

C 1-ca

- COBFPICIBHTS FOR DBTERAININO THE THERHAL EXPANSION VALVE BEHAVIOR

NOTE: THE INPOT DATA CONSTANTS ARE FOR REFRIGERANT 22 ONXY

OOTEOT PARABETEBS

TSATE ANC TSATC POR A REPRIGERANT FLOR BALANCE (P)

XHR - REPRIGEEANT MASS PLOW RATE AT BALANCE CONDITIONS (LBH/RR)

POR - TOTAL CCMPRESSOR INPOT PORER AT PLOD

BALANCE CONDITIONS (K⿻)

TIC - TEMPERATORE OF REFRIGERANT ENTERING COND. (P)

REGARKS

THIS SOBROUTINE CALLS SUBROUTINE 'SATPRP' TO DETRRAINE

SATORATICN PROPERTIES OF REPRIGBAANTS

THIS PROGRAM CALIS SOBROUTINE ' COAP' TO DETERHINE

CCMPRESSOF PERFCRMANCE

THIS PROGRAM CAILS SUBROUTINE -DPLIHE TO DETERMINE

PEESSORE DROPS IN SINGLE PHASE REGIONS OP

CONNECTING PIPING

THIS PROGRAM CAILS SOBROOTINE PDROP' TO DETERAINE PRESSURE DROPS IN THO-PRASE FLOR IN THE BEAT EXCH:

THIS PROGBAM USES FONCTIUN SUBPROGRAE 'TSAT' TU DETERHINE SATURATTON TEMPERATORES CORRESPONDING TO

GIVEN PBESSURES

COMKON/PLONBA，DLLCC,XLEQLO,DLLIC, XLEQLI,DSL, XLEQSL, DDL, XLEQDL, 1 DOC,DZOC,DIC, DZIC,DTROC, NCORH, NSECTO, NSBCTI, TSAT EI, DTE, NE,

1 TSATCI, DTC, NC, SORER, NCAP, CAPPIO, IREFC,

1 DISPL, ETAVOL, ETAMOT, ETAISN, OCAN,OHILO

C

COHHON/PPASS/XMRIC,TSAC,TRIC,TSATC,TSATE

C

COMHON/COAPR/NCYL, VR, VD,SYNC, RPG, EPPIS, DPDI,DPS DPPRAC, SDEIAY . 1 PAC, PHT, PHTC, EAD, EAS, X HR , POH, T IC, HIC, H 1OE, PIC, P 10E, T1OP, POPHAX. 1 PRRNL, EQAREA, DOQLAY, XOIL, EFPME, DDISL, ELDISL, XHBT,DPDL 
DATA SLPEHV, XIREV/.0000759,.0272/

DATA XM1,XH2,XH3,XE4/-5.625E-08,1.525E-05,-2.982E-03,.646/

DATA C1,C2,C3/2.128E-03,.2491.9.455/

DDISI = DDI

ELDISL $=$ XLEQDI

$\mathrm{NR}=22$

C

C------IOOP POR ITERATIRG ON CONDENSER TEHPERATORE---.--

c

ITERATE TO PIND THE CONLENSER TERPBRATORE VHICH

GIVES A SYSTEL FLO BALAKCE POR THE GIVEN TSATE,

THER

c

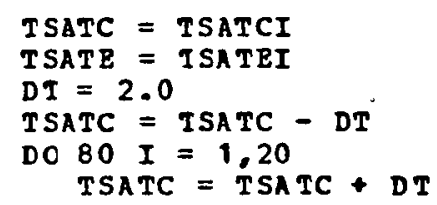

PRINT 11300

IF (IREFC. BQ-1) PRINT 11400, TSATE,TSATC,DPSYS,DPACT

IP (IREFC.EQ.2) PEINT 11450, TSATB,TSATC,XBR,CXMR

IF (IREFC.IT. 1 OR. IREPC.GT.2) CALL BRROR

$c$
$C$
$C$
$C$
$C$
$C$

Calculate THE GOESSED TEMP. 'TROC' POR EXIT TEMP. OP

REFRIGERANT FROH CONDENSER (THIS HOST BE CHECKED

MANOALIY UTTA THE CUTPOT OP THE CONDENSER PERPORAARCE

PROGBAE)

TROC $=$ TSATC - DTROC

C
C

DETERAINE PROPERTIES OP LIQUID REPRIGERANT LEATING COND.

CALL SATPRP (NR,TROC,P,VP, VG,H3,HPG,HG,SP,SG)

$\mathrm{BHO3}=1.0 / \mathrm{VF}$

$X H O L=X \& 1 * T F O C * * 3+X \# 2 * T R O C * * 2+X \# 3 * T R O C+X H 4$

C
C
C
C

CALL GOBROUTINE COMP TO DRT RRAI YP TAR TOMPRRSSOR

PERPOREANCE AND REFRIGERANT PIOR RATE 'XIR'

2

CALI CONP (NE,TSATE,TSATC, SOPER,DISPL, BTAVOL, ETAHOT, BTAISA,

IP (NCORH. BQ. 1) GO TO 10

IP (NCORH.EQ.2) GO TO 20

C

DEPIRE VARTABLES IF OPERATING IA THB COOLIRG HODE

10

DERC $=$ DOC

GRC $=4.0 * X \forall R /($ PLOAT (NSECTO) *3.14*DERC**2)

DZTPC $=$ DZOC

$D E R E=D I C$

GRE $=4.0 * X H R /(P L O A T$ (NSECTI) *3. 14*DERE**2)

DZTPE = DZIC

DLL $=$ DLLOC

XLECLL = XLRCLO

NSECT = NSECTI

c

GO TO 30 


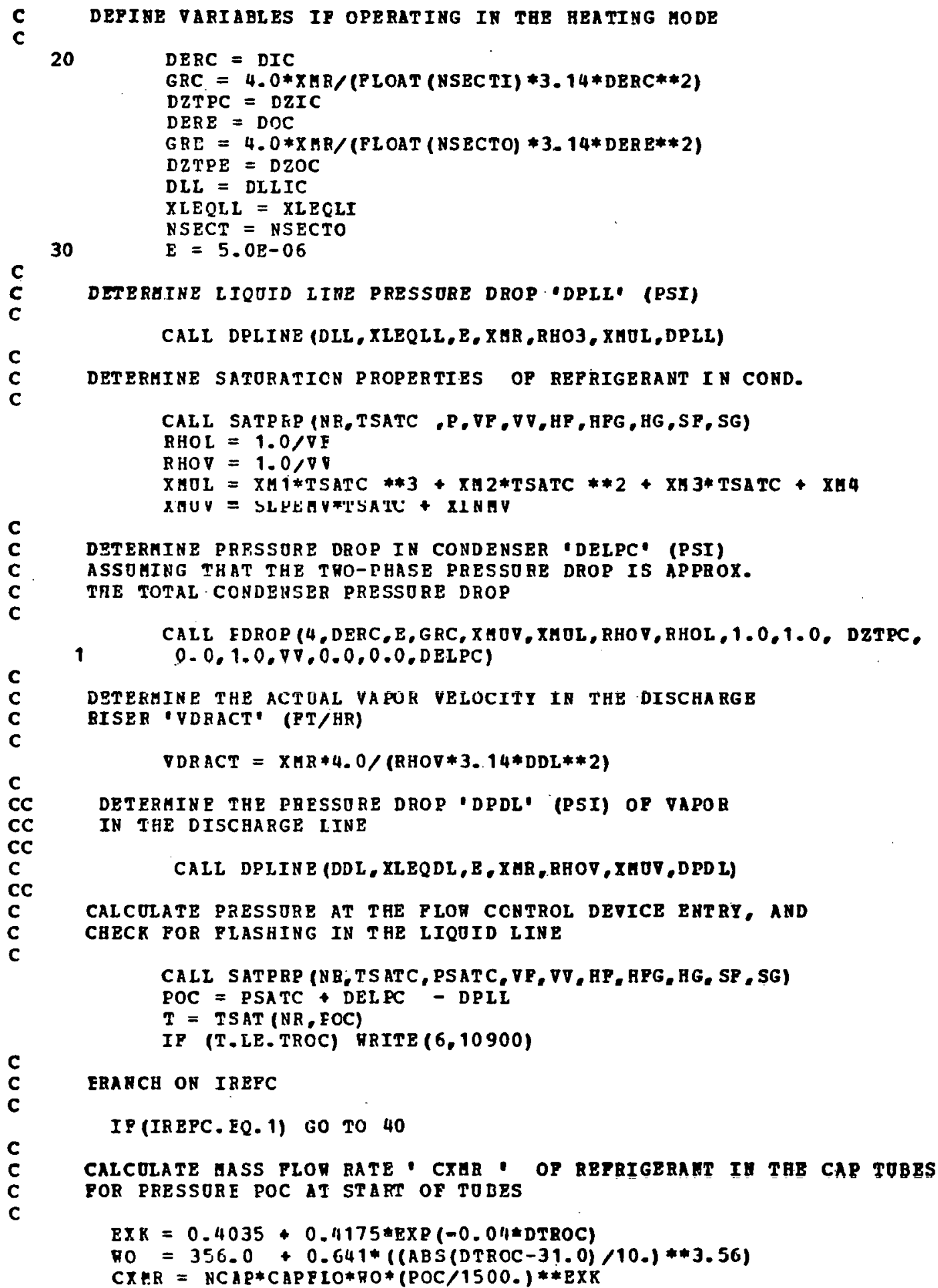




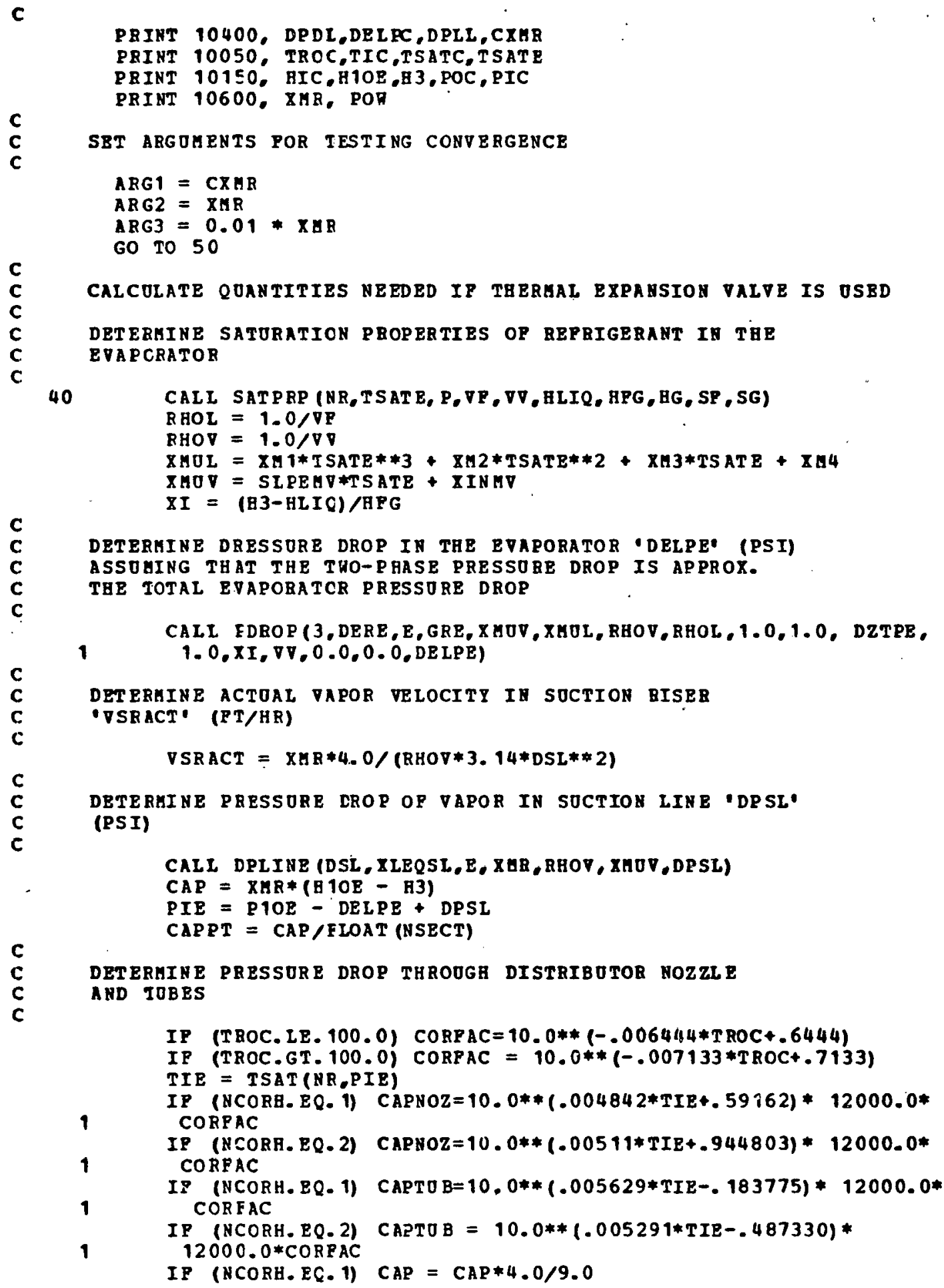




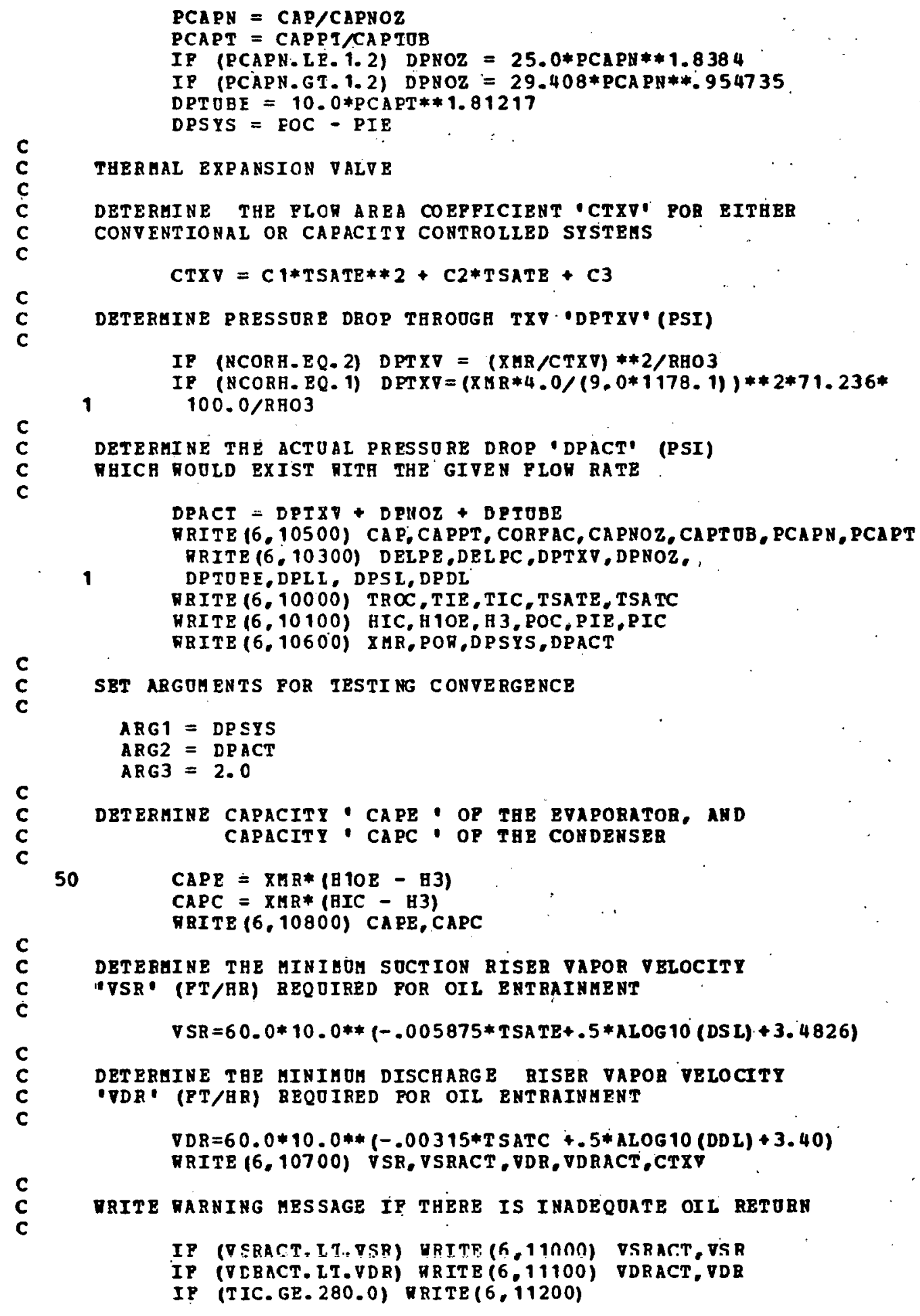



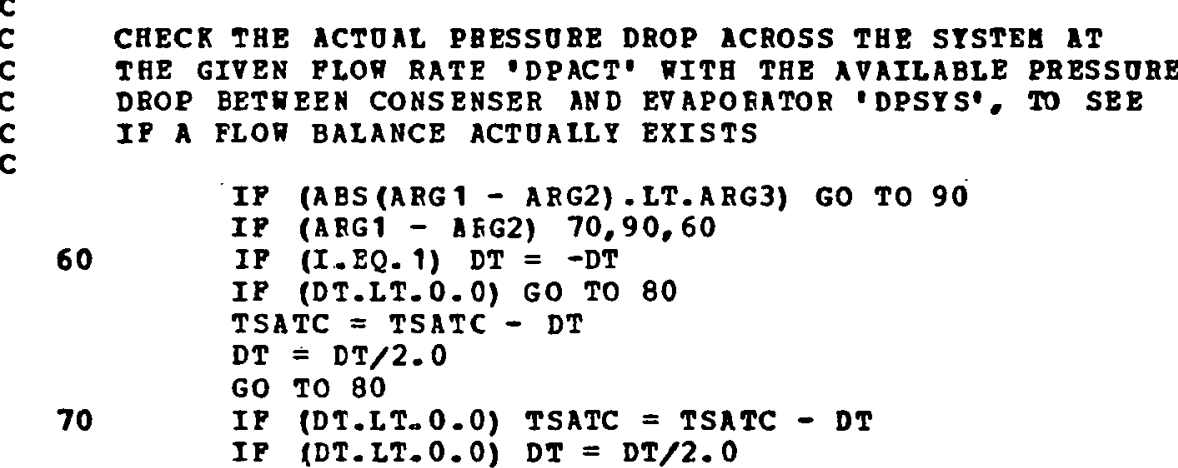


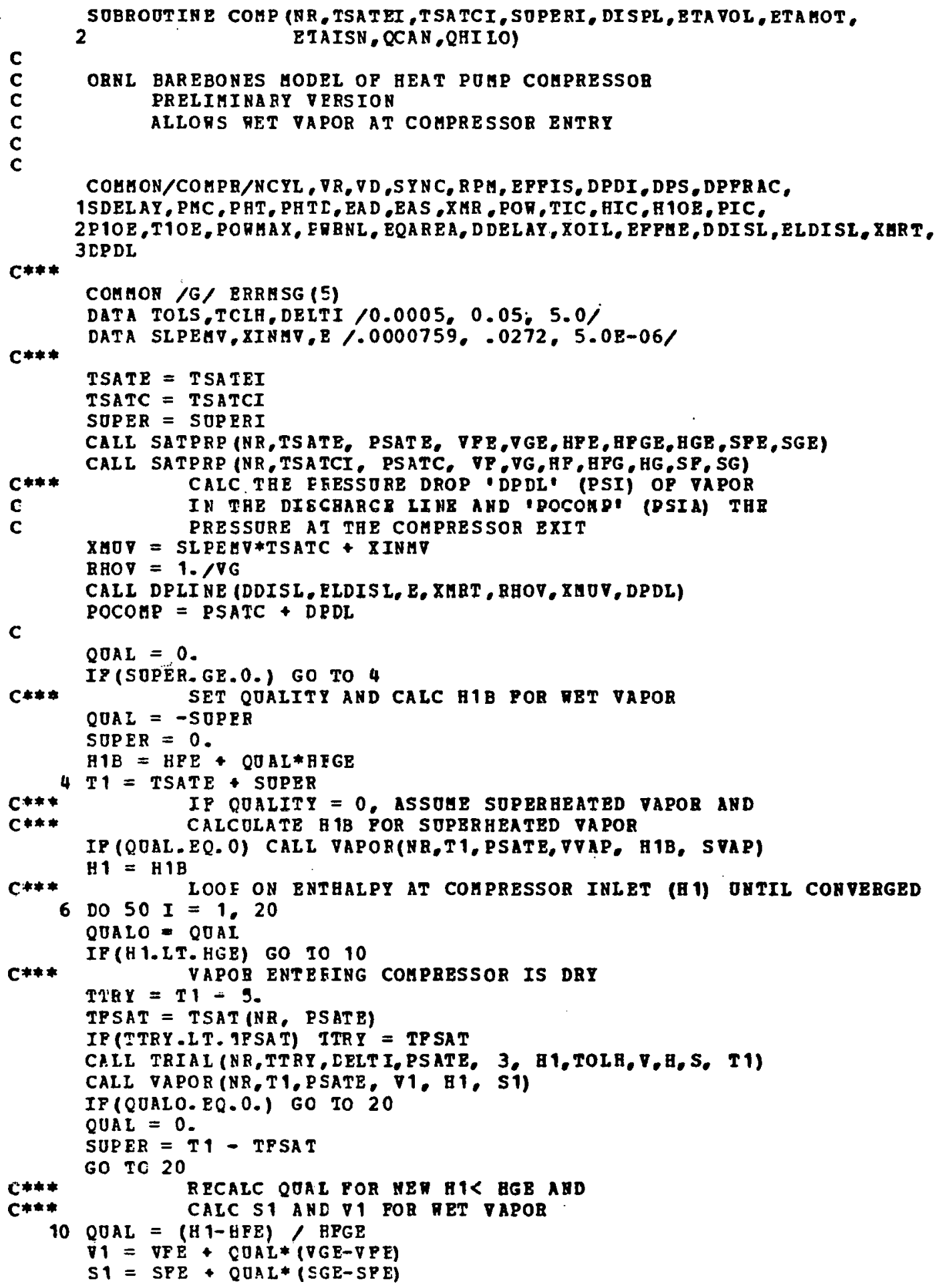




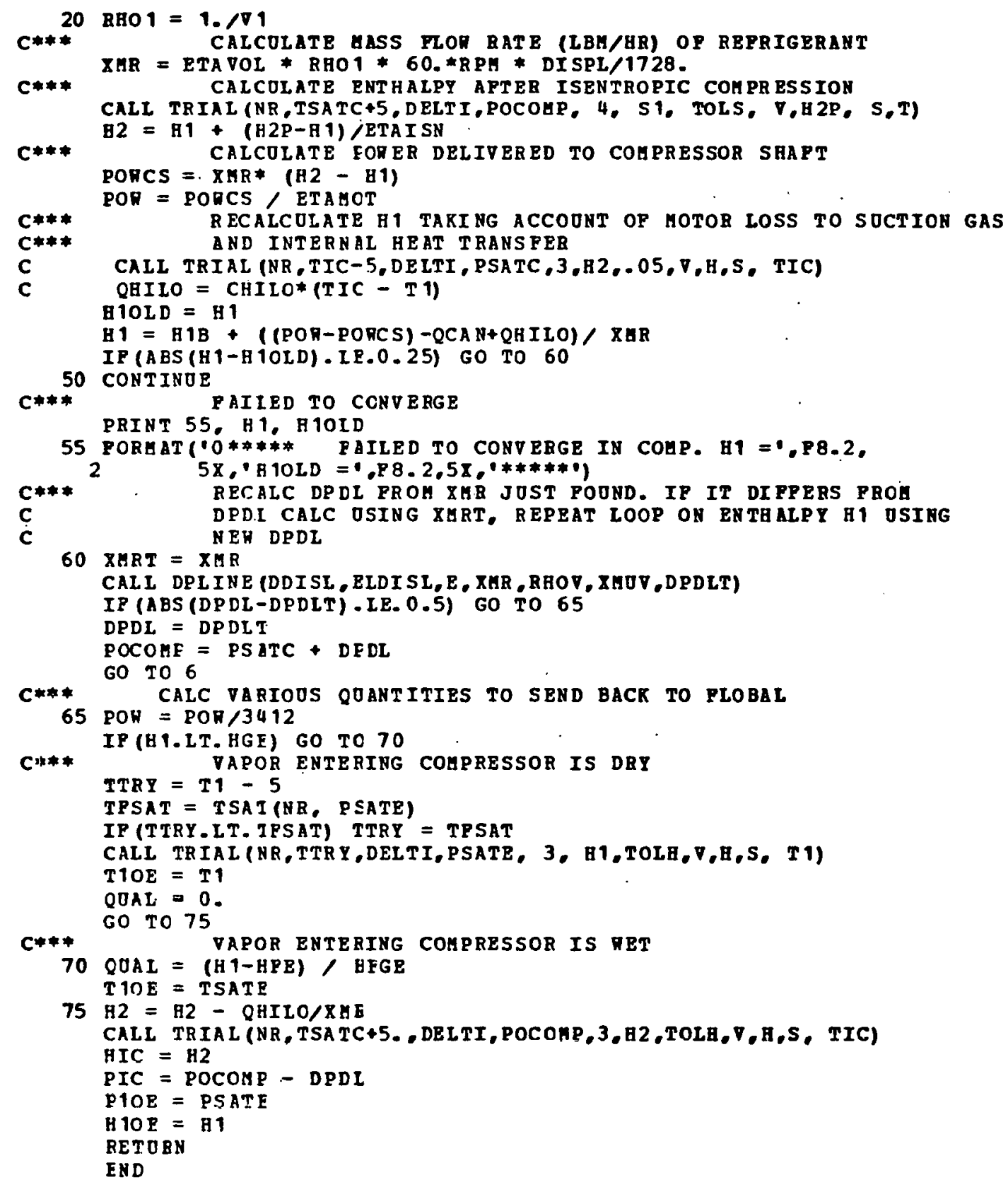




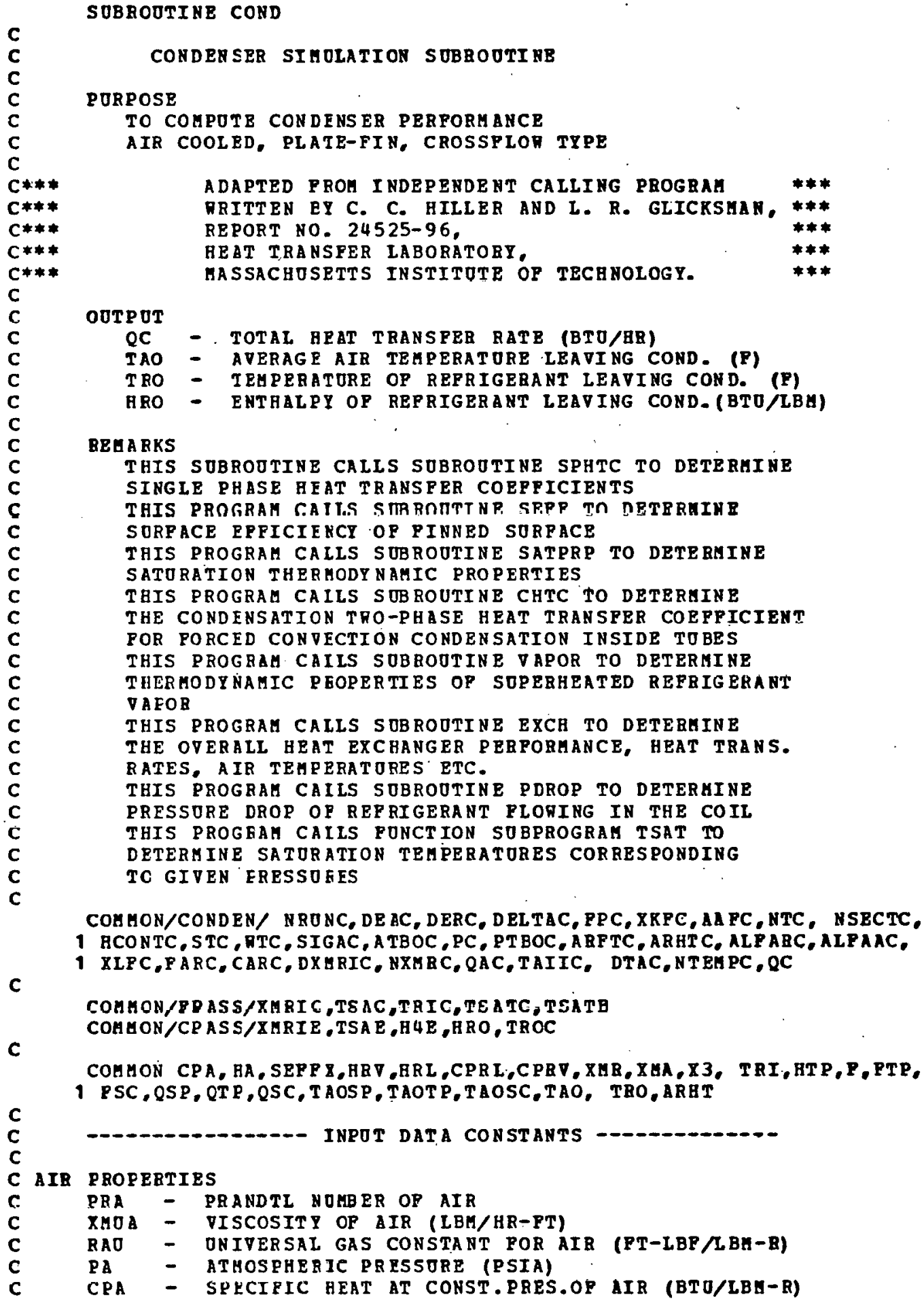




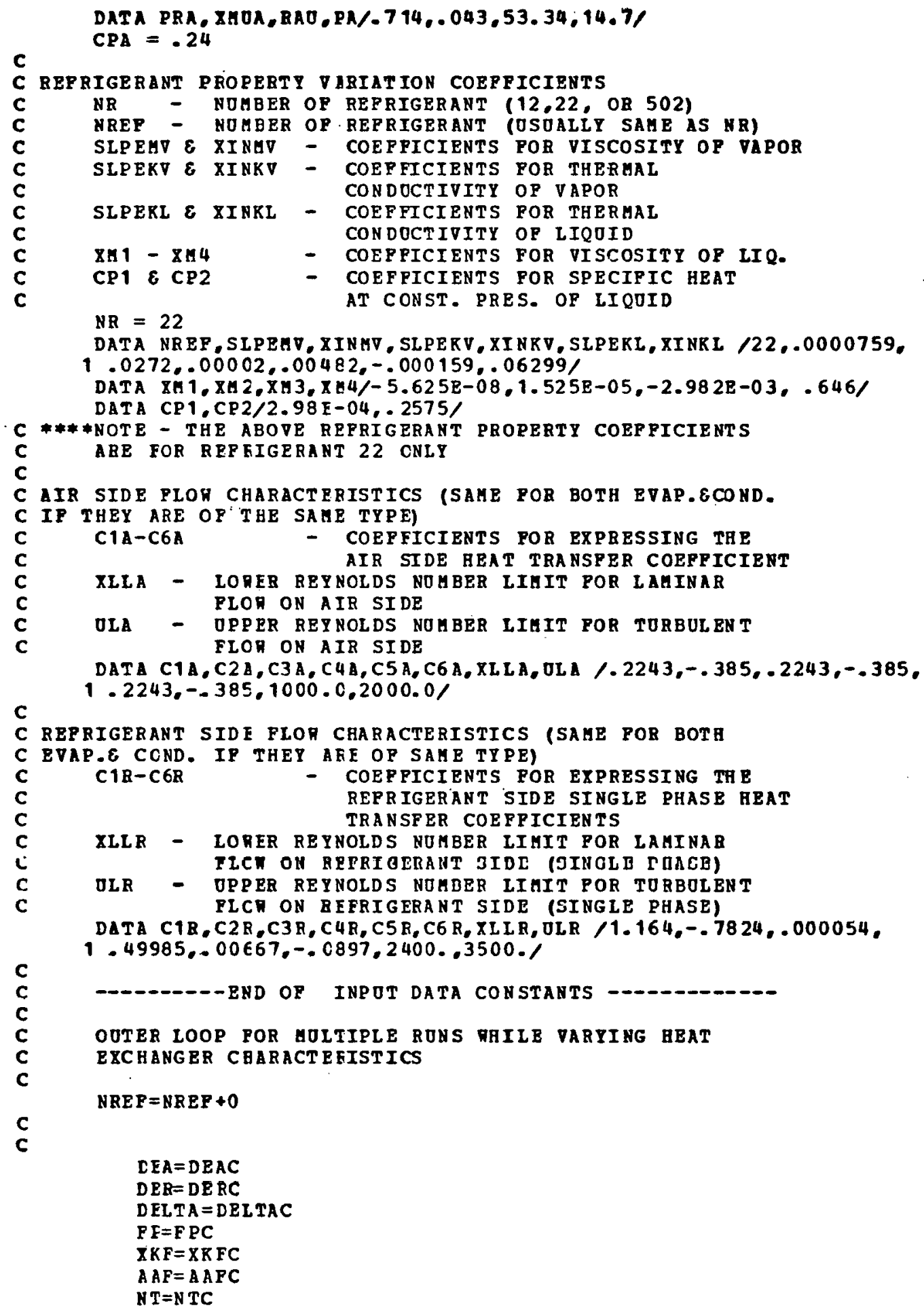




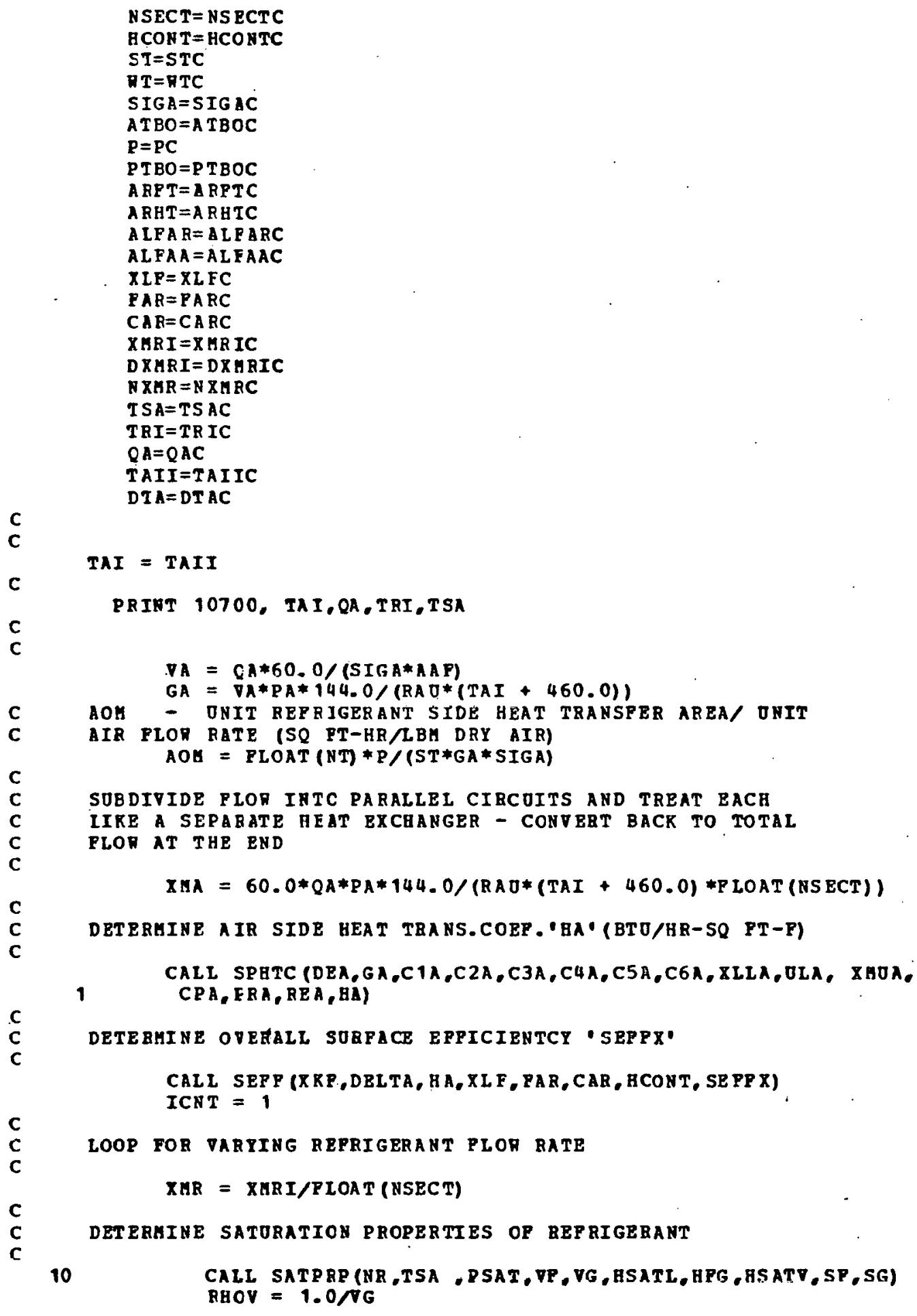




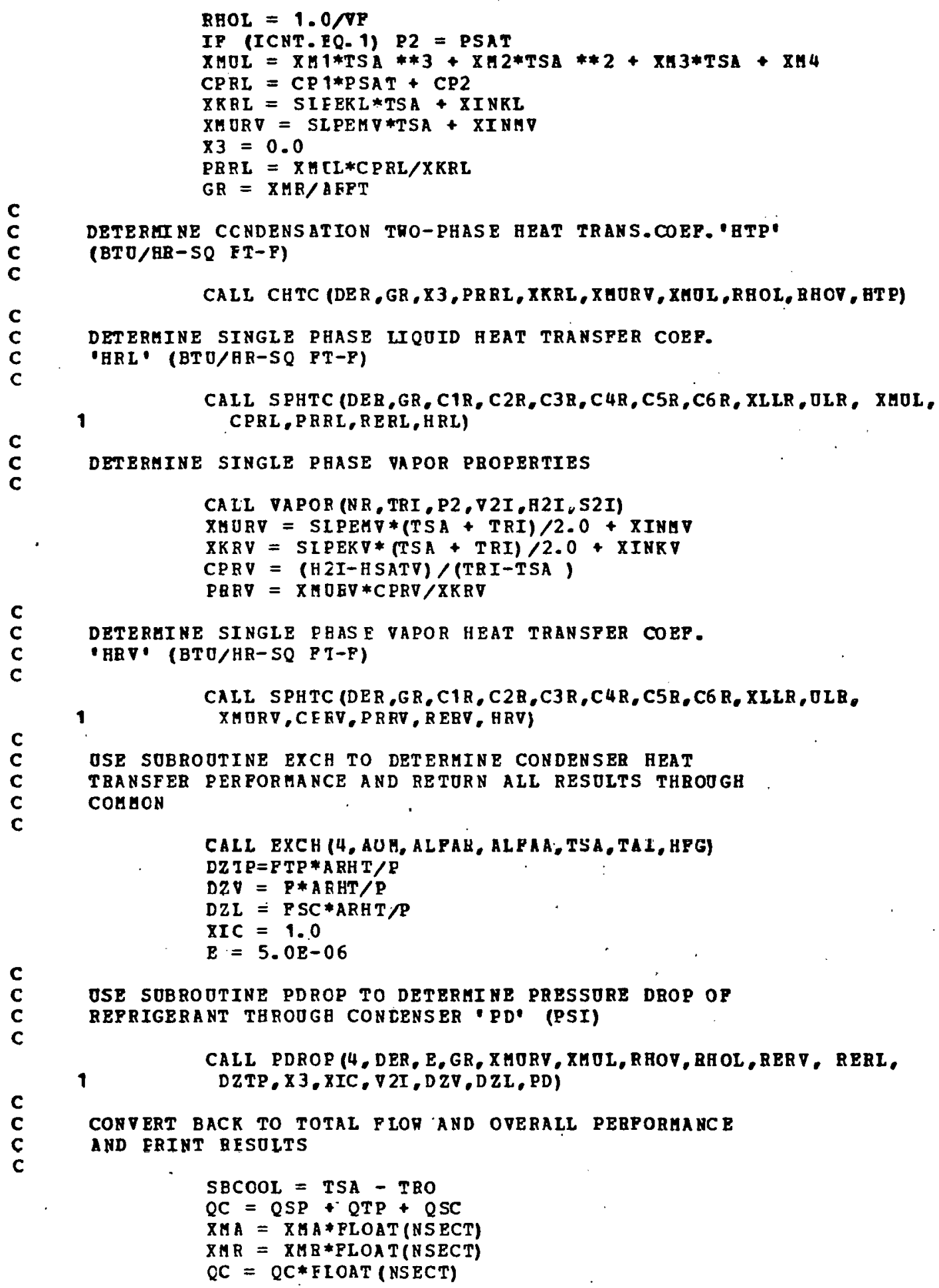




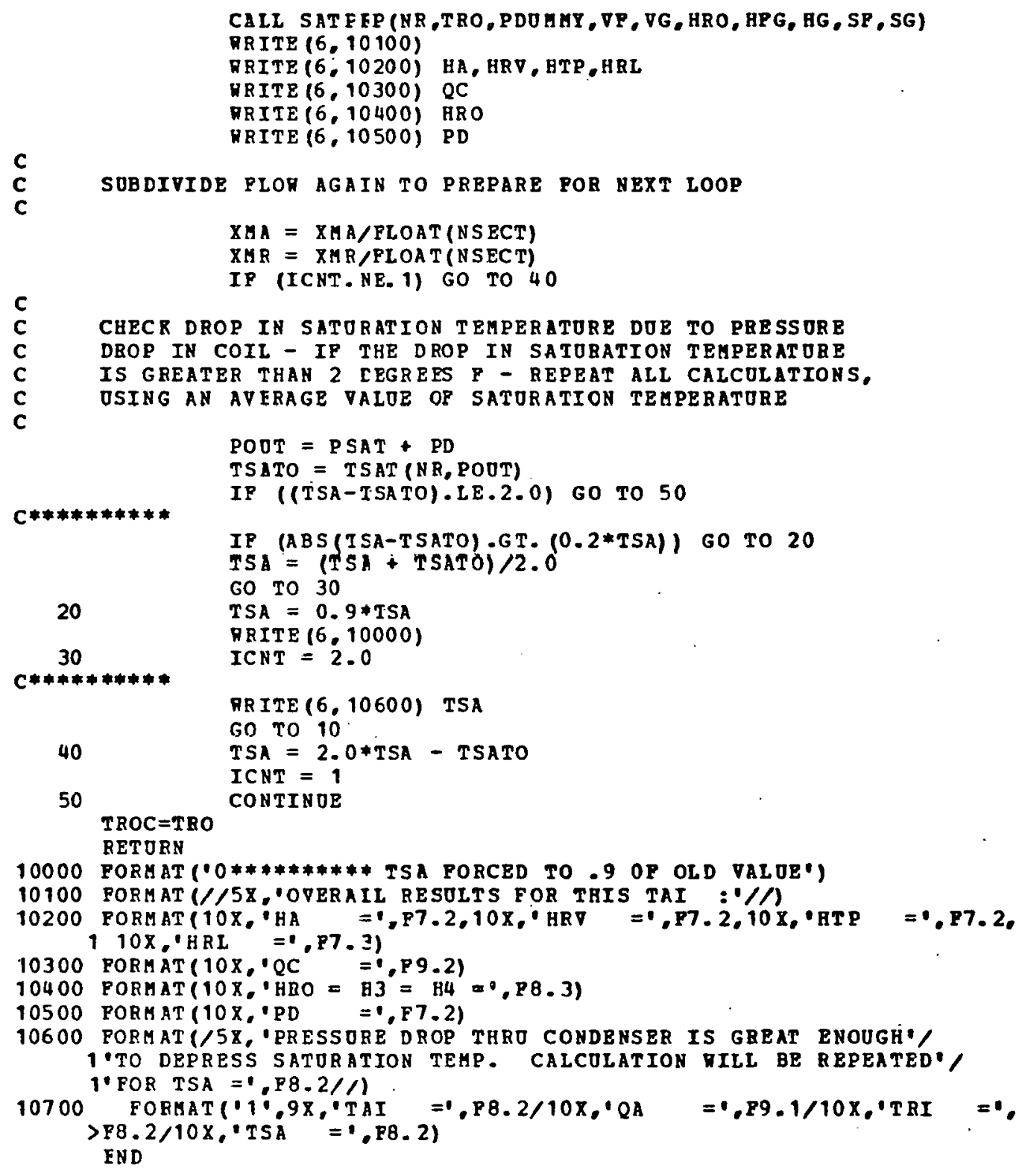




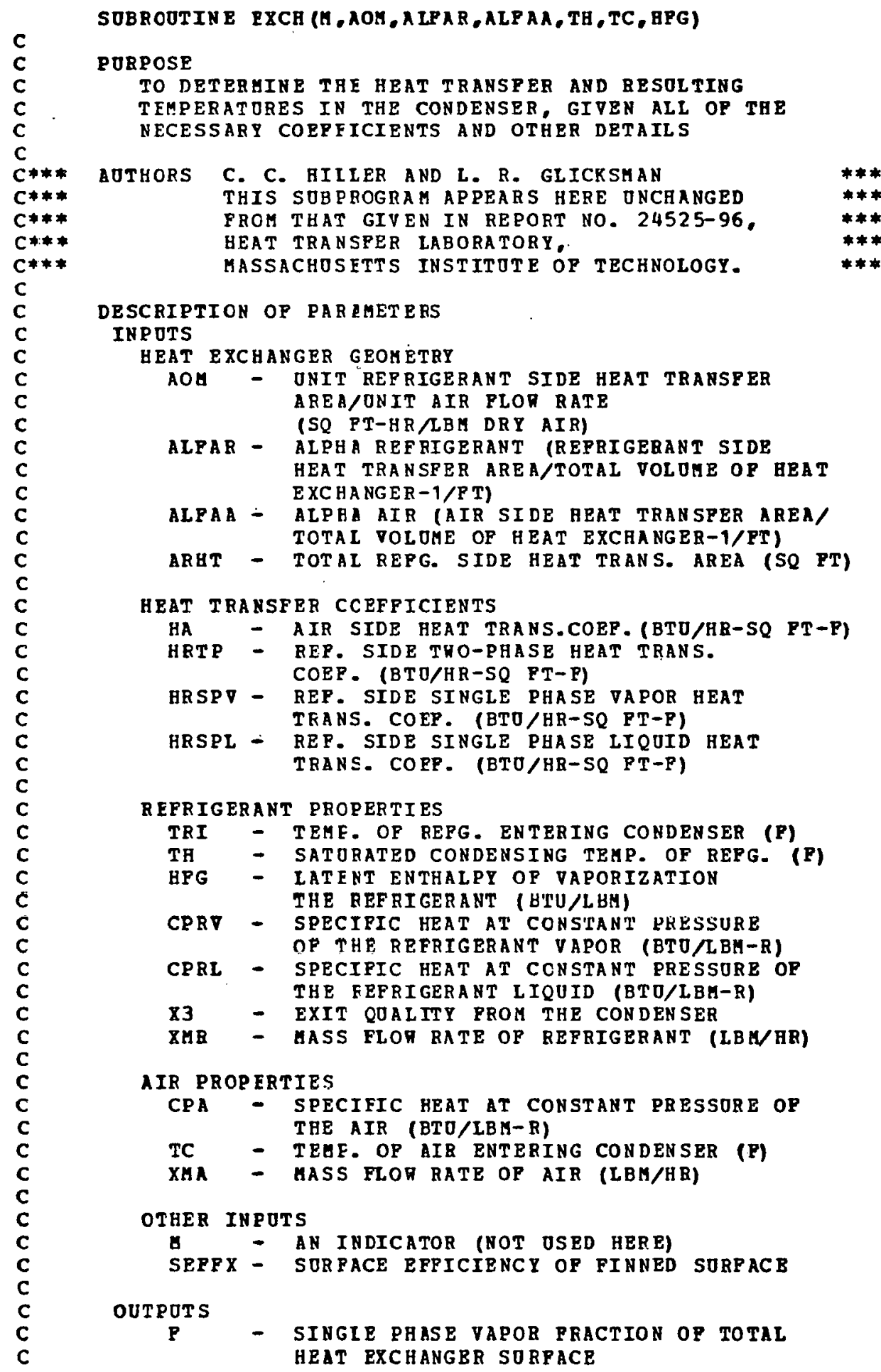




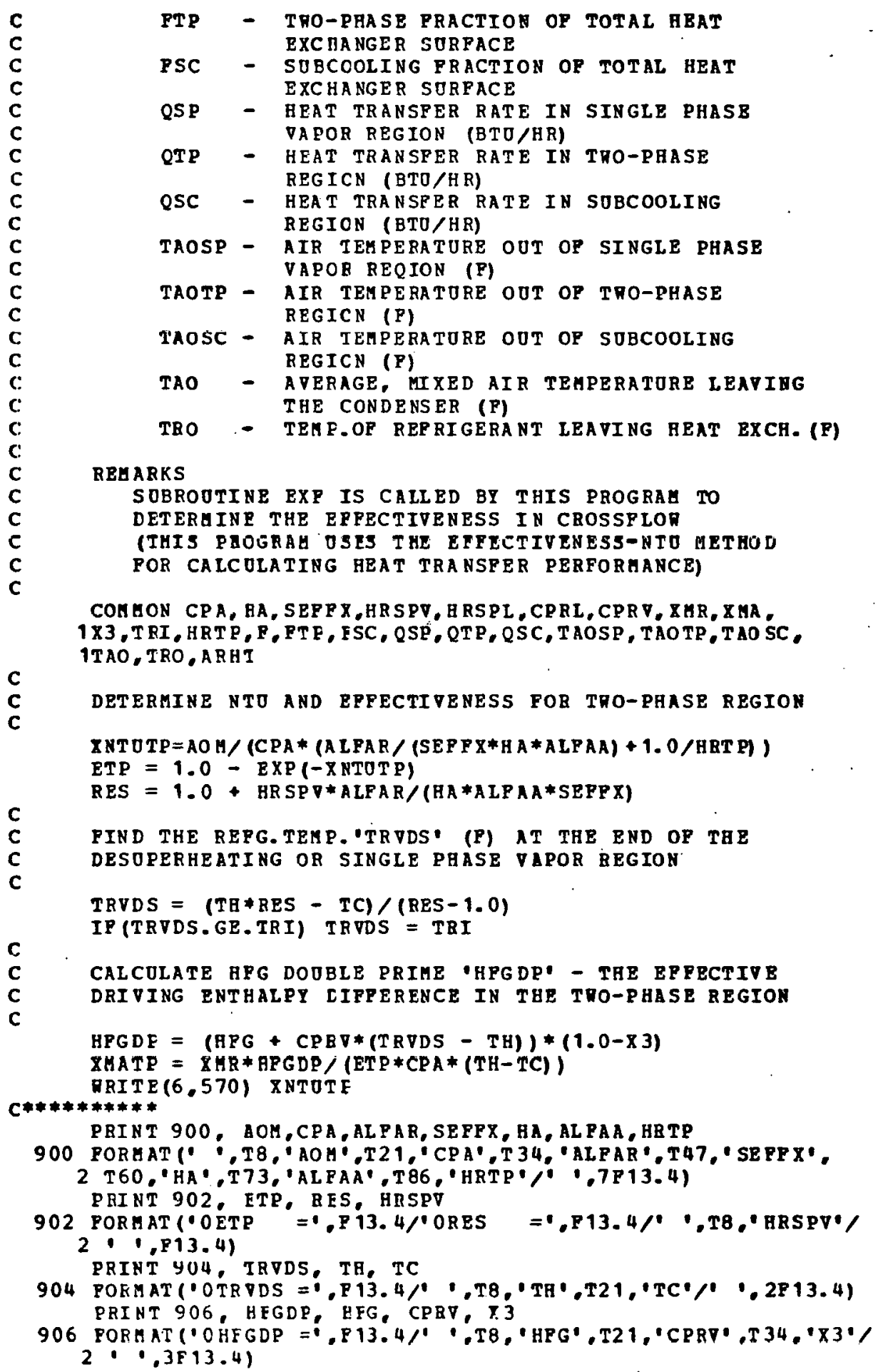




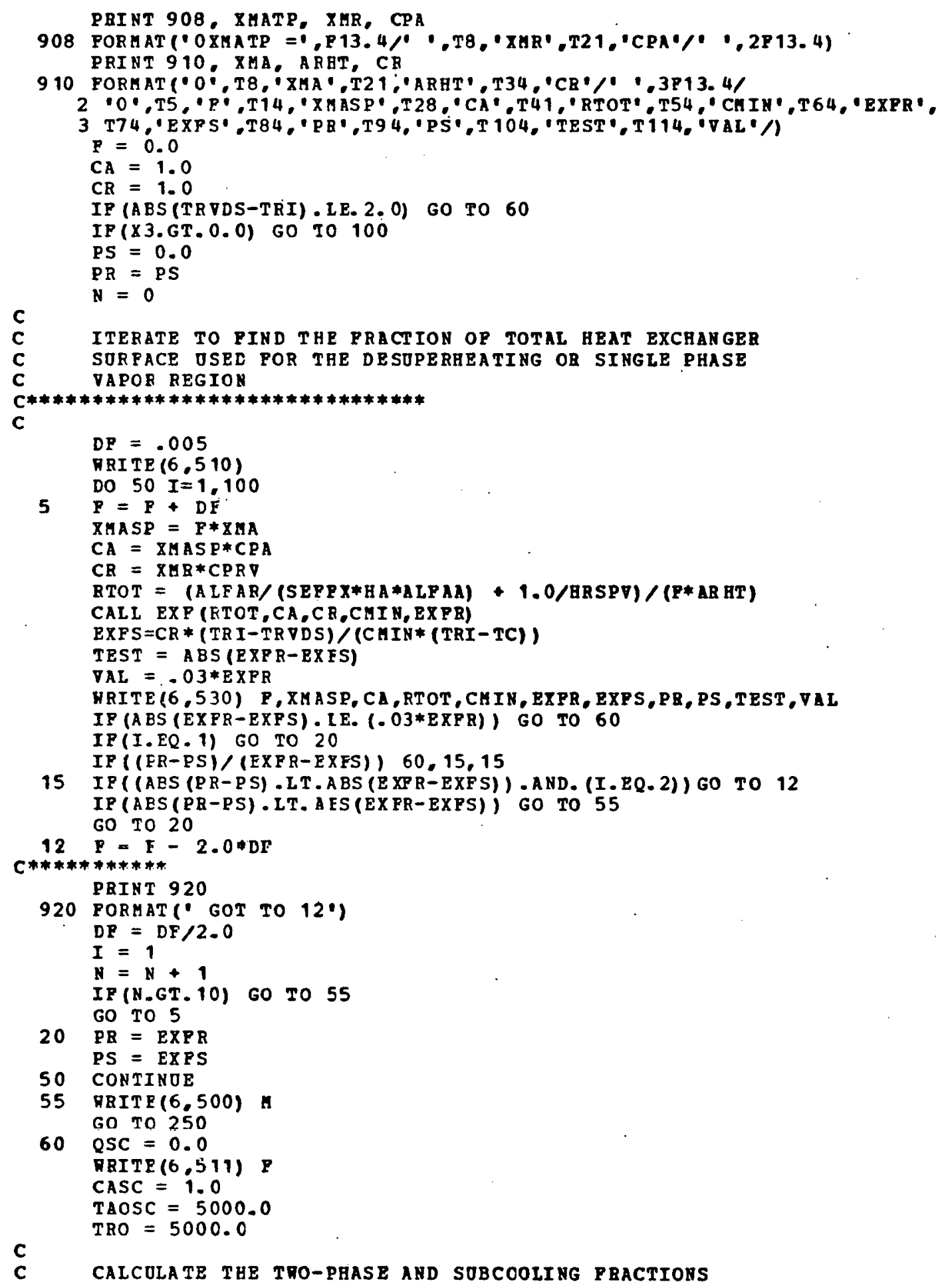




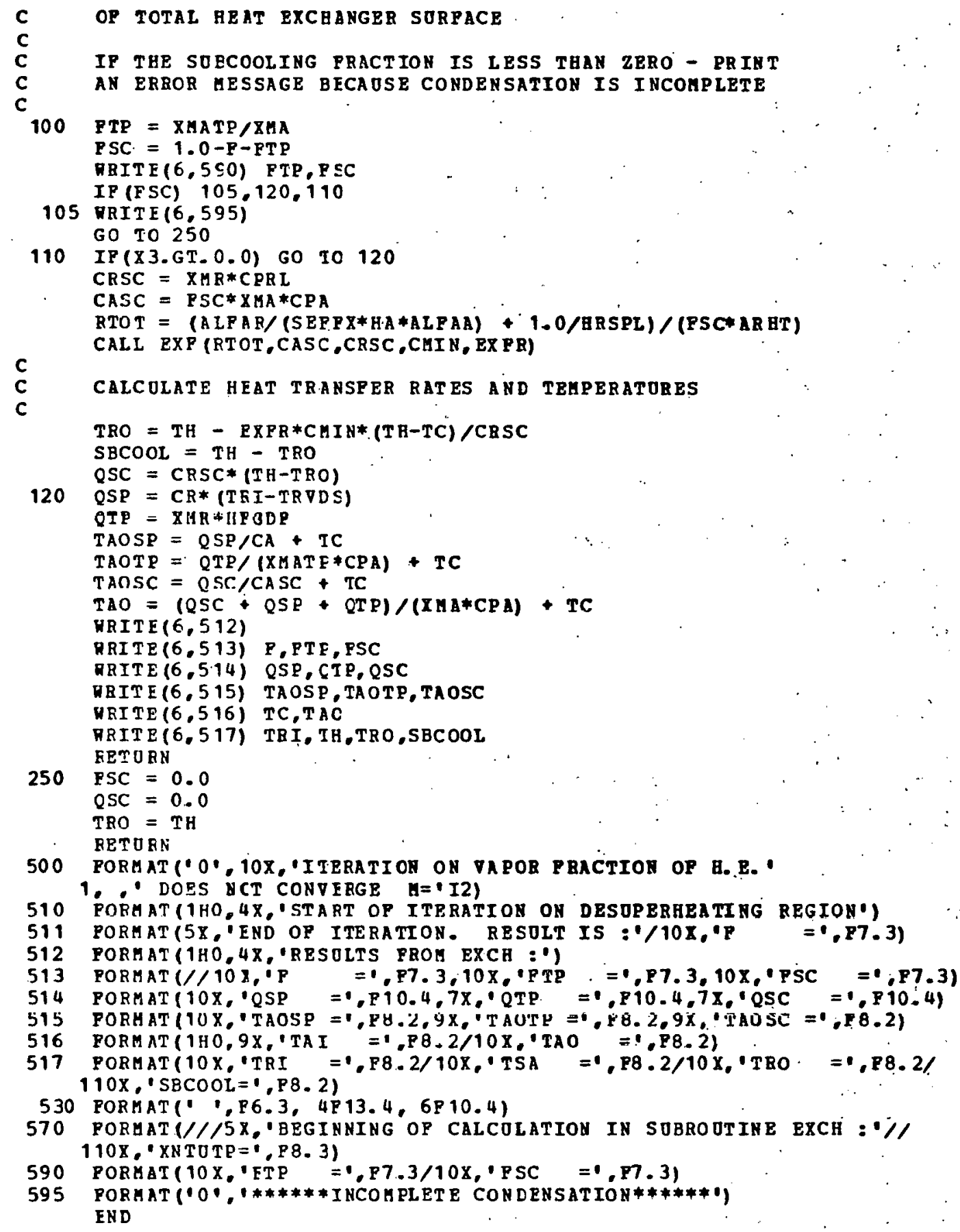




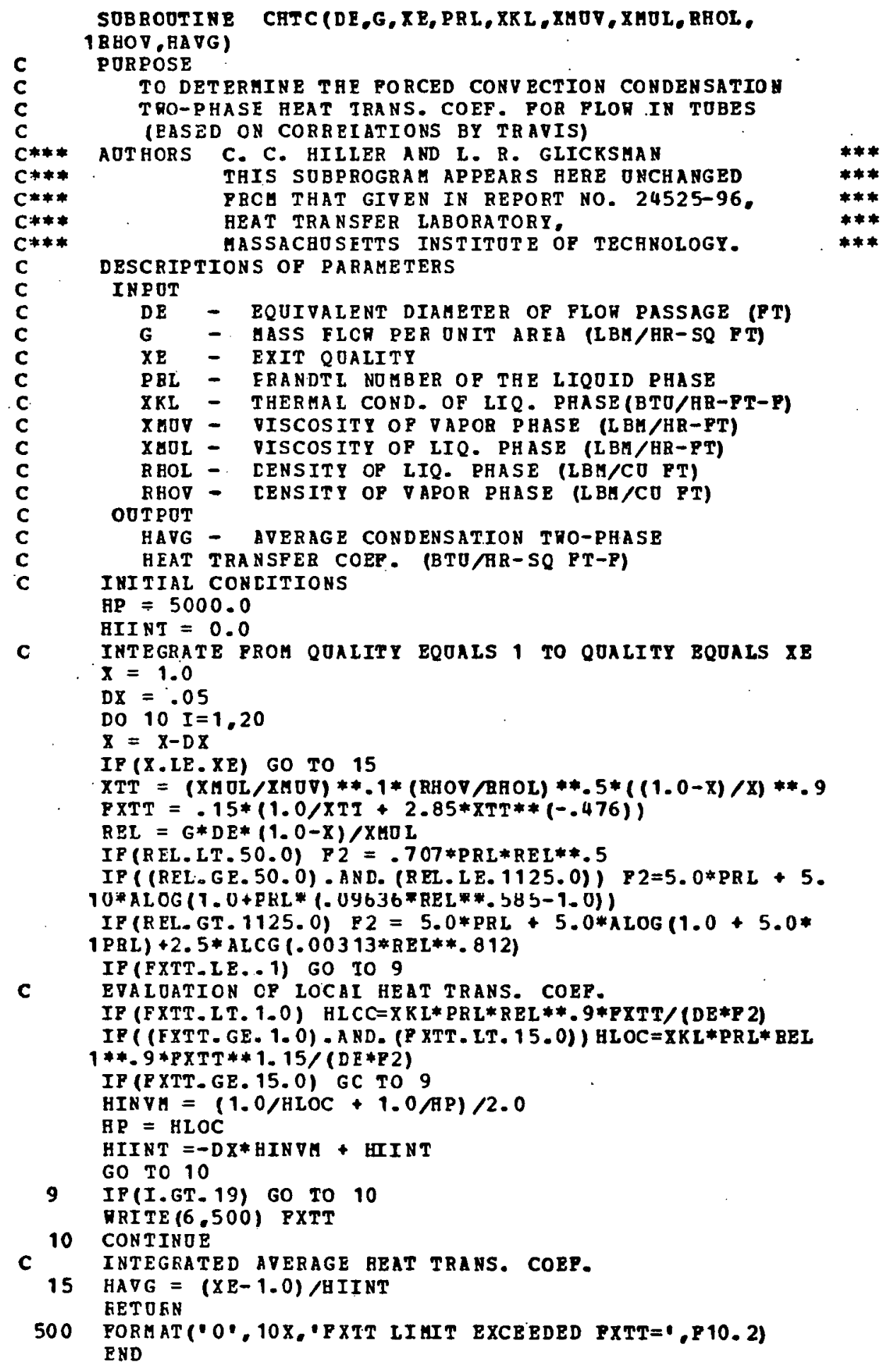




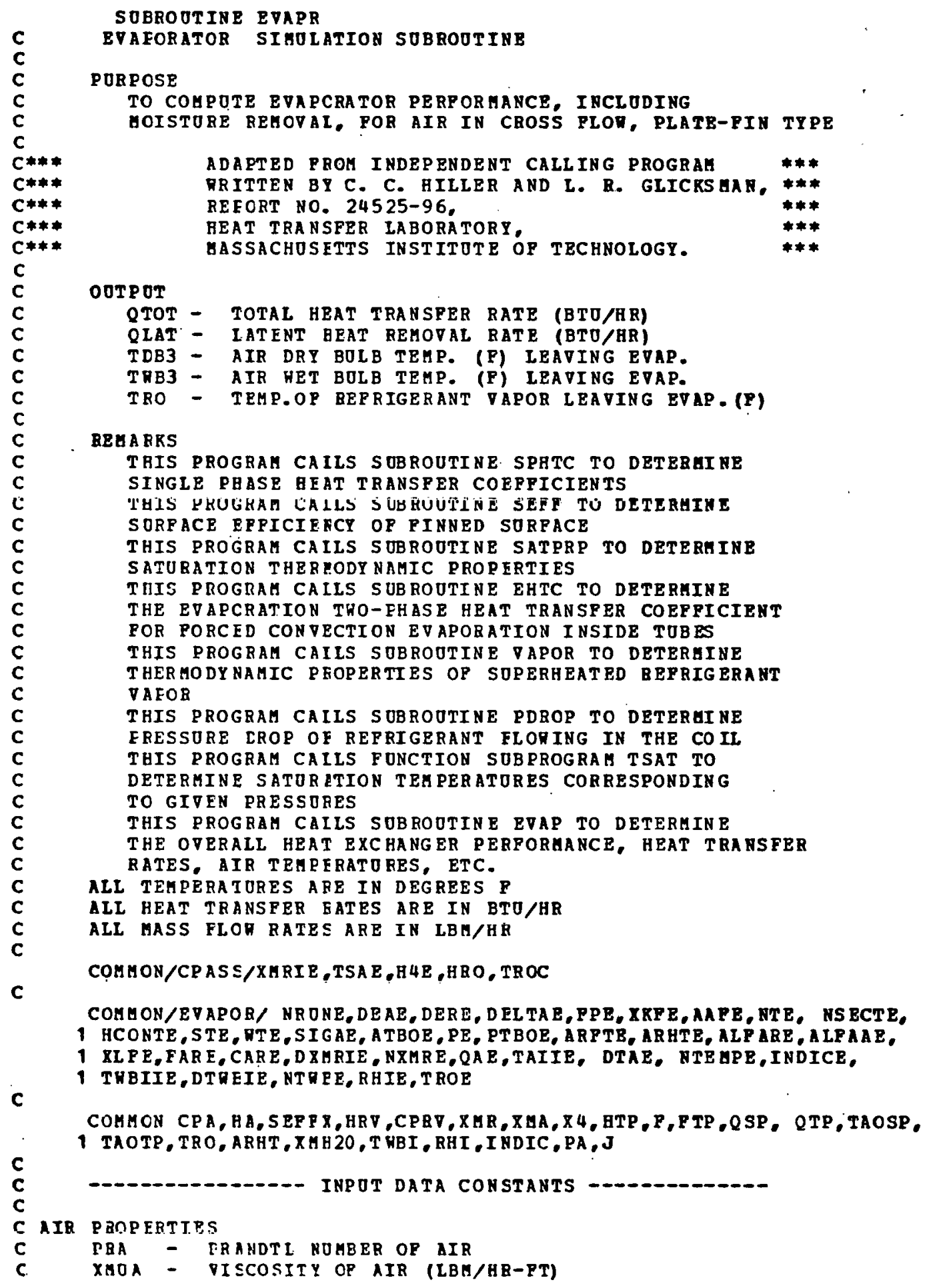




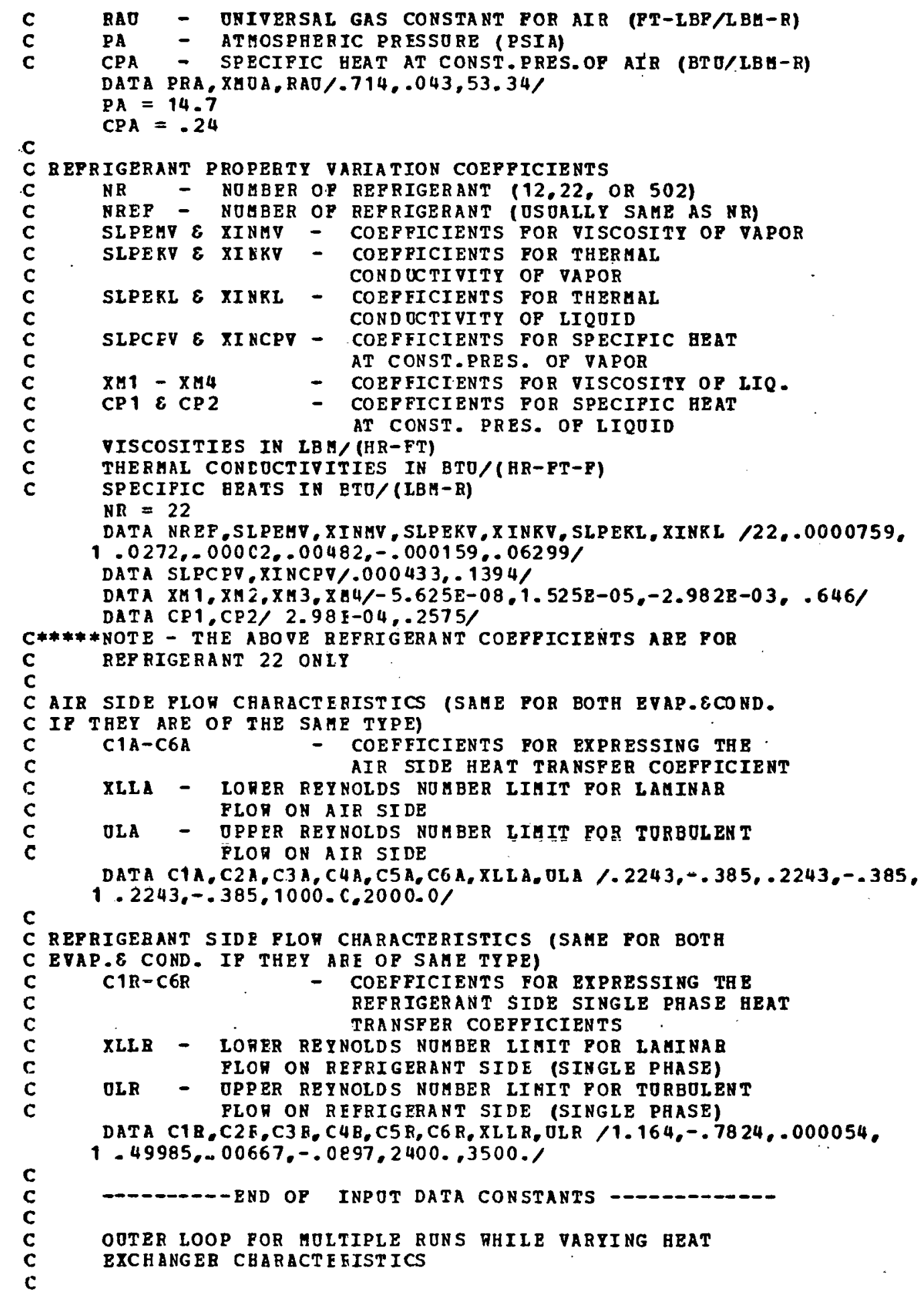




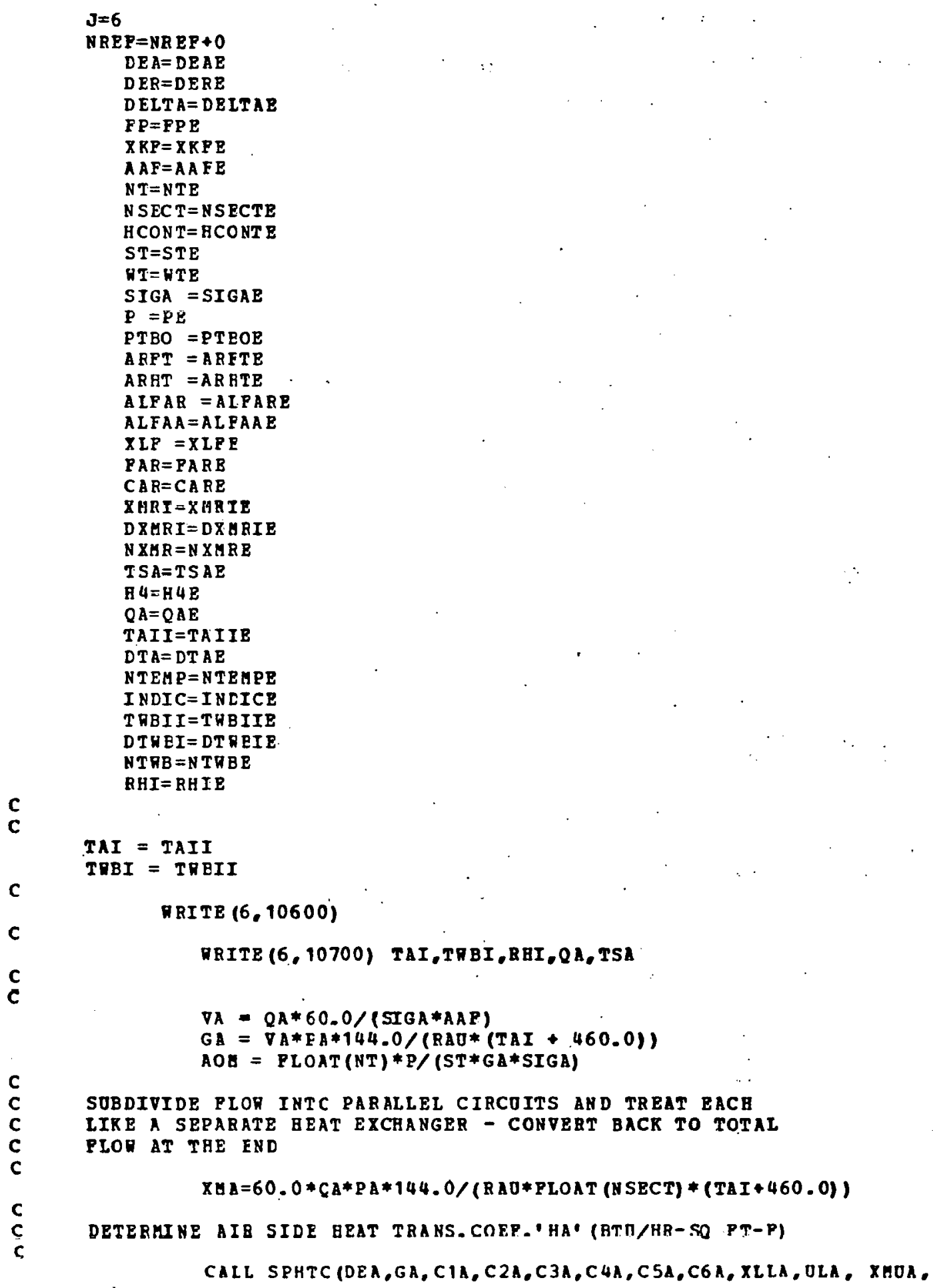




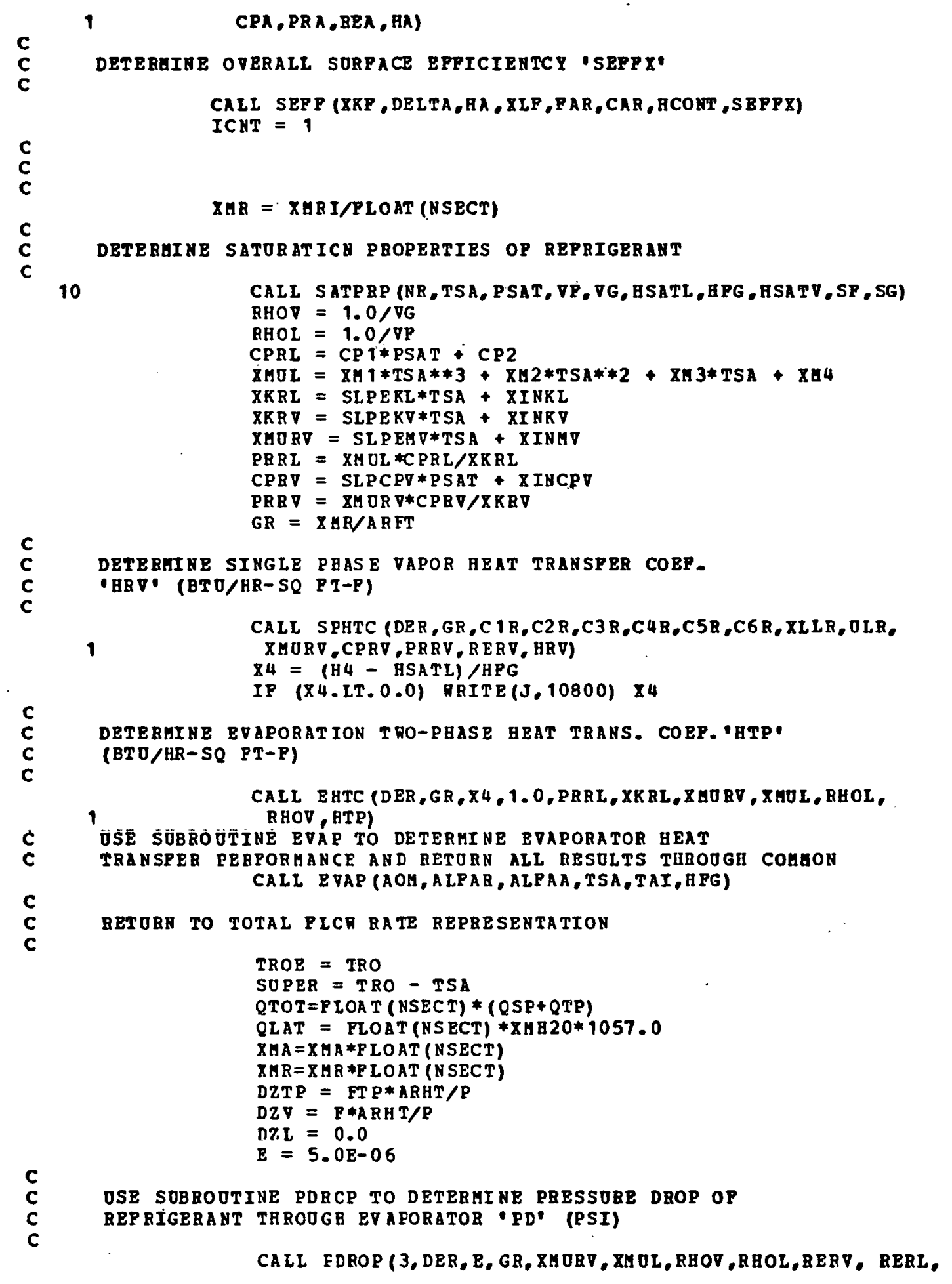




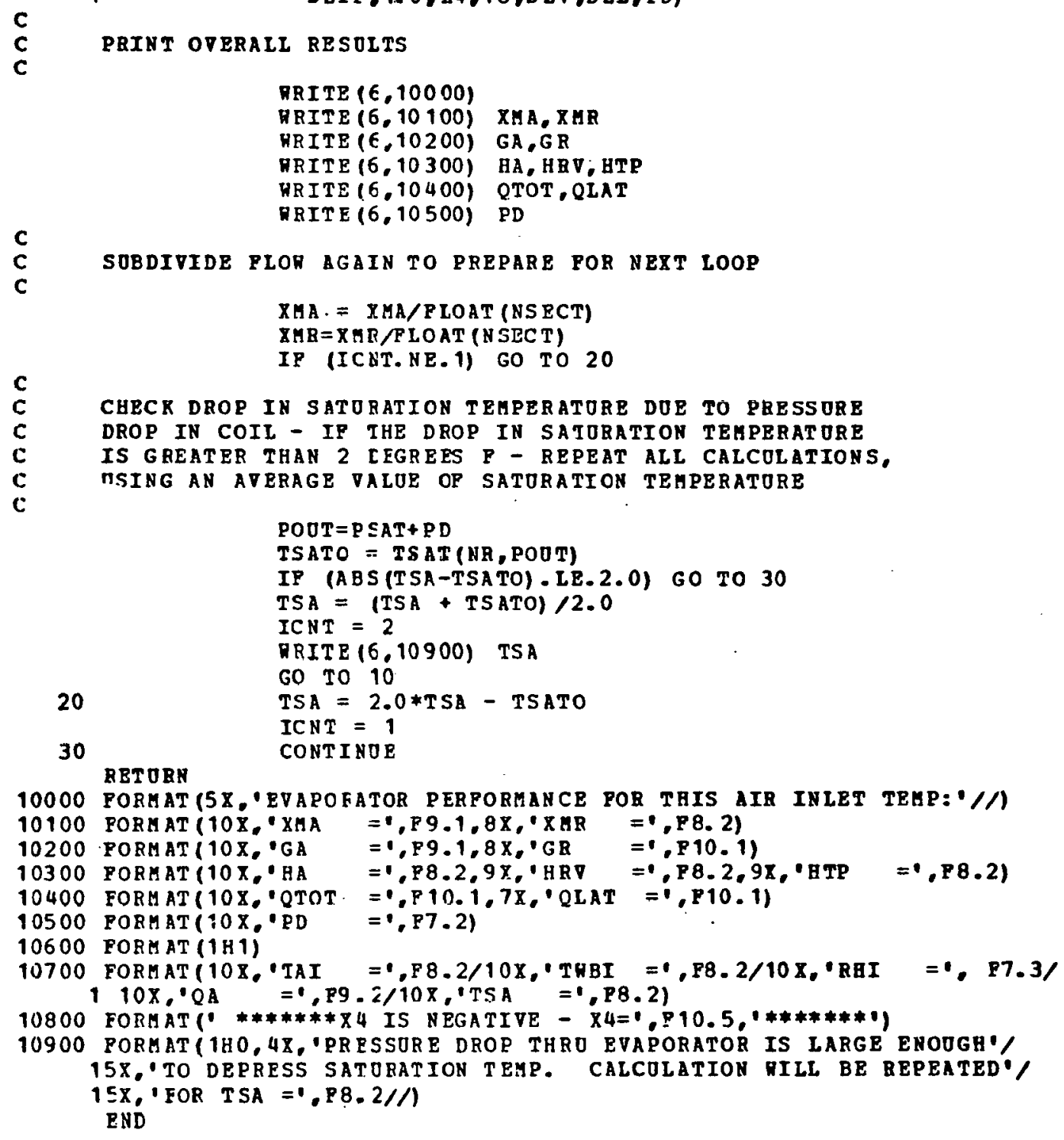


SUBROOTIYE EVAP (AOE,ALPAR, ALPAA, TSA, TAI, HPG)

PORPCSE

TO DETERUINE HEAT TRANSFER HOISTORE REHOVAL

AND RESUITING TEMPERATORES AND HOMIDITIES

IN THE EVAPORATOR, GIVEN ALL OP THE NECESSARY

COEPPICIENTS ANE OTHER DETAILS

AOTHOBS C. C. BIILER AND L. R. GLICKSHAN

THIS SUBPROGRAM APPEARS HERE ONCHANGED

FRCM THAT GIVEN IN REPORT NO. 24525-96,

BEAT TRANSFER LABORATOBY.

MASSACHOSETTS INSTITOTE OP TECHNOLOGY.

DESCRIPTION OF PABLETERS

IN P OTS

HEAT EXCHANGER GEOMETRY

ALPAR - ALPHA BEPRIGERANT (REPRIGERANT SIDE HEAT TRANSFER AREA/TOTAL VOLOME OF REAT EXCHANGER - 1/FT)

ALPAA - ALPBA AIR (AIR SIDE HEAT TRANSPER AREA/ TOTAL VOLDHE OP HEAT EXCHANGER -1/PT)

ARHT - TOTAI REPG. SIDE HEAT TRANS. AREA (SQ PT)

AOA - ONIT REPRIGERANT SIDE BEAT TRANSEER AREA ONIT AIR PLOQ RATE (SQ FT-HR/LBM DRY AIR)

BEAT TRANSPER CCEFFICIENTS

HA - AIR SIDE HEAT TRANS. COEPP. (BTO/HR-SQ PT-P)

HTP - REP. SIDE TTO-PHASE HEAT TRANS.

COEP. (BTO/RR-SQ PT-P)

HRV - REP. SIDE SINGLE PHASE VAPOR HEAT TRANS.COEP. (BTO/RR-SQ PT-P)

REPRIGERANT PROPERTIES

TSA - REPAIGERANT SATUBATION TEMP. (P)

HPG - LATENT ENTHALPY OF VAPORIZATION OF THE FEF RIGERANT (BTO/LBR)

Z4 - ENTERING QOALITY OP THE BEPBIGEBANT

XHR - MASS FLOR RATE OP REPRIGERANT (LBH/BR)

CPBV - SEECTEIC HEAT AT CONJTANT PRE33ORE

AIR PROPERTIES OF THE REPRIGERANT VAPOR (BTO/LBM-B)

CPA - SPECIFIC HEAT AT CONSTANT PRESSURB OP THE AIR (ETO/LBM-B)

XMA - MASS FLOR RATE OP AIR (LBH/HB)

TAI - DRY EOIB TEKP,OP AIR ENTERING EVAP. (P)

TRBI -

RHI - RELATIVE HOMIDITY OP AIR ENTERING EVAP. INDIC - INPOT INDICATOR

IP INDIC' EQOALS 1, INPUTS ARE TAI, AND TRBI

IF 1INIIC, EQOALS 2, INPOTS ABE TAI, AND BHI

PA - ATMOSPHERIC PRESSURE (PSIA)

OTHER INFOTS

SEPPX - SURPACE EFICIENCY OP PINNED SORFACE OOTPOTS

F - SINGLE PHASE VAPOR FRACTION OF TOTAL HEAT EXCHANGER SORPACE

FTP - THO-PRASE FRACTION OP TOTAL HEAT EXCHANGER SORPACE

QSP - HEAT TRANSPER RATE IN SINGLE PHASE 


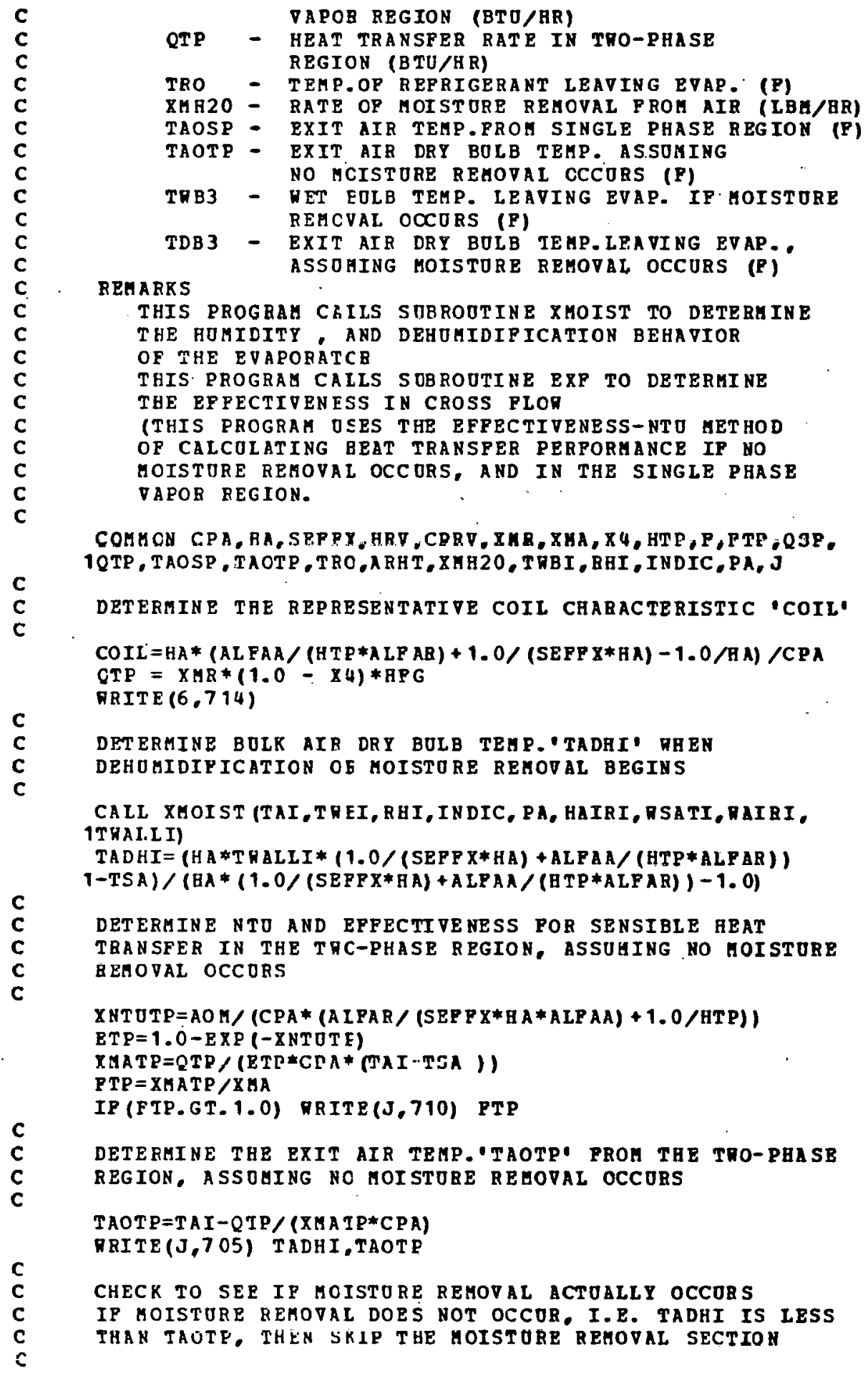




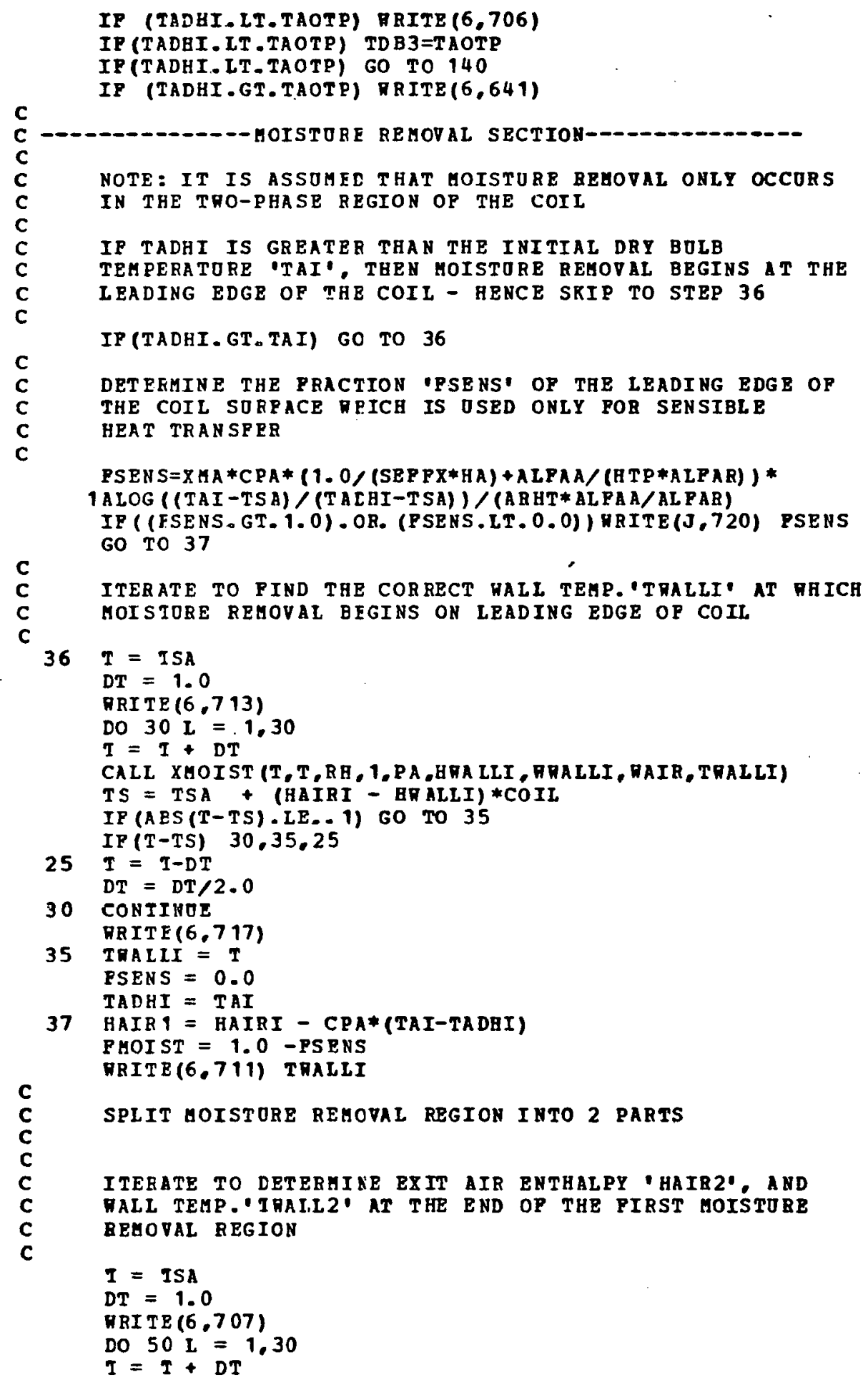




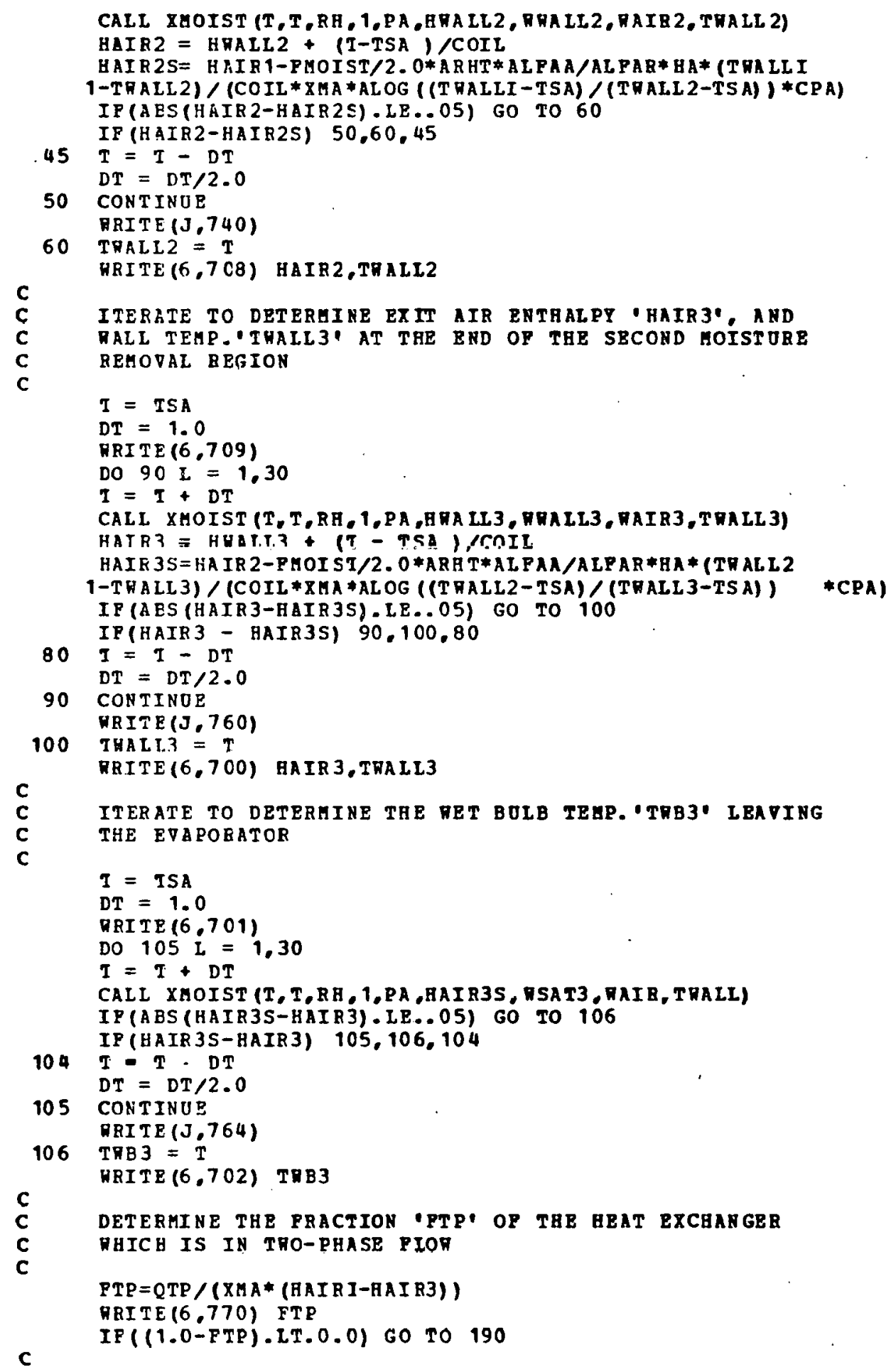




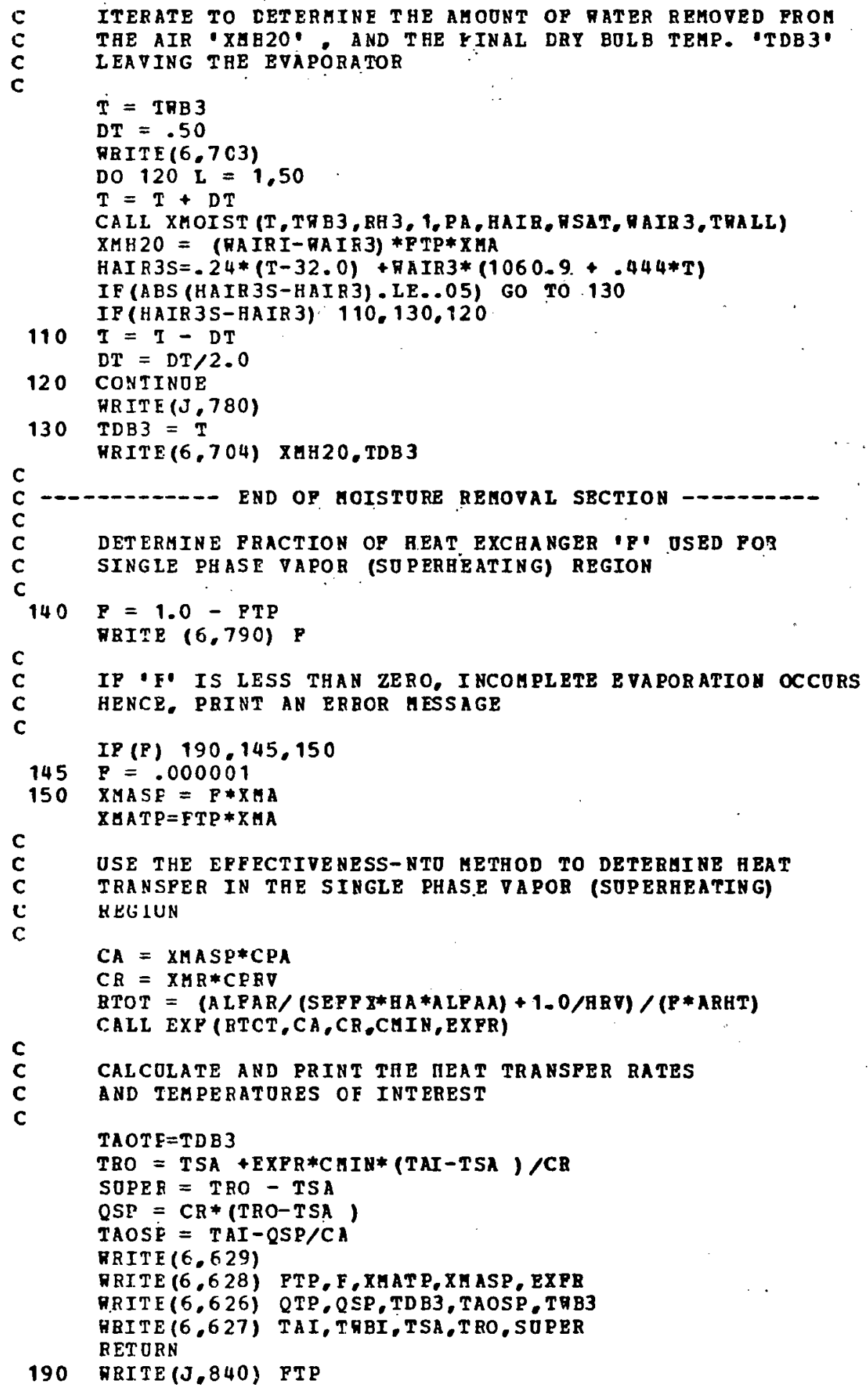


$Q S P=0.0$

$P=0.0$

XHASP $=0.0$

$X$ MH $20=($ AAIRI- RAIR3) $\$ X M A$

RETORN

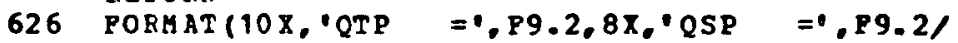

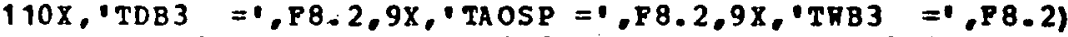

627 PORAAT (1H0,9X, TAI = .P8.2/10X, THBI =. T8.2\%

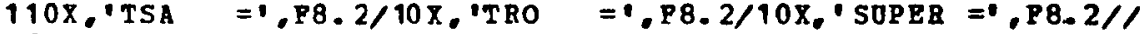

$25 x_{0}$. NOTE THAT THESE HEAT AND MASS PLORS ARE POR ONE SBCTION ONLF• $3 / / / / 1$

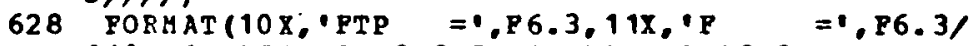

$110 \mathrm{X}$, 'XAATP $=1$, P8. $2,9 \mathrm{X}_{\circ} \cdot \mathrm{XMASP}=1, \mathrm{P} 8.2 /$

$234 X$. EXPR $=$ E. PG.3)

629 PORMAT $/ / / / / 5 X, 1 R E S O L T S$ FROB SUBROUTIRE EVAP:

641 PORMAT (5X, MOISTORE REHOVAL OCCURS $/ /)$

700 FORMAT $(5 X$, 'END OE ITERATION. BESOLTS ARE"

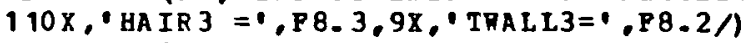

701 PORMAT (5X,'START OE ITERATION ON EXIT MET BOLB TBHP')

702 PORMAT $5 X, ' E N D$ OP ITERATION. RESULT IS'/

$110 \mathrm{X}$. TWB $3=$ TF8. $2 / 1$

703 FORMAT(5X,'START OF ITERATION ON RATER REHOVAL RATE AHD PINAL'. 1 A A.R TEME'")

704 FORMAT ( $5 \mathrm{X}^{-1}$ END OP ITERATION. RESOLTS ARBY

$110 \mathrm{X}, \cdot \mathrm{XHH} 20=1, \mathrm{P9}, 3,8 \mathrm{X}, \cdot \mathrm{TDB} 3=1, \mathrm{FB} .2 \mathrm{C}$

705 FORA

706 FORMAT ( $5 X$. NO MOISTURE REMOVAL OCCURS' $/ /)$

707 PORMAT (5X, START OP ITRRATION ON PIRST MOISTORE REHOVAL SECTION')

708 FORMAT ( $5 X^{\circ}$ 'END OP ITEPATION. RESOLTS ARE'/

$110 \mathrm{X}$, 'HAIR2 $=\bullet$, P8. $2,9 \mathrm{X}$, 'THALL $2=1, F 8.2 /)$

709 FORHAT (5X. START. OP ITERATION ON SECOND MOISTORE REMOVAL SECTION')

710 PORMAT ('0****FTP IS LARGER THAN 1 FTP=',P10.5, *****०/)

711 PORMAT (5X, END OF ITERATION: RESOLT IS'

110X. 'TRALII = , F8.2

713 PORAAT (5X, 'START CP ITERATION ON DALL TEHP.')

714 POREAT $/ / / 5 \mathrm{X}$, 'BEGINNING OF CALCOLATION IN SOBROOTIRE EVAP: $)$

715 PORMAT (3F 10.4, I 10, 4P 12.5)

717 PORMAT (' *********NO SENSIBLE HEAT REMOVAL"

$1 \ldots$ ITERATION DOES HOT CONVERGE*********1)

720 PORHAT( ****FSENS IS IN ERROR FSENS=1, P10.5,****1)

740 PORAAT $(1 * * * * * * * * *$ PIRST MOISTORE REHOVAL REGIOU ITER'

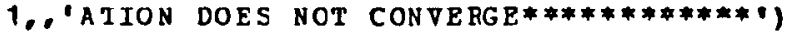

760 POEMAT (*******5ECOND MOISTORE REMOVAL REGION ITERA

1..'TION DOES NOT CCNVERGE********')

764 PORMAT(1 *********ITERATION ON TRB3 DOES NOT -

1. 'CONVERGE *********1)

770 PORHAT (1H0, 4X, 'PRACTION OP COIL OSED POR THO-PHASE PLOR IS\% $110 X$, 'PTP $=0$, P8.4/1

780 PORMAT("*********EXIT DRY BOLB TEMP DOES NOT ・

1..'CCNVERGE ********1)

790 PORGAT 11 HO, $4 \times$. 'PRACTION OF COIL OSED POR SINGLE-PHASE VAPOR PLOP'. 1. IS $/ 10 X, \cdot E=9, F 8.4 / 1$

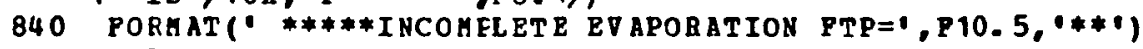
END 


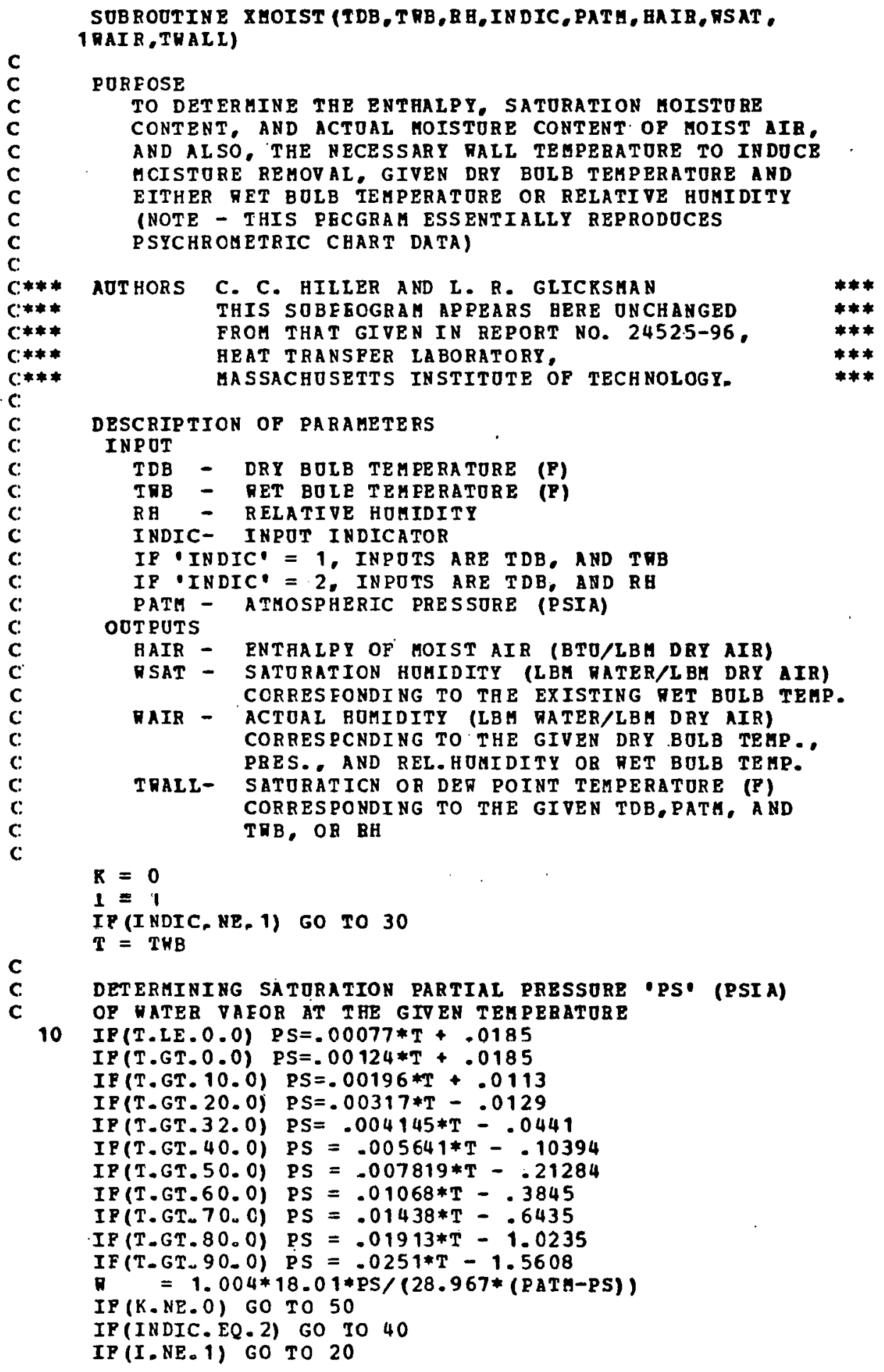




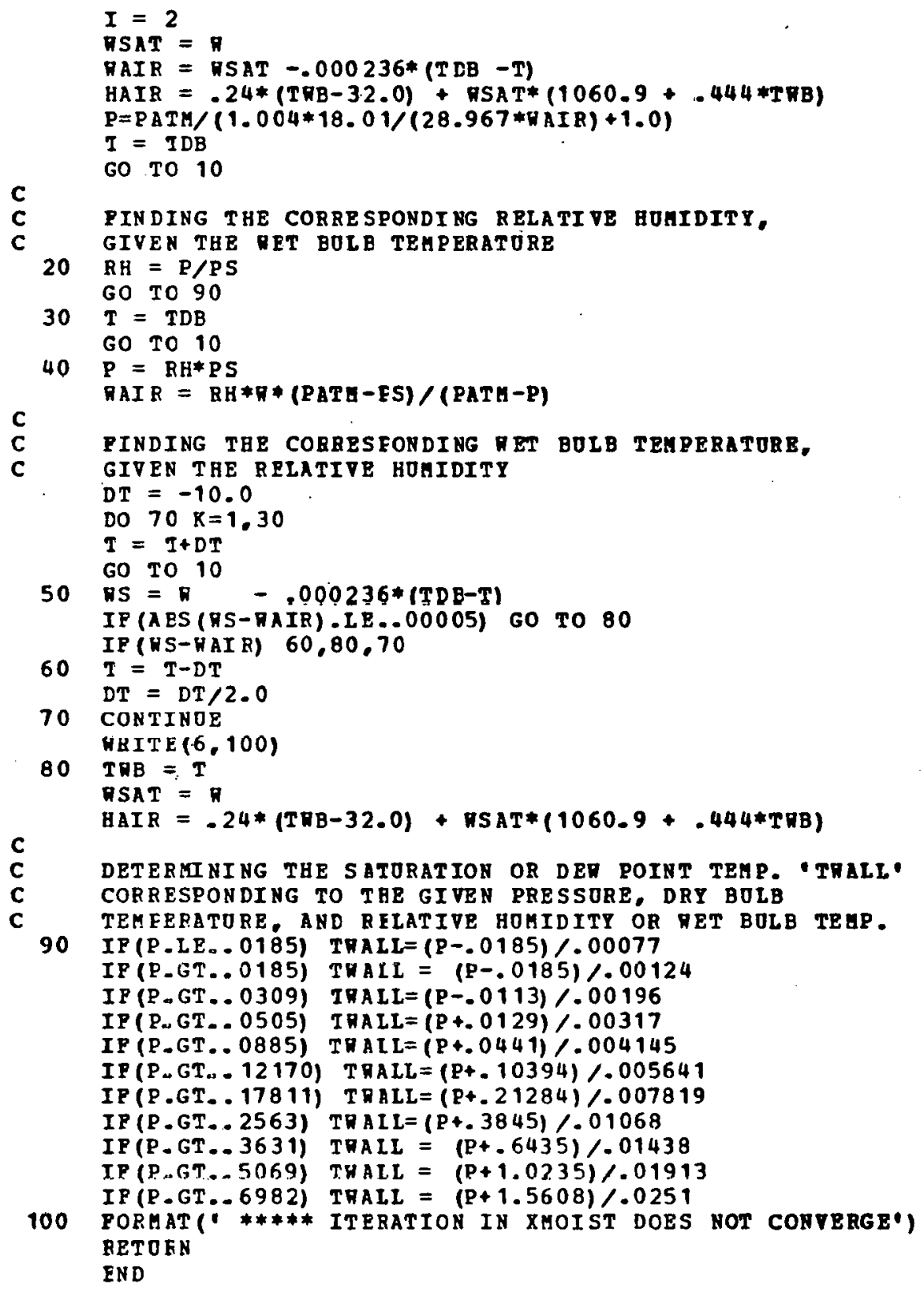




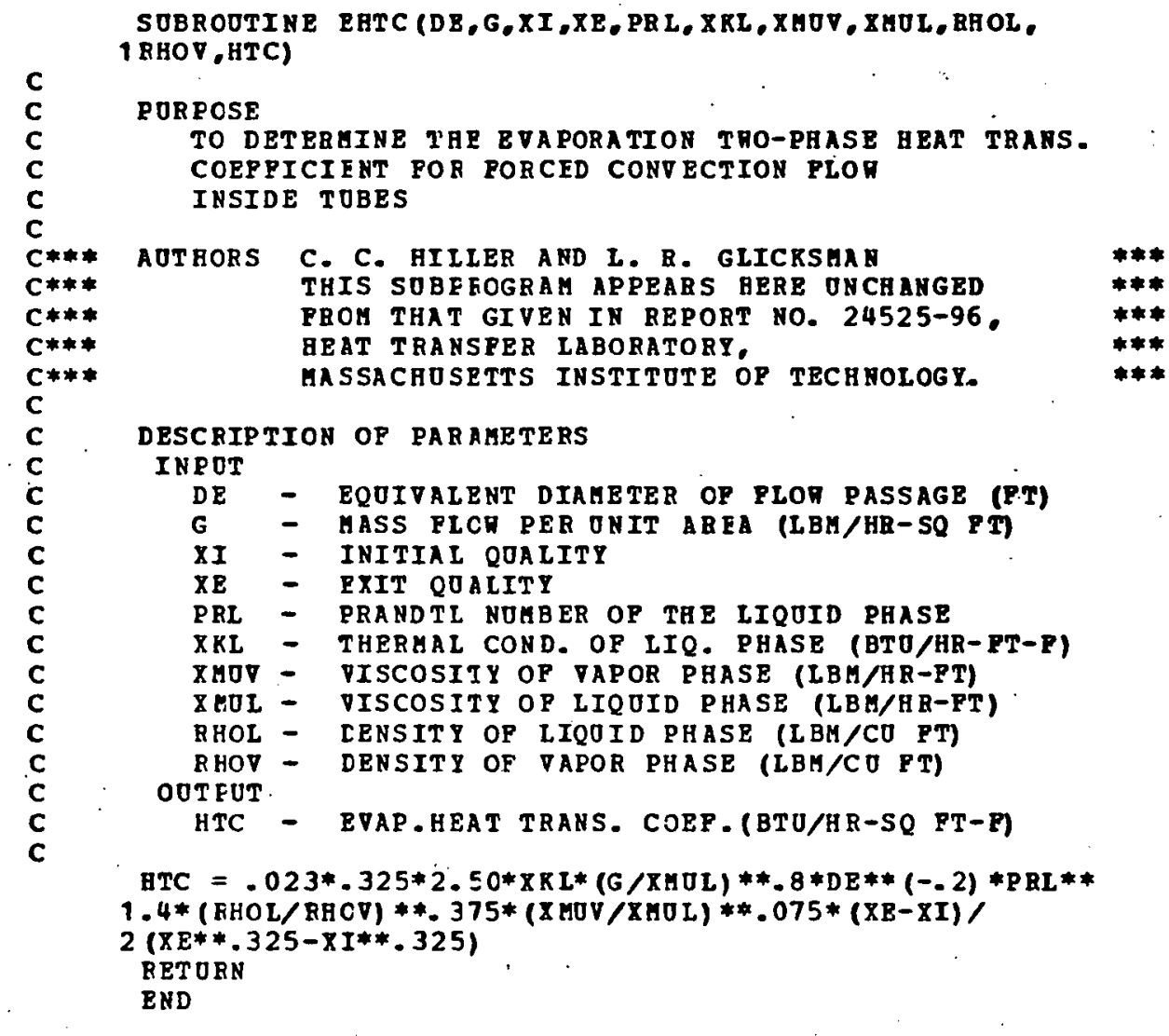


SUBROOTINE PDROP (N,D,E, G, X BOP, XHOL, RHOV, RHOL, REV, REL .

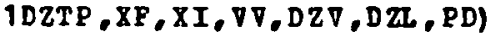

C

PORPOSE

TO DETERHINE BOTH ST NGLE PHASE AND TRO-PHASE PRESSURE DROPS FOR PLOR IN TUBES

C** AOTHORS C. C. HIIIER AND L. R. GLTCKSHAN

$C * * *$

$C * * *$

$C * * *$

$C * * *$

C

C

DESCRIPTION OF PARAMETERS

INPOT

N - INDICATOR (2 OR 3 UEANS EVAPORATOR)

D - EQUIVAIENT DIAMETER OP RLOR PASSAGE (PT)

E - SORPACE ROUGHNESS OP PLOR PASSAGE (PT)

G - MASS PLOR PER ONIT AREA (LBH/HR-SQ PT)

XMOV - VISCOSITY OP VAPOR PHASE (LBM/HR-PT)

XHOL - VISCOSITI OP LIQ. PHASE (LBH/HR-PT)

RHOV - LENSITY OP VAPOB PHASE (LBH/CO PT)

RHOL - EENSITY OP LIQ. PHASE (LBH/CO PT)

REV - REYNOLDS NOMBER OP VATON PIIAEB REOIOR

REL - REY NOLDS NOLEER OP LIQOID PHASE REGION

DZTP - LENGTH CP TRO-PHASE REGION (FT)

$X 8$ - FINAL COALITY

XI - INITIAL QJALITY

VV - EXIT SERCIPIC VOL.OP VAPOR PHASE (CO PT/LBZ)

DZV - LENGTH OP SINGLE PHASE VAPOR BEGION (PT)

DZL - IENGTH CP SINGLE PHASE LIQ. REGION (PT)

OOTEOT

DPV - PRES:DROP IN SINGLE PHASE VAPOR REGION (PSI)

DEL - PRES. DBOP IN SINGLE PHASE LIQ. REGION (PSI)

DPTP - PRES.DROP IN TRO-PHASE-REGION (PSI)

PD - TOTAL PRESSURE DROP (PSI)

C **** CAOTION - DATCB SIGN CONVENTION ***********

REHABKS

THIS PROGRAH CALLS SUBROOTINE PRICT, POR

DETERAINING THE GRNEFAL MOODY PRICTION PACTOR

FOR SINGLE PHASE PLOR IN TOBES

DOMENTUM CORPONENT OP TRO-PHASE PBES. DROB

$D P M=((X F * * 2-X I * * 2) *(1.0+R$ HOV $/$ R HOL $-($ B HOV $/ R$ HOL $) * * .333$

$1-(\mathrm{RHOV} / \mathrm{BHOL}) *$ *667) $-(\mathrm{XP}-\mathrm{XI}) *(2.0 * \mathrm{RHOV} / \mathrm{RHOL}-(\mathrm{RHOV} /$

3 RHOL) *. $333=($ RHOV $/$ RHOL $) * .667)) * G * * 2 /($ BHOV*32.2*

$33600.0 * * 2 * 144.01$

$\mathrm{CI}=(\mathrm{XP}-\mathrm{XI}) / \mathrm{DZTP}$

$C 2=.09 * X$ Y OV**. $2 * G * * 1.8 /(C 1 * R$ ROV*D**1. $2 * 32.2 * 3600.0$

$1 * 2 * 144.0)$

$C 3=2.85 *(X$ HOL $/ X M O V) * .0523 *(R H O V / R$ HOL $) * .262$

C

PRICIION COHPONENT OP THO-PHASE PRES. DROP

$D P F=C 2 *(.357 *(X P * * 2.8-X I * 2.8)+2.0 * C 3 *(.429 *(X F * 2.33$

$1-X I * * 2.33)-.141 *(X F * * 3.33-X I *+3.33)-.0287 *(X F * * 4.33$

$2-X I * * 4.33))+C 3 * 2 *(.538 *(X P * * 1.86-X I * 1.86)-.329 *(X P$

$\dot{c}$

$3 * * 2.86-X I * * 2.86))$ )

TOTAL THO-PRASE PRESSORE DROP 


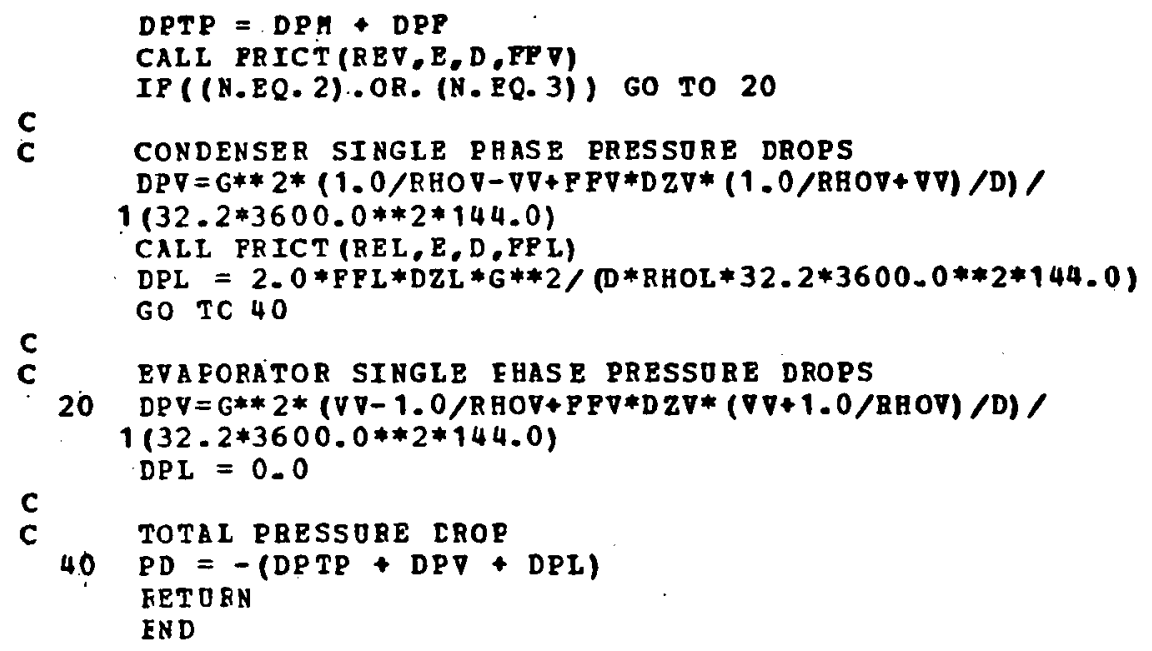




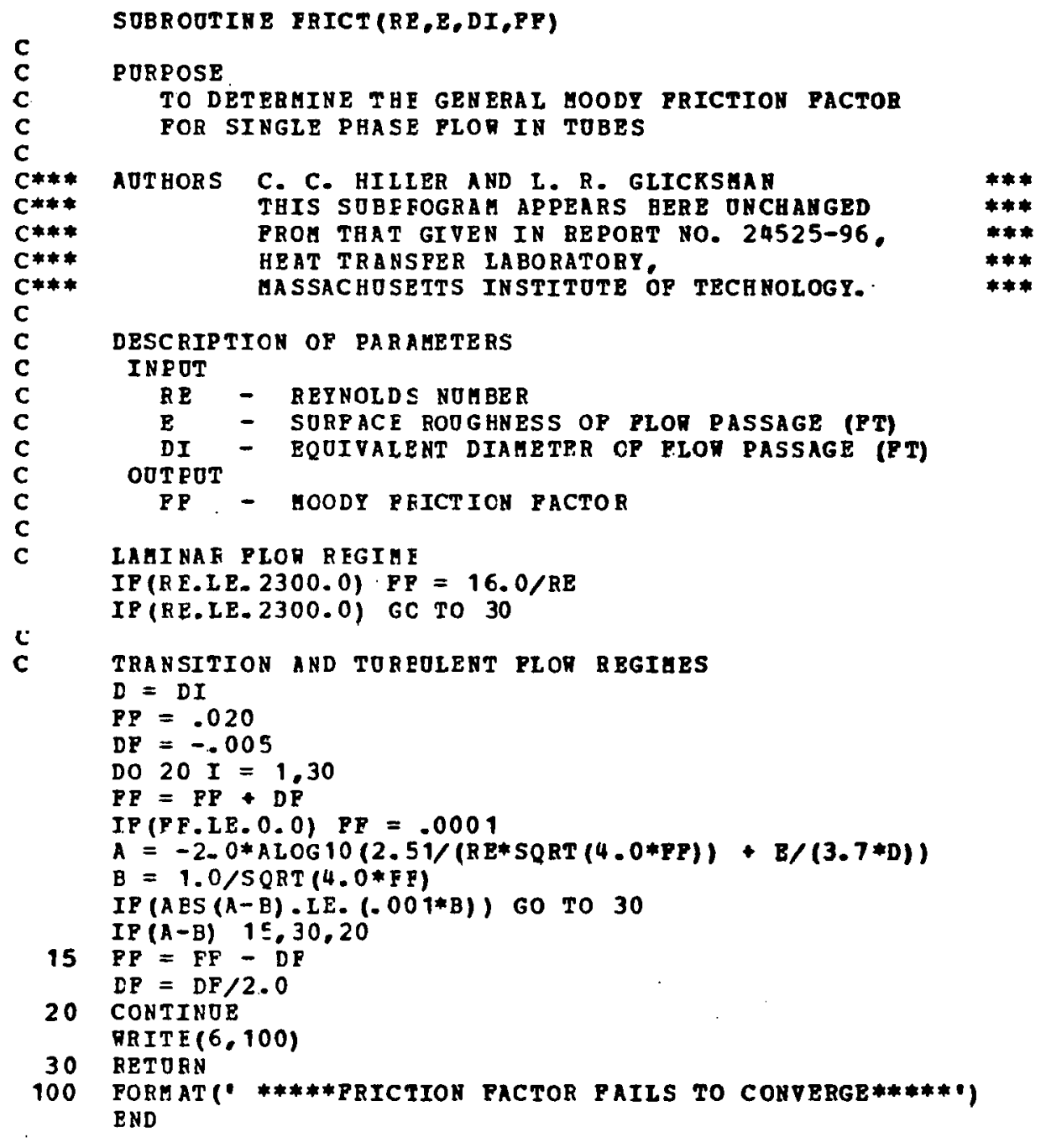




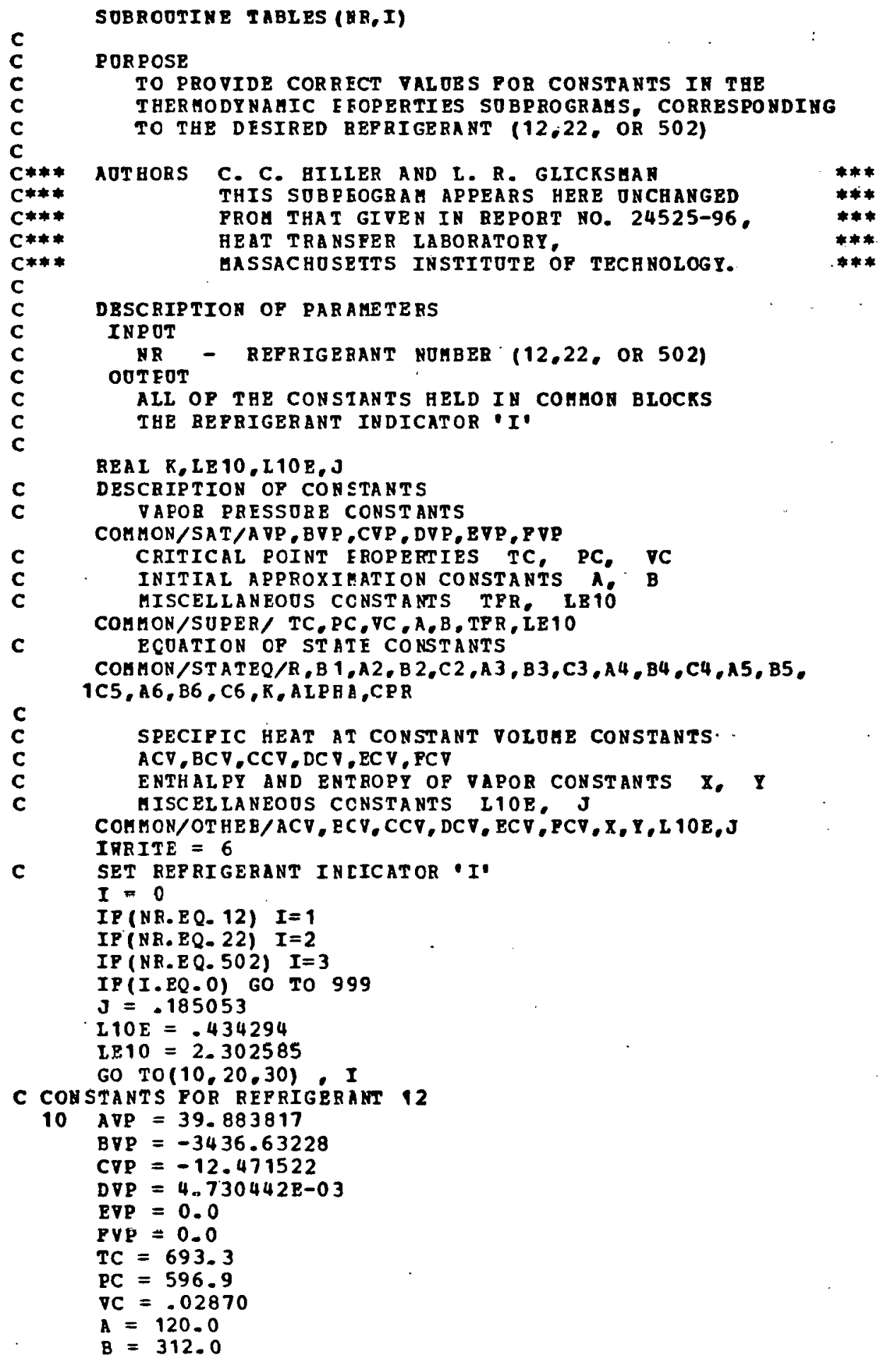




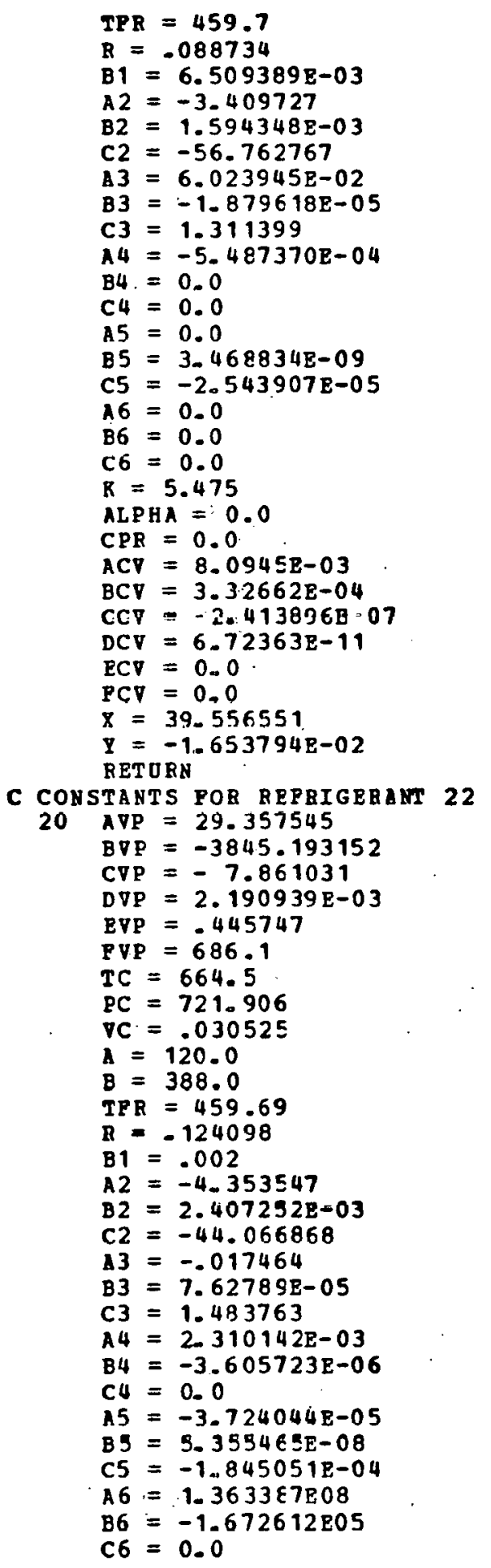




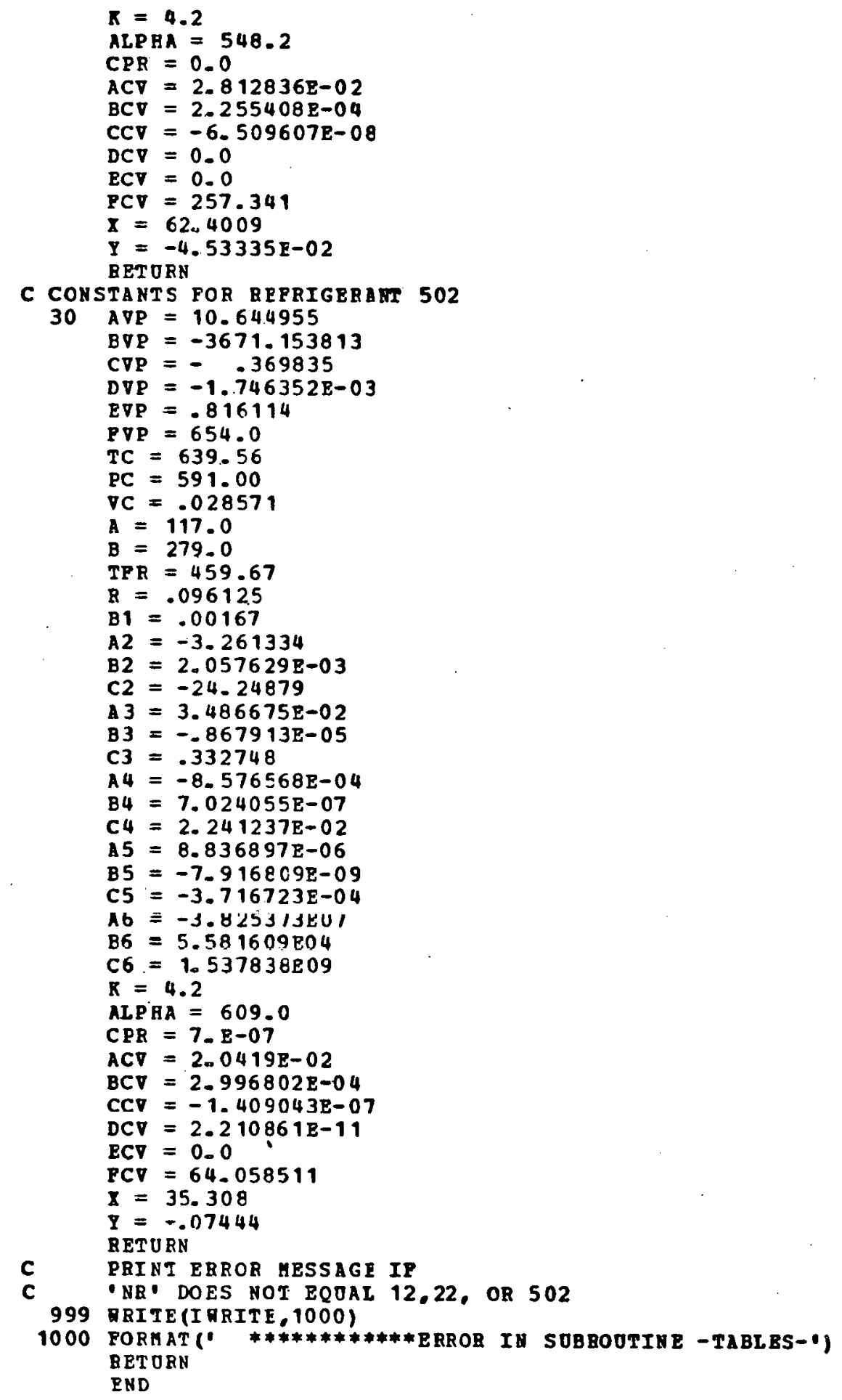




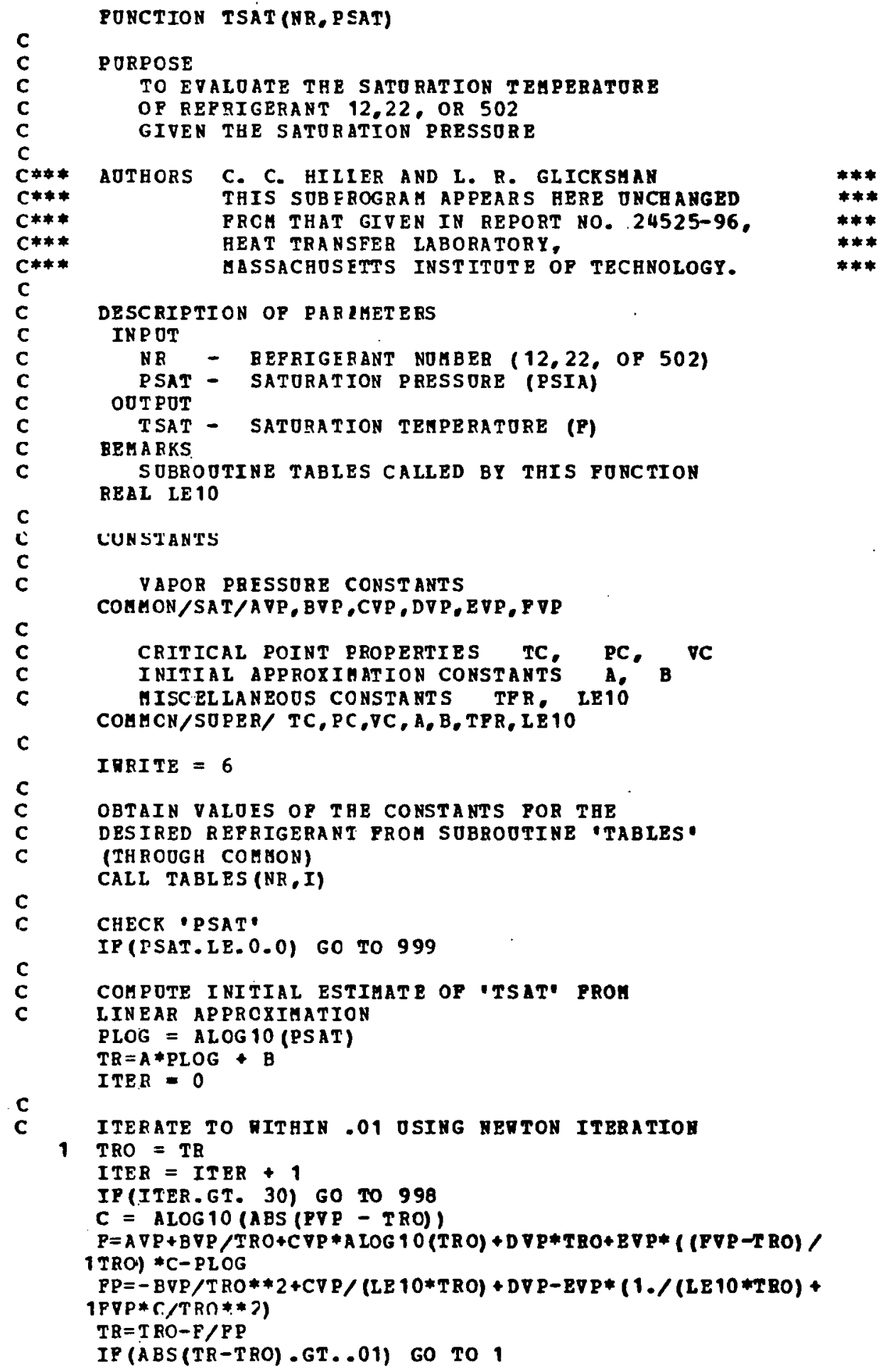




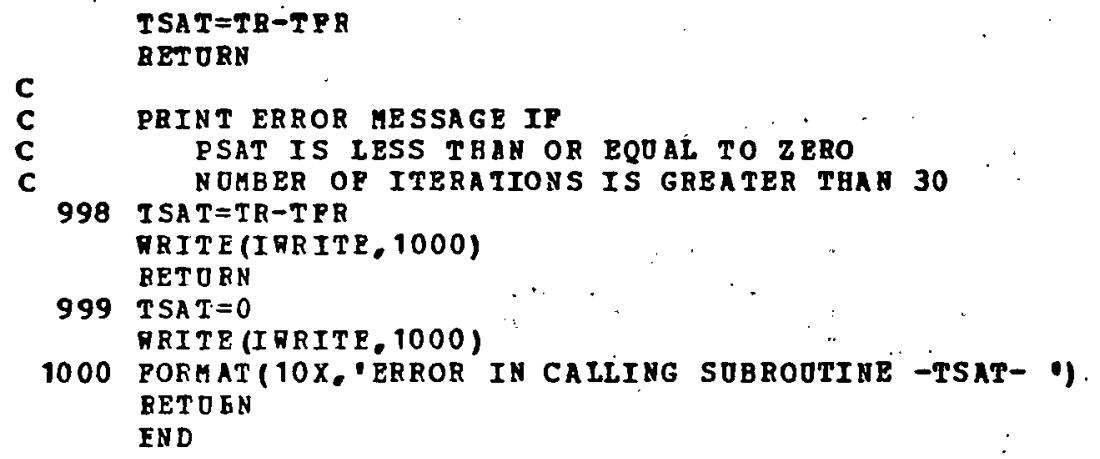


PONCTION SPVOL (NR,TP,PPSIA)

$\mathrm{C}$
$\mathrm{C}$
$\mathrm{C}$
$\mathrm{C}$
$\mathrm{C}$

PORPOSE

TO EVALUATE TBE SPECIFIC VOLOHE OP THE VAPOB PHASE

OF REPRIGERANT 12,22 , OR 502

GIVEN THE PRESSURE AND TEMPERATORE

C*** AOTHORS C. C. HIILER AND L. R. GLICRSHAN

$C * * *$

$C * * *$

$C * * *$

$C * * *$

C

c

C

c

C

C

c. 


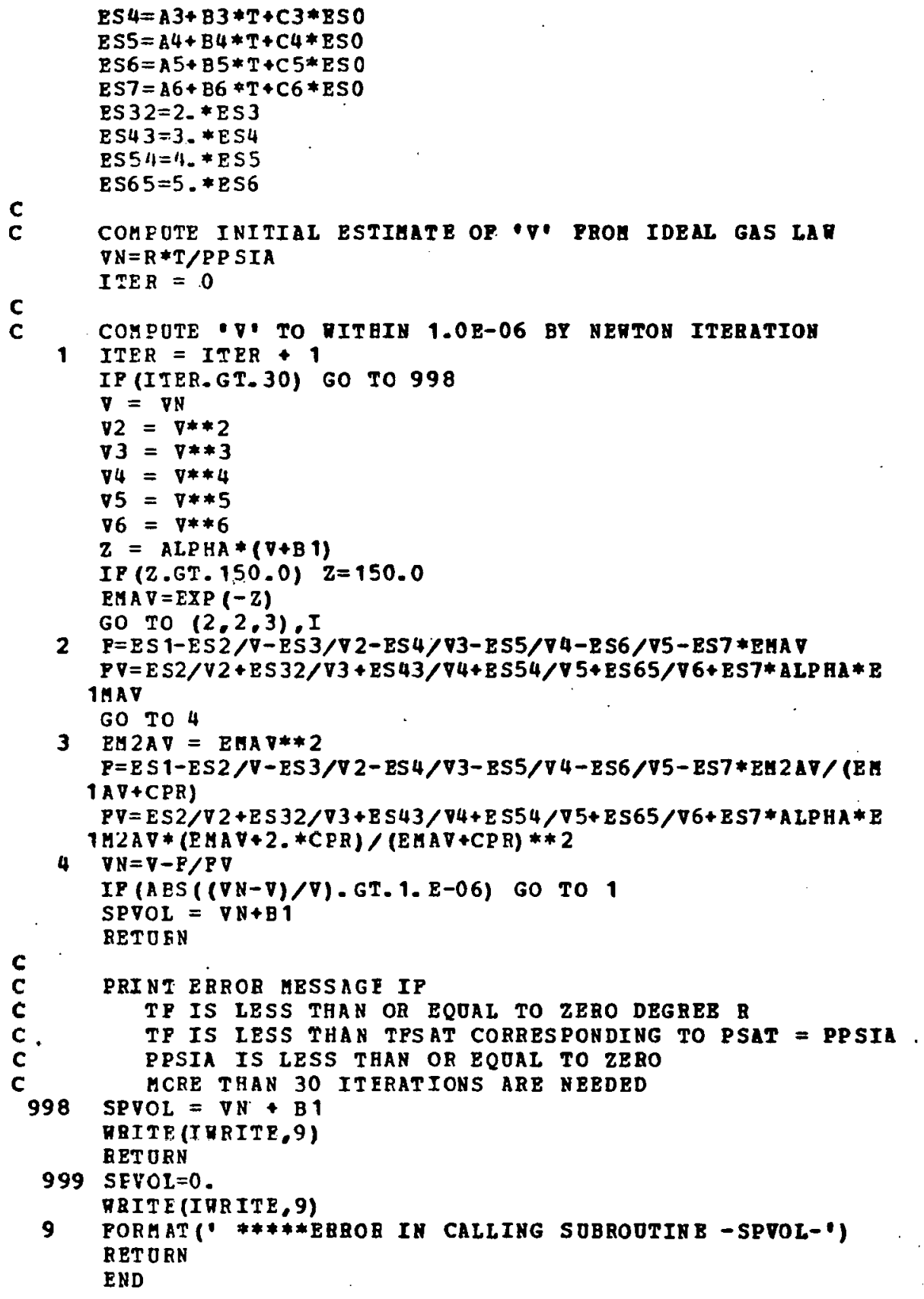




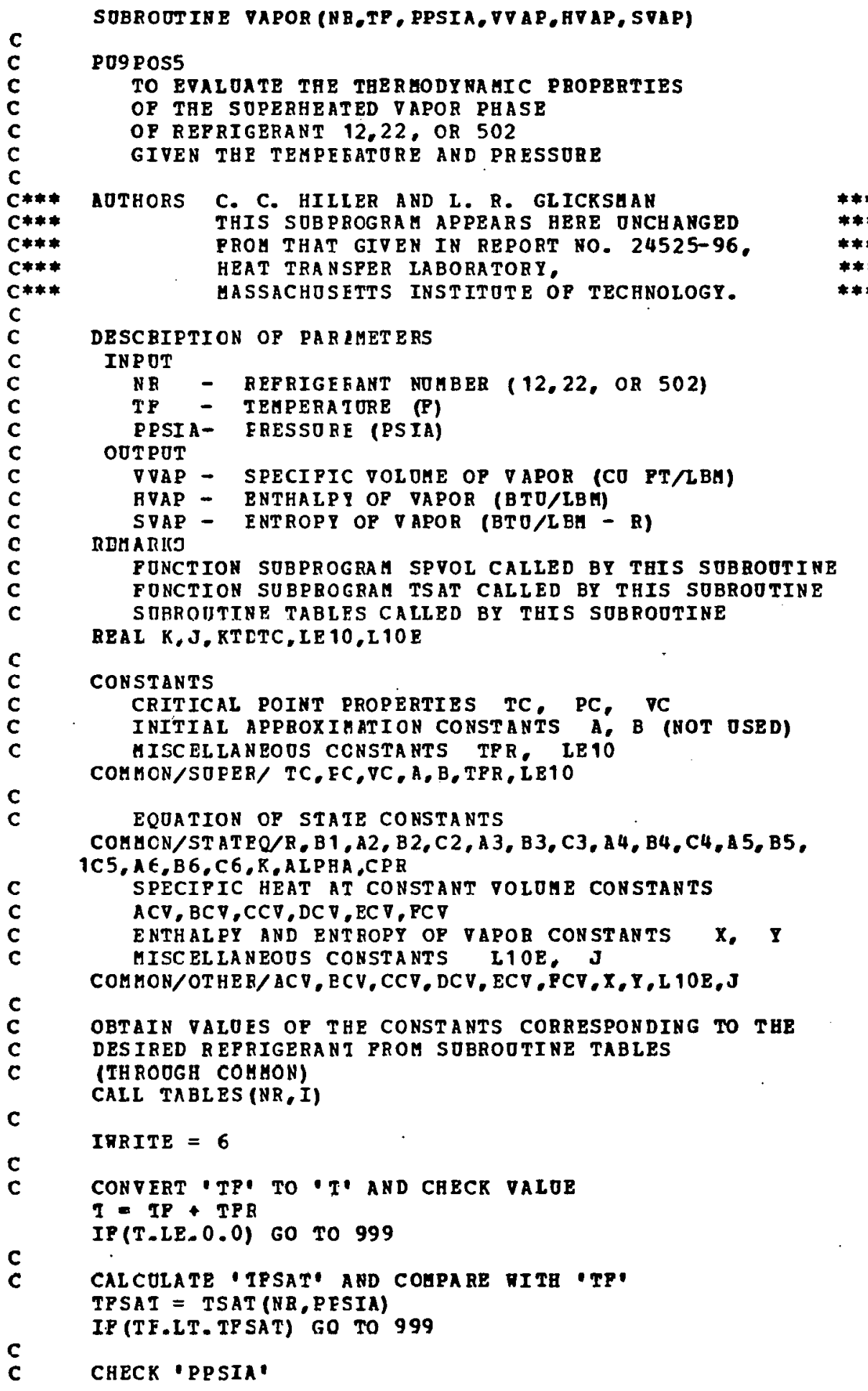




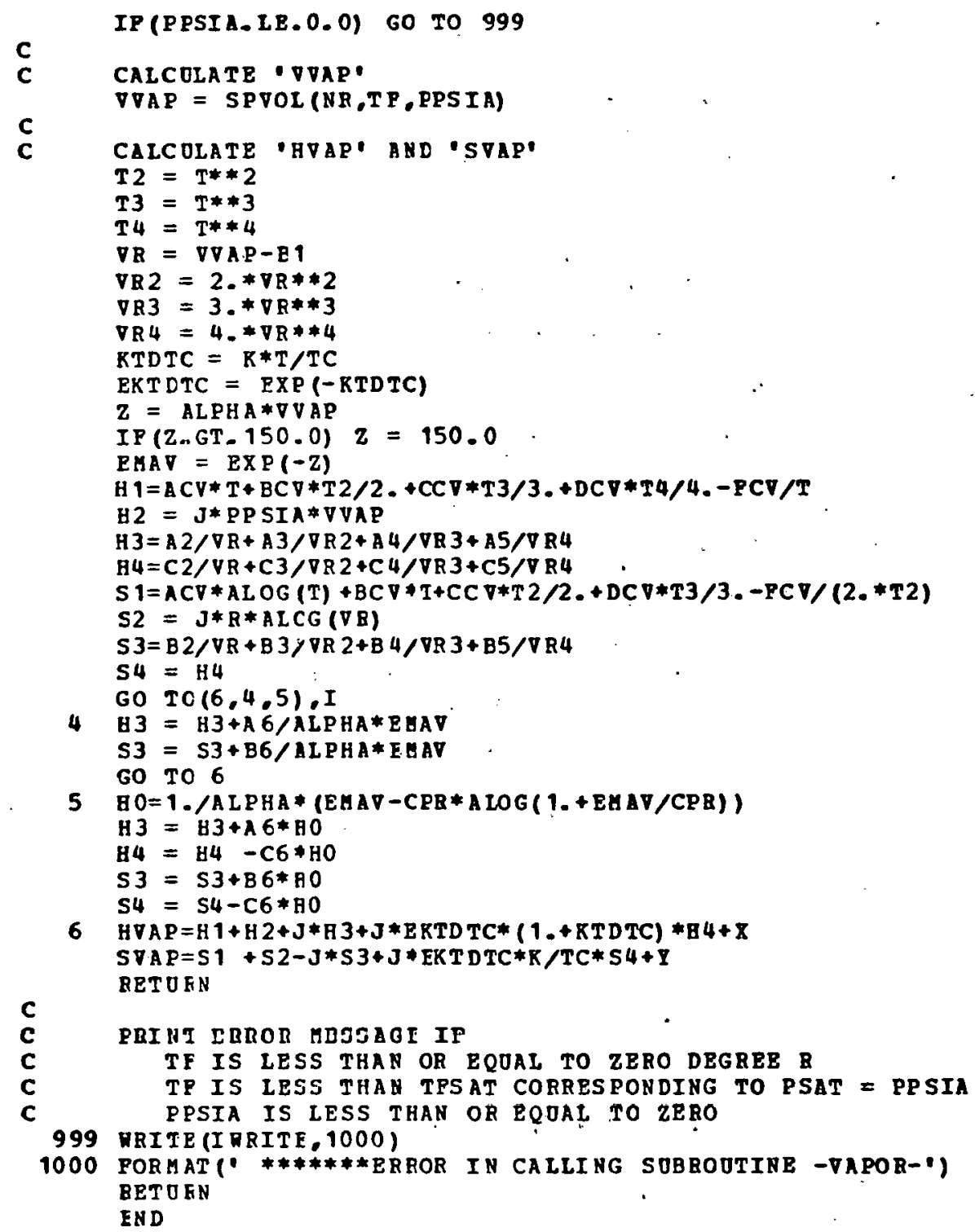




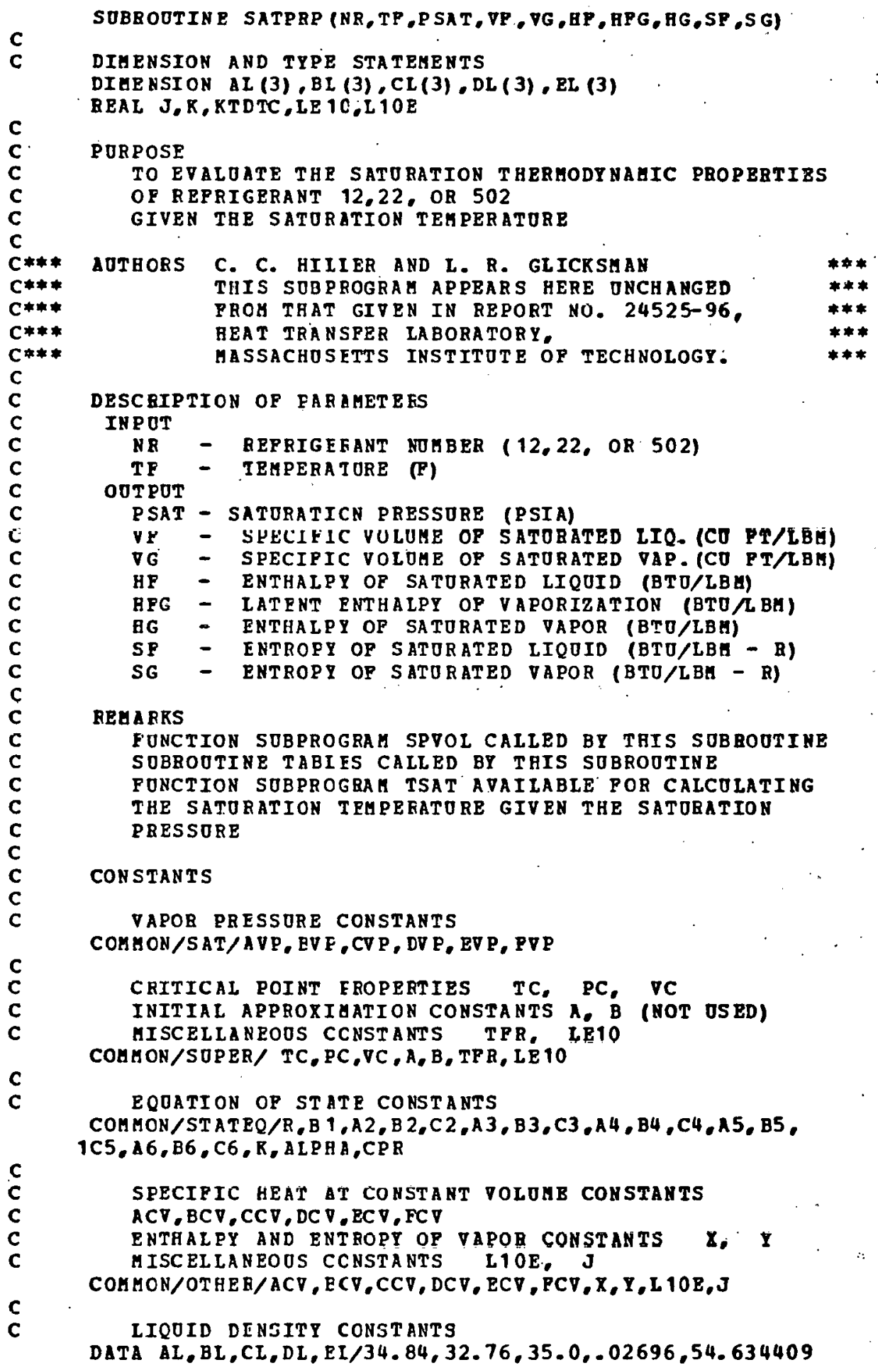




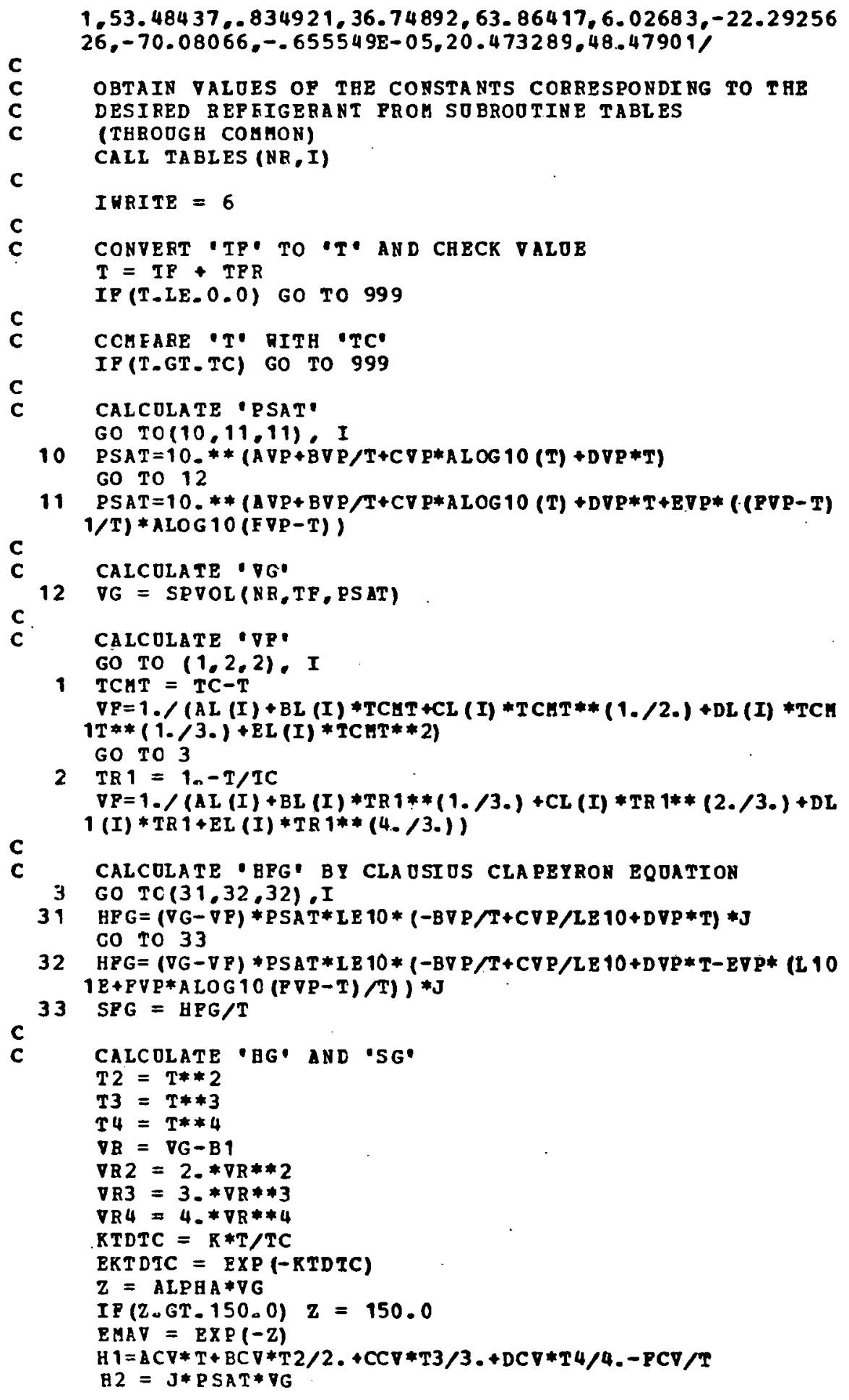




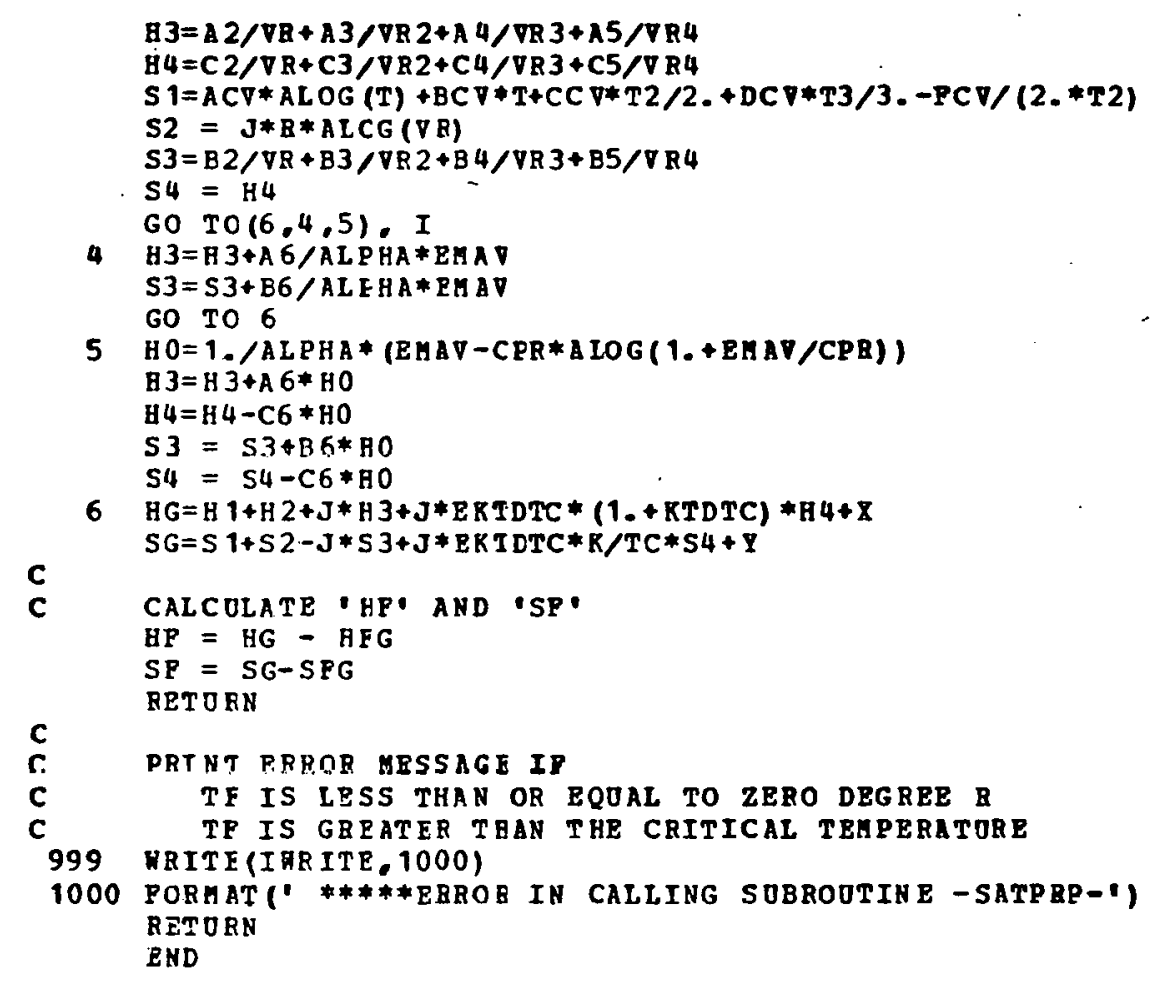




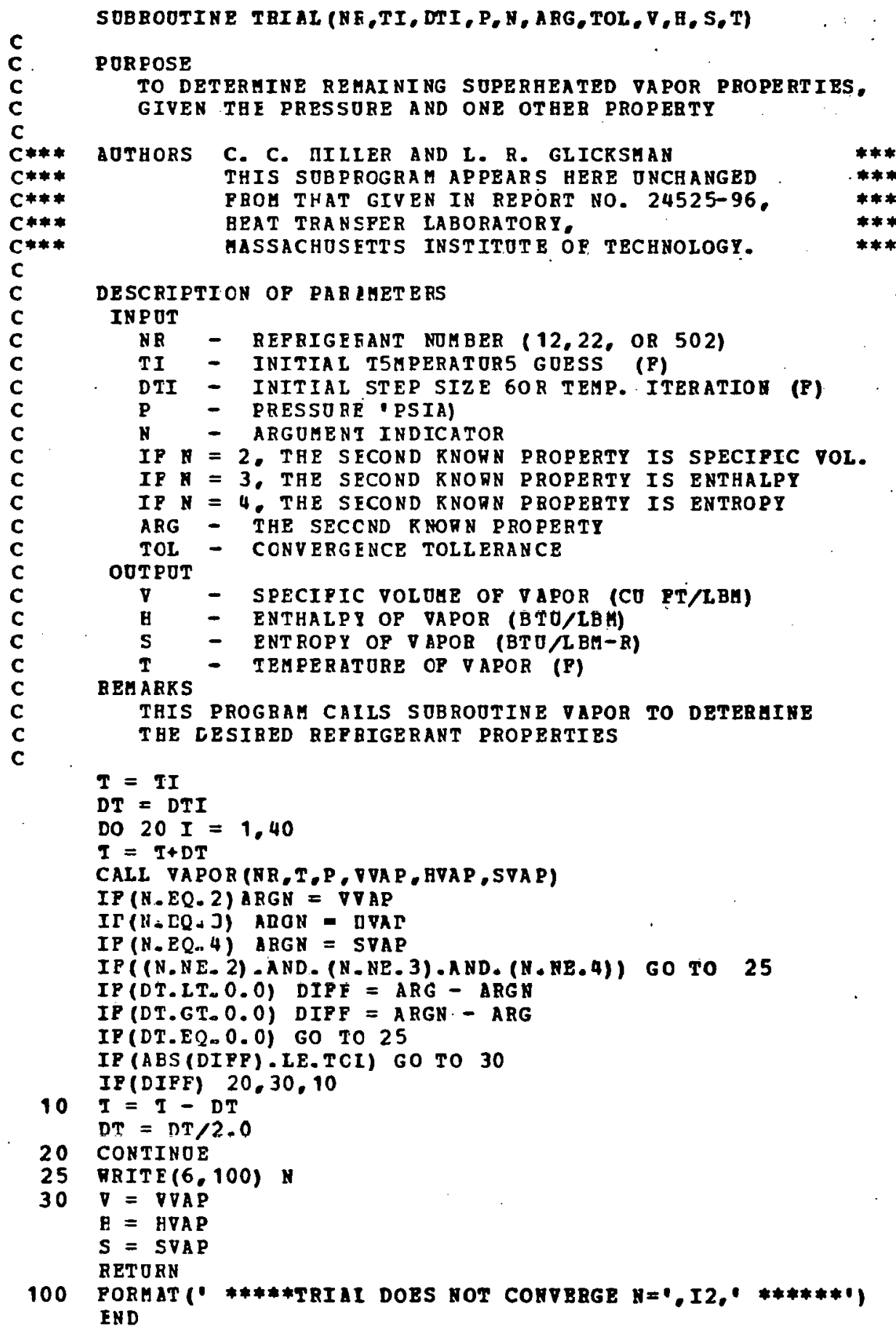




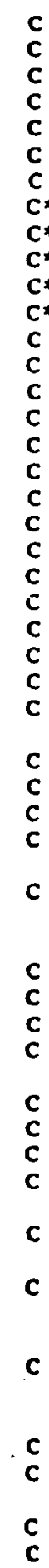

SOBROUTINE SPPHT (RE,TP,PPSIA,CV,CP,GAGAA,SONIC)

PORPOSE

TO CALCOLATE SPECIPIC HEAT AT CONSTANT VOLUAB,

SFECIPIC HEAT AT CONSTANT PRESSORE, SPECIPIC

BEAT RATIO, AND SONIC VELOCITY POR

REPRIGERANT 12,22, OR 502

AOTHORS C. C. HILIER AND L. R. GLICKSHAN

THIS SUBPROGRAM APPEARS HERE ONCHANGED

PRCM THAT GIVEN IN BEPORT NO. 24525-96,

HEAT TRANSPER LABORATORY.

MASSACHOSETTS INSTITOTE OF TECHNOROGY.

DESCRIPTION OF PAREHETEES

IN P OT

NR - RPPRIGEFANT NOMBER (12,22, OR 502)

TP - TEHPERATORE (P)

PESIA- PRESSUEE (PSIA)

OOTPOT

CV - SPECIPIC HEAT AT COBSTANT VOL (BTO/LBA-B)

CP - SPECIPIC HEAT AT CONSTART PRES. (BTO $/ A B-R$ )

GAMHA- SEECIFIC HEAT RATIO

SCNIC-' SUNTC VHLOCIHY (YPS)

BEMARKS

FONCTION SOBPROGBAH SPVOL CALIED BY THIS SOBROUTINE

FONCTION SUBPROGRA TSAT CALLED BY THIS SUBROOTIRE

SOBROOTINE TABLES CALLED BI THIS SUBROOTINE

REAL $K$

CONSTANTS

CRITICAL POINT EROPERTIES TC, PC, VC

INITIAL APPROXIBZTION CONSTANTS A, B (NOT OSED)

MISCELIANEOUS CCNSTANTS TPR, LE10

CO\& $O$ ON/SUPER/TC, PC,VC,A,B,TPR, LE1O

EQDATION OF STATE CONSTANTS

CONGON/STATEQ/R,B 1,A2,B2,C2,A3,B3,C3,A4,B4,C4,A5,B5,

$1 C 5, A 6, B 6, C 6, K, A I P H A, C P R$

SPECIPIC BEAT AT CONSTANT VOLOHE CONSTANTS

$A C V, B C \nabla, C C V, C C V, E C V, F C V$

ENTHALPY AND ENTROPY OP VAPOR CONSTANTS $x_{*} \quad z$.

MISCELLANEOOS CCNSTANTS

L 1OE, J

COMHON/OT BER/ACV,BCV,CCV,DCV,ECV,PCV,X,Y,L10E,J

OBTAIN VALUES OP THE CONSTANTS CORRESPONDING TO THE

DESI GED REPEIGERANT FBOM SUBROOTINB TABLBS

(TRROOGH COMAON)

CALL TABLES (NR., I)

c

CONVERT 'TP' TO 'T' AND CHECK VILOE

$T=T P+T P R$

IP(T.LE.0.0) GO TO 999

C

CALCULATE 'TPSAT' AND CCAPARE IITH 'TP'

TPSAT = TSA I (NR,PPSIA)

IP (TP.LT. TFSAT). GO TO 999

C

CHECR - PPSIA-

IP (PPSIA.LE.0.0) GO TO 999

c

CALCULATE ' TPAP' 


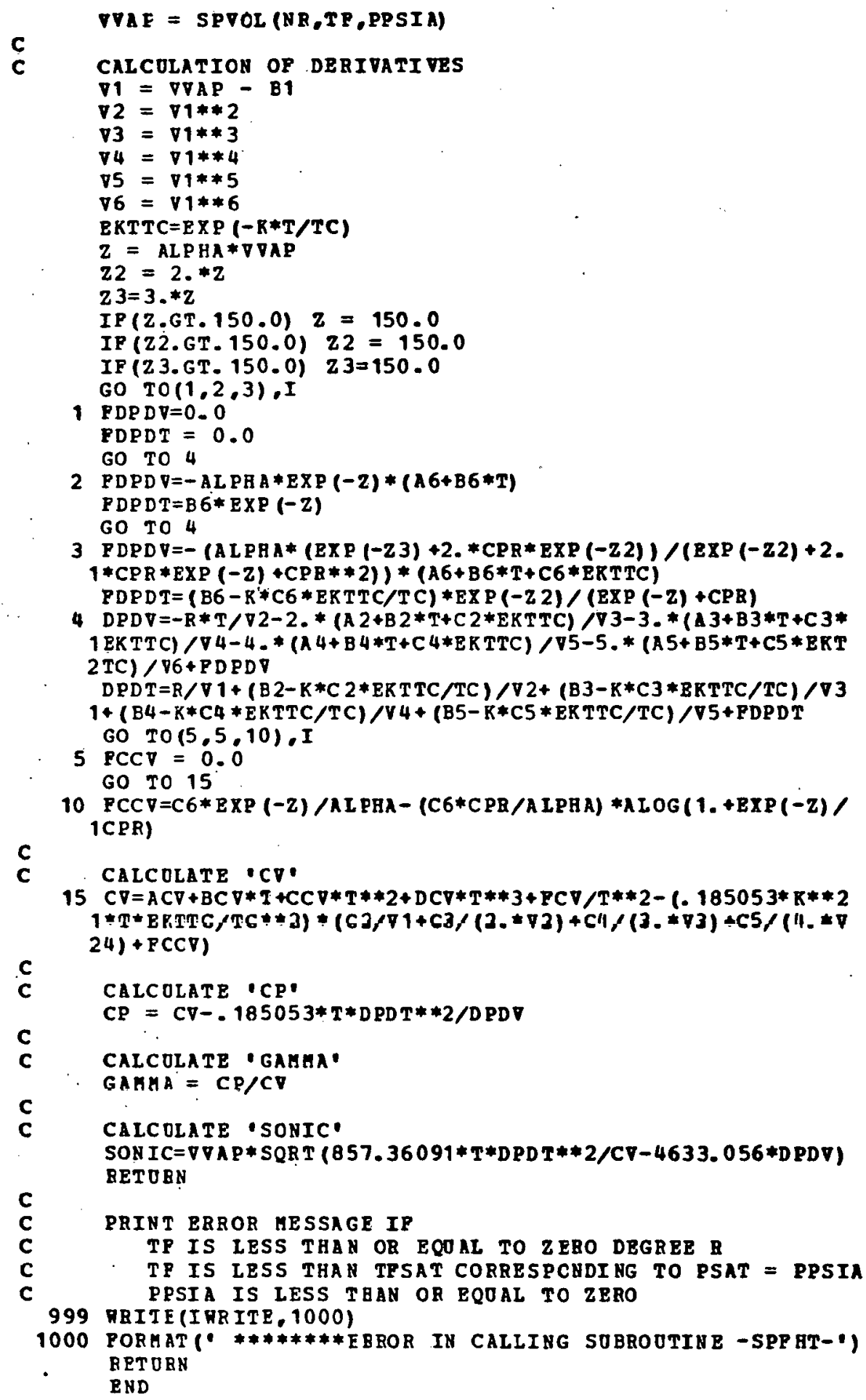




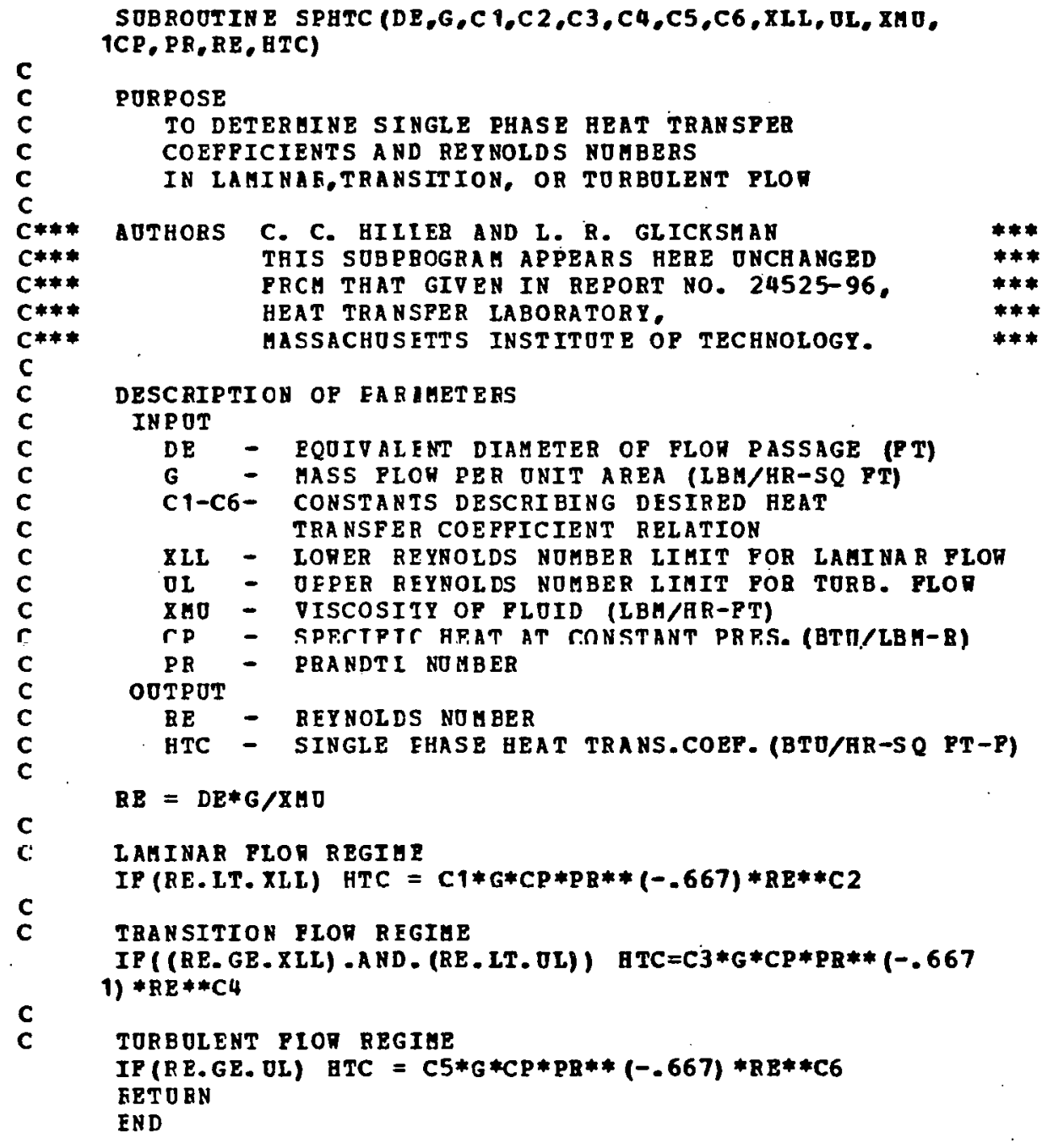


SUBROOTINE SEPF (XR,DELTA, HA,XL,FAR,CAR,HCONT,SEPPR)

C

C

C

C

C

$C * *$

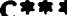

$C * * *$

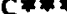

$C * * *$

C

C

$\mathrm{C}$

c

C

C

C

C

C

C

c

C

C

C

C PIN EPFICIENCY

$X H=\operatorname{SQRT}(2.0 *$ HA $/(X K * D E L T A))$

PIN EP $=(\operatorname{EXP}(X M * X I)-E X P(-X H * X I)) /((B X P(X B * X L)+\operatorname{EXP}(-X B)$

C 


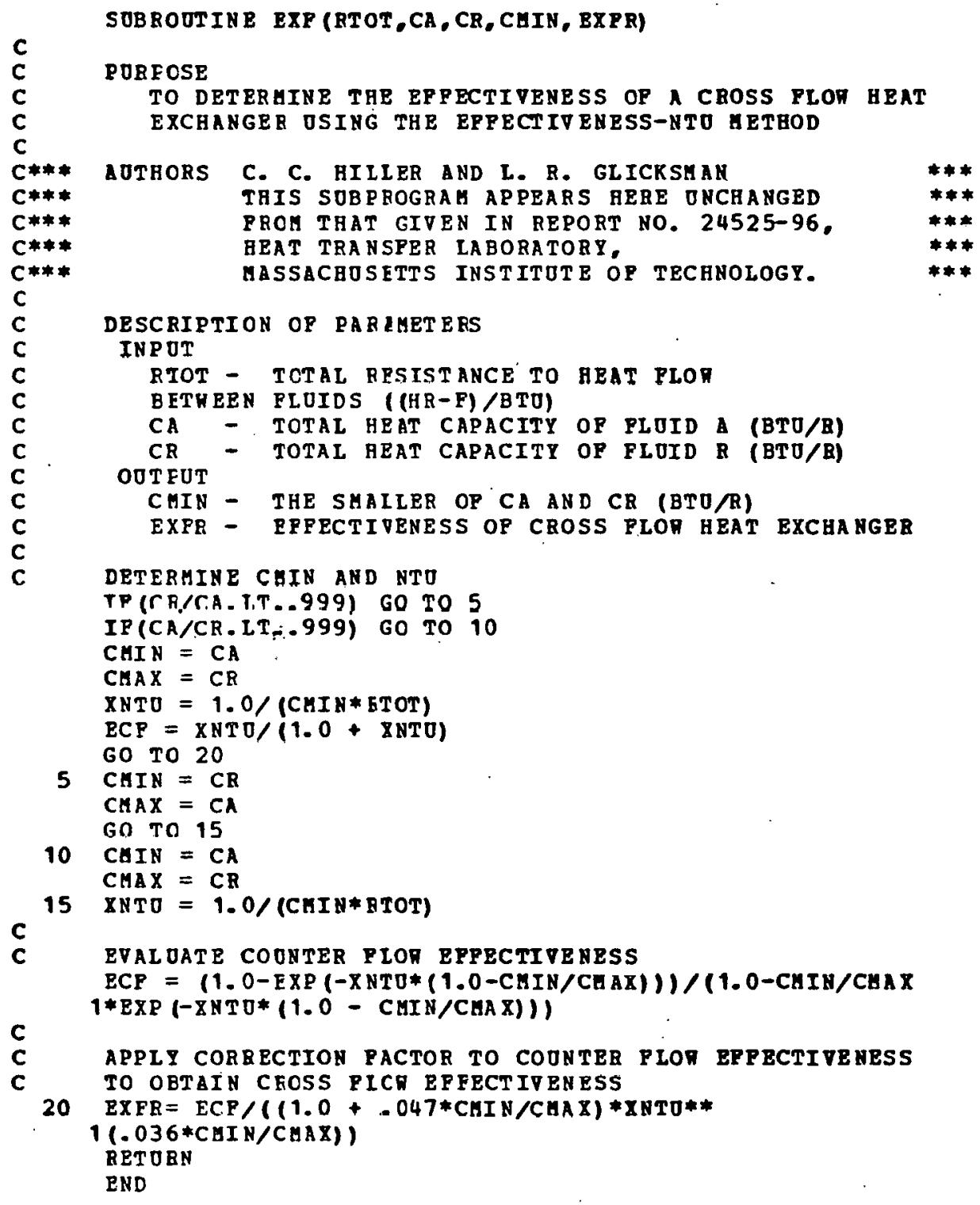


THIS PAGE

\section{WAS INTENTIONALLY \\ LEFT BLANK}


ORNL/CON-16

INTERNAL DISTRIBUTION

1. S. I. Auerbach

2. M. Baker

3. V. D. Baxter

4. S. E. Beall

5. D. J. Bjornstad

6. J. R. Buchanan

7. R. S. Carlsmith

8. W. S. Chern

9. C. V: Chester

10. T. J. Clifford

11. F. A. Creswick

12. R. M. Davis

13. J. G. Delene

14. A. A. Domingorena

15. R. D. Ellison

16. W. Fulkerson

17. V. 0. Haynes

18. N. E. Hinkle

19. E. A. Hirst

20. E. C. H1se

21. A. S. Holman

22. L. Howard

23. J. R. Jackson

24. W. L. Jackson

25. P. L. Johnson

26. S. I. Kaplan

27. D. Kaserman

28. R. S. Livingston
29. H. M. Long

30-49. P. M. Love

50. R. N. Lyon

51. J. W. Michel

52. R. E. Minturn

53. W. R. Mixon

54. J. C. Moyers

55. E. A. Nephew

56. D. L. O'Neal

57. H. Postma

58. M. W. Rosenthal

59. T. H. Row

60. G. G. 3laughter

61. R. L. Spore

62. E. G. Struxness

63. D. B. Trauger

64. G. U. Ulrikson

65. D. J. Walukas

66. T. J. Wilbanks

67. J. V. Wilson

68. H. E. Zittel

69. A. Zucker

70. Biology Division Library

71-72. Central Research Library

73. Document Reference Section

74. Laboratory Records - RC

75-77. Laboratory Records Dept.

78. ORNL Patent office

EXTERNAL DISTRIBUTION

79. Dr. Ervin Bales, Department of Energy, Division of Buildings and Community Systems, 20 Massachusetts Avenue NW, Washington, D.C. 20545.

80. Mr. B. Cleveland, Duratherm Company, LaGrange, Indiana 46761.

81. Mr. E. G. Ehlers, Electric Power Research Institute, Palo Alto, California 94304.

82. Mr. G. W. Gatecliff, Research Laboratory, Tecumseh Products Company, Ann Arbor, Michigan 48105.

83. Dr. L. R. Glicksman, Department of Mechanical Engineering, MIT, Cambridge, Massachusetts 02139.

84. Mr. S. D. Goldstein, Advanced Energy Systems, Exxon Enterprises, Inc., Post Office Box 192, Florham Park, New Jersey 07932.

85. Mr. Gerald C. Groff, Research Division, Carrier Corporation, Syracuse, New York 13201. 
86. Dr. C. C. Hiller, Sandia Laboratories, Livermore, California. 94550 .

87. Mr. T. Jacoby, Tecumseh Products Company, Tecumseh, Michigan 49286.

88. Mr. H. Jaster, General Electric Corporate Research and Development, General Electric Corporation, Schenectady, New York 12301 .

89. Mr. R. W. King, Copeland Corporation, Sydney, Ohio 45365.

90. Mr. L. L. Lawrence, Gas Research Institute, Chicago, Illinois 60690 .

91. Mr. N. Nenov, Linde Division, Union Carbide Corporation, Tonawanda, New York . 14150:

92. Mr. Michael Perlsweig, Department of Energy, Division of Conservation Research and Technology, 20 Massachusetts Avenue NW, Washington, D.C. 20545.

93. Mr. J. A. Pietsch, Air Conditioning Division, General Electric Corporation, Ann Arbor, Michigan 48105.

94. Mr. P. J. Reynolds, Department of Energy, Division of Buildings and Community Systems, 20 Massachusetts Avenue NW, Washington, D.C. 20545.

95. Mr. D. E. Scherpereel, Research and Engineering Center, Whirlpool Corporation, Benton Harbor, Michigan 49022.

96. Dr. M. H. Somerville, Engineering Experiment Station, University of North Dakota, Grand Forks, North Dakota 58202.

97. Mr. W. F. Stoecker, University of Illinois, Urbana, Illinois 61801 .

98. Mr. M. Wilden, University of New Mexico, Albuquerque, New Mexico 87115 .

99. Institute of Energy Analysis, ORAU Library.

100. Research and Technical Support Division, DOE-ORO.

101-127. Technical Information. Center, DOE, Post Office Box 62, Oak Ridge, Tennessee 37830.

128-300. External Energy Conservation Distribution Mailing List and Energy Conservation Office (9102-1, Room-2). 